\title{
Molecular signaling mechanisms behind polyphenol-induced bone anabolism
}

\author{
Elisa Torre $\mathbb{B}$
}
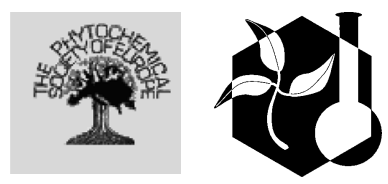

Received: 27 January 2017/ Accepted: 20 August 2017/Published online: 31 August 2017

(C) The Author(s) 2017. This article is an open access publication

\begin{abstract}
For millennia, in the different cultures all over the world, plants have been extensively used as a source of therapeutic agents with wide-ranging medicinal applications, thus becoming part of a rational clinical and pharmacological investigation over the years. As bioactive molecules, plant-derived polyphenols have been demonstrated to exert many effects on human health by acting on different biological systems, thus their therapeutic potential would represent a novel approach on which natural product-based drug discovery and development could be based in the future. Many reports have provided evidence for the benefits derived from the dietary supplementation of polyphenols in the prevention and treatment of osteoporosis. Polyphenols are able to protect the bone, thanks to their antioxidant properties, as well as their anti-inflammatory actions by involving diverse signaling pathways, thus leading to bone anabolic effects and decreased bone resorption. This review is meant to summarize the research works performed so far, by elucidating the molecular mechanisms of action of polyphenols in a bone regeneration context, aiming at a better understanding of a possible application in the development of medical devices for bone tissue regeneration.
\end{abstract}

E. Torre $(\square)$

Nobil Bio Ricerche srl, Via Valcastellana, 26,

14037 Portacomaro, AT, Italy

e-mail: etorre@nobilbio.it
Keywords Anti-inflammation - Antioxidant $\cdot$ Bone disease $\cdot$ Pathway $\cdot$ Polyphenols

$\begin{array}{ll}\text { Abbreviations } \\ \text { AD } & \text { Adipose tissue-derived } \\ \text { ALPL } & \text { Alkaline phosphatase liver/bone/kidney } \\ \text { AMPK } & \begin{array}{l}\text { Adenosine monophosphate protein } \\ \text { kinase }\end{array} \\ & \text { Activator protein-1 } \\ \text { AP1 } & \text { Active pharmaceutical ingredient } \\ \text { API } & \text { Antioxidant response } \\ \text { ARE/ } & \text { element/electrophile responsive element } \\ \text { EpRE } & \text { Activating transcription factor } \\ \text { Atf } & \text { Adenosine triphosphate } \\ \text { ATP } & \text { Bcl-2-associated X } \\ \text { Bax } & \text { B cell lymphoma 2 } \\ \text { Bcl-2 } & \text { Bone morphogenetic protein-2 } \\ \text { BMP-2 } & \text { Bone morphogenetic proteins } \\ \text { BMPs } & \text { Bone sialoprotein } \\ \text { BSP } & \text { Calcium } \\ \text { Ca } & \text { Caffeic acid 3,4-dihydroxy-phenethyl } \\ \text { CADPE } & \text { ester } \\ & \text { Caviunin 7-O-[ } \beta \text {-D-apiofuranosyl-(1-6)- } \\ \text { CAFG } & \beta \text {-D-glucopyranoside] } \\ & \text { Cyclic adenosine monophosphate } \\ \text { cAMP } & \text { C-C chemokine receptor type 2 } \\ \text { CCR2 } & \text { Cyclic guanosine monophosphate } \\ \text { cGMP } & \text { Collagen type 1 } \\ \text { Col1 } & \text { G protein-coupled receptor 30 } \\ \text { GPR30 } & \text { Glutathione peroxidase } \\ \text { Gpx } & \end{array}$




\begin{tabular}{|c|c|c|c|}
\hline GTDF & $\begin{array}{l}\text { 6-C- } \beta \text {-D-glucopyranosyl-(2S,3S)-(+)- } \\
3^{\prime}, 4^{\prime}, 5,7 \text {-tetrahydroxyflavanol }\end{array}$ & $\begin{array}{l}\text { ERE } \\
\text { ERK }\end{array}$ & $\begin{array}{l}\text { Estrogen response elements } \\
\text { Extracellular signal-regulated kinase }\end{array}$ \\
\hline HCA & P-hydroxycinnamic acid & FGF-2 & Basic fibroblast growth factor 2 \\
\hline HIF-1 $1 \alpha$ & Hypoxia-inducible factor 1 -alpha & FLICE & FADD-like IL-1 $\beta$-converting enzyme \\
\hline $\mathrm{HO}$ & Heme oxygenase & FLIP & FLICE-inhibitory protein \\
\hline HSP & Heat shock protein & FoxO & Forkhead box O \\
\hline ICAM & Intercellular adhesion molecule & GM-CSF & Granulocyte-macrophage colony- \\
\hline $\mathrm{IFN} \gamma$ & Interferon $\gamma$ & & stimulating factor \\
\hline IGF & Insulin-like growth factor & GPCR & 7-Transmembrane $\mathrm{G}$ protein-coupled \\
\hline IKK & Iкb kinase & & receptor \\
\hline IL & Interleukin & GPER & G protein-coupled estrogen receptor 1 \\
\hline iNOS & Oxide synthase & $\mathrm{PGE}_{1}$ & Prostaglandin E1 \\
\hline $\mathrm{IP}_{3}$ & Inositol trisphosphate & $\mathrm{PGE}_{2}$ & Prostaglandin E2 \\
\hline $\mathrm{IP}_{3} \mathrm{R}$ & IP3 receptor & PGF2 $\alpha$ & Prostaglandin F $2 \alpha$ \\
\hline JNK & C-Jun N-terminal kinase & PI3K & Phosphatidylinositol-4,5-bisphosphate \\
\hline LPS & Lipopolysaccharide & & 3-kinase \\
\hline LRP & Lipoprotein receptor-related protein & PKA & Protein kinase A \\
\hline MAPKs & Mitogen-activated protein kinases & $\mathrm{PKB} / \mathrm{Akt}$ & Protein kinase B \\
\hline MCP & Monocyte chemotactic protein & $\mathrm{PKC}$ & Protein kinase $\mathrm{C}$ \\
\hline MIP & Macrophage inflammatory protein & $\mathrm{PGD}_{2}$ & Prostaglandin D2 \\
\hline MMP & Matrix metalloproteinase & PLC & Phospholipase C \\
\hline mPGES & Microsomal prostaglandin E synthase & $\mathrm{PP} 2 \mathrm{~A}$ & Protein phosphatase $2 \mathrm{~A}$ \\
\hline MSCs & Mesenchymal stem cells & $\operatorname{PPAR} \gamma$ & Peroxisome proliferator-activated \\
\hline mTORC & Mammalian target of rapamycin complex & & receptor gamma \\
\hline NAD & Nicotinamide adenine dinucleotide & RANK & Receptor activator of nuclear factor \\
\hline NCoR & Nuclear receptor co-repressor & & kappa-B \\
\hline NFATc1 & Nuclear factor of activated T-cells 1 & RANKL & Receptor activator of nuclear factor \\
\hline $\mathrm{NF}-\kappa \mathrm{B}$ & Nuclear factor kappa-light-chain- & & kappa-B ligand \\
\hline & enhancer of activated B cells & RANTES & Regulated on activation, normal $\mathrm{T}$ cell \\
\hline NO & Nitric oxide & & expressed and secreted \\
\hline Nrf2 & Nuclear factor E2-related factor 2 & RNS & Reactive nitrogen species \\
\hline $\mathrm{OCN}$ & Osteocalcin & ROS & Reactive oxygen species \\
\hline OPG & Osteoprotegerin & Runx2 & Runt-related transcription factor 2 \\
\hline OPN & Osteopontin & SAPK & Stress-activated protein kinases \\
\hline OSCAR & $\begin{array}{l}\text { Osteoclast-associated immunoglobulin- } \\
\text { like receptor }\end{array}$ & $\begin{array}{l}\text { SERMs } \\
\text { sGC }\end{array}$ & $\begin{array}{l}\text { Selective estrogen receptor modulators } \\
\text { Soluble guanylyl cyclase }\end{array}$ \\
\hline Osx & Osterix & Sir2 & Silent information regulator 2 \\
\hline $\mathrm{COX} 2$ & Cyclooxygenase 2 & Sirt1 & Sirtuin 1 \\
\hline CREB & Camp response element binding protein & SMAD & Small mother against decapentaplegic \\
\hline CREs & Camp response elements & SOD-1 & Superoxide dismutase 1 \\
\hline CXCL & Chemokine (C-X-C motif) ligand & SOST & Sclerostin \\
\hline DP & Dried plum & SP1 & Specificity protein-1 \\
\hline E2 & $17 \beta$-estradiol & $\mathrm{TF}$ & Transcription factor \\
\hline EA & Ellagic acid & TGF- $\beta 1$ & Transforming growth factor- $\beta 1$ \\
\hline ECM & Extracellular matrix & TNFR & Tumor necrosis factor receptor \\
\hline EGCG & Epigallocatechin gallate & TNF- $\alpha$ & Tumor necrosis factor- $\alpha$ \\
\hline eNOS & Endothelial NOS & TRAF & TNF receptor associated factor \\
\hline ER & Estrogen receptor & TRAP & Tartrate-resistant acid phosphatase \\
\hline
\end{tabular}


TRKs Receptor tyrosine kinases

VA Vanillic acid

VCAM Vascular cell adhesion molecule

VEGF Vascular endothelial growth factor

\section{Introduction}

Bone loss is a consequence of changes that occur in the bone cell activity during bone remodeling, which causes an imbalance between bone resorption and formation and leads to bone disorders, such as osteoporosis and increased fracture risk (Manolagas 2000). During normal physiological remodeling, in which the mature skeleton undergoes continuous regeneration, bone formation follows resorption in a "coupled" mechanism controlled by varied molecular factors. Unequal effects of these factors could lead to the imbalance responsible for the decrease of bone mass, in which extension of the working lifespan of the osteoclast coexists with shortening of the working lifespan of the osteoblast (Khosla et al. 2012). Various cell types are involved in the remodeling process, each type playing different roles in bone turnover: osteoblasts supporting bone formation, osteoclasts involved in bone resorption and osteocytes playing a central role by acting as master signal sensors, integrators and transducers in the remodeling compartment, with their multiple endocrine functions implicated in the regulation of both osteoclast and osteoblast activities (Bonewald 2011).

Polyphenols are phytochemicals commonly found in the plant kingdom, whose multiple biological effects have been reported to be protective against chronic diseases, including neurodegenerative and cardiovascular disease, cancer and osteoporosis (Scalbert et al. 2005). The beneficial actions of phenolic compounds are mainly due to their antioxidant properties, since they can act as scavengers of reactive oxygen species (ROS) (Procházková et al. 2011), but also to their interaction with intracellular signaling cascades such as phosphatidylinositol-4,5bisphosphate 3-kinase (PI3K), protein kinase B (PKB)/Akt, tyrosine kinases, protein kinase $\mathrm{C}$ (PKC) and mitogen-activated protein kinases (MAPKs) (Nomura et al. 2001; Lin 2002; Kern et al. 2007; Larsen et al. 2010), that lead to anti-inflammatory, chemopreventive and chemotherapeutic activities.

Depending on the number of phenol rings they contain and on the radicals bound to them, polyphenols can be divided into different groups: phenolic acids, flavonoids, stilbenes, tannins, coumarins and lignans (Fig. 1-2) (D'Archivio et al. 2007). Given that the chemical structure of a compound is related to its biological/toxicological activity (McKinney et al. 2000), polyphenols mode of action can be different, depending also on which concentration and on which biological system is used (Khlebnikov et al. 2007). However, it is quite difficult to quantitatively establish the benefits afforded by polyphenols, because of the limited understanding of their bioavailability; generally, the small intestine can absorb polyphenols in the form of aglycones, but many of them in their native form are esters, glycosides or polymers that cannot be absorbed by the gut barrier (Crozier et al. 2009). Hence, these compounds must be metabolized by intestinal enzymes or the gut microflora (D'Archivio et al. 2007). Many studies have found correlations between intake of polyphenols and bone health (Henrotin et al. 2011; Shen et al. 2011; Rao et al. 2012; Welch and Hardcastle 2014), mainly due to their antioxidant properties, because oxidative stress plays an important role in the pathogenesis of osteoporosis with its promotion of an increase in bone resorption linked to direct/indirect actions on the differentiation and activity of osteoclasts (Callaway and Jiang 2015). Besides their scavenging properties, polyphenols can influence bone metabolism through downregulation of inflammatory mediators (Bodet et al. 2007), such as cytokines, primarily implicated in sustaining osteoclast differentiation and activity (Palmqvist et al. 2002; Park and Pillinger 2007; Yao et al. 2008), thus contributing to a reduction in bone resorption. Another important aspect to be taken into account is the bone anabolic effect exerted by polyphenols, shown by many experimental evidence which highlighted how it is promoted by effects on the osteoblast involving different signaling pathways such as $\mathrm{Wnt} / \beta$-catenin (Chen et al. 2010), insulin-like growth factor (IGF1) (Bu et al. 2009), bone morphogenetic proteins (BMPs) (Trzeciakiewicz et al. 2010a), Runt-related transcription factor 2 (Runx2) (Byun et al. 2014) and Osterix (Osx) (Santiago-Mora et al. 2011). Furthermore, because of a structural similarity to mammalian estrogens, some polyphenols such as isoflavones are 


\section{POLYPHENOL CLASSES}

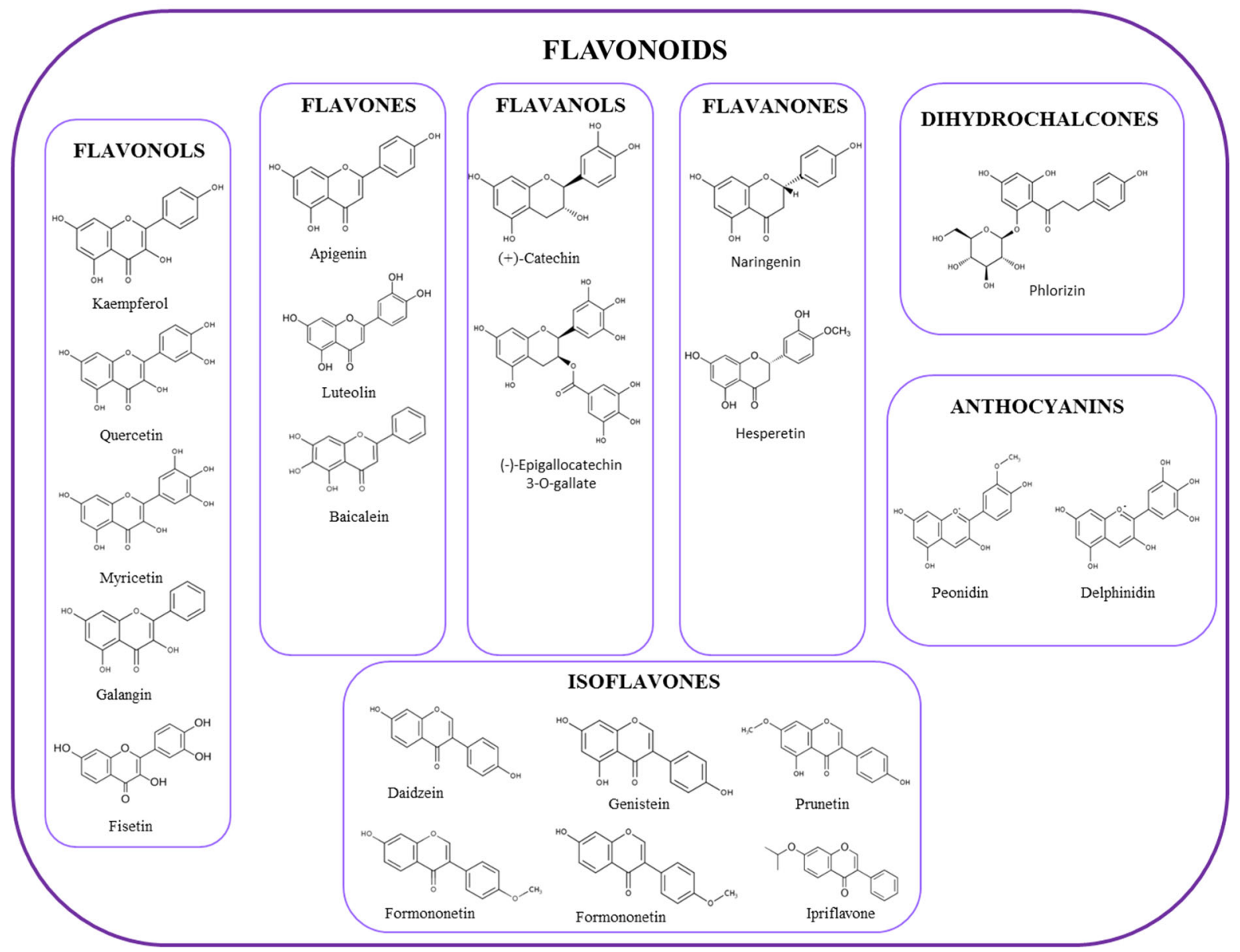

Fig. 1 Polyphenol classification. Principal classes of polyphenols and their relative most effective compounds (Rothwell et al. 2013)

also called phytoestrogens and are able to bind to estrogen receptors (ERs) $\alpha$ and $\beta$, thus acting as hormone analogs with different agonistic or antagonistic actions, depending on the tissue (Patisaul and Jefferson 2011).

As can be seen, their involvement in pathways that can cross-talk to other multiple transduction signals makes phenolic compounds a promising natural source to be employed in the development of plantbased therapeutics, with a wide application ranging from bone diseases, to cancers (Chen et al. 2014b), atherosclerosis (Loke et al. 2010), obesity (Tucakovic et al. 2015), diabetes (Dragan et al. 2015) and neurodegenerative disorders (Ebrahimi and Schluesener 2012). However, despite the renewed scientific interest in drug discovery from natural sources and the increasing demand in today's society for natural compounds (Chang and Jeong 2015; Rajesh et al. 2015; Farha and Brown 2016), still insufficient data are available to establish the real value of these compounds in the context of public health or clinical practice. Hence, it will be necessary a deeper study of the molecular mechanisms underlying polyphenol modes of action, with an even more detailed knowledge of the interaction of phenolic compounds with their molecular targets, to better clarify their pharmacological activity and, subsequently, to properly optimize medicinal chemistry approaches and more appropriate clinical trial designs, as well as the development of advanced biomaterials and improved tissue-engineering approaches.

Here, we discuss the molecular mechanisms involved in the anabolic effects induced by polyphenols, highlighting the signaling pathways shared 
between the diverse classes of phenolic compounds, in terms of a better understanding of an even greater application of these natural compounds in the bone tissue regeneration field.

\section{Estrogen signaling pathway}

Among sexual steroids, estrogens are the main female hormones that, in addition to their action in the development and maintenance of normal sexual and reproductive functions, play important roles in the control of different biological processes, with effects on the cardiovascular, musculoskeletal, immune and central nervous system (Gustafsson 2003).

The biological effects of estrogens are mediated through two distinct intracellular receptor forms, ER $\alpha$ and ER $\beta$, each encoded by different genes located on different chromosomes (Gosden et al. 1986; Kousteni et al. 2003).

Polyphenolic non-steroidal plant compounds with estrogen-like biological activity, estrogen receptor binding, ER-transactivation and estrogen dependent target gene expression are classified as phytoestrogens (Cos and Apers 2003) or selective estrogen receptor modulators (SERMs) and, as such, they can modulate the estrogen-dependent pathway by acting as partial agonists and/or antagonists of the ER in a tissue type and ligand concentration-dependent manner (Moutsatsou 2007). By activating the estrogen pathway, polyphenols are thus molecules able to regulate the expression of genes which, in bone, are responsible for the maintenance of bone mass, through a proper balancing between bone resorption and bone formation (Cauley 2015) (Fig. 3).

Based on their chemical structure, they can be classified into four main groups, which include isoflavonoids, flavonoids, stilbenes and lignans. Because of the structural similarity between phytoestrogens and $17 \beta$-estradiol (E2), based on the phenolic ring required for binding to the ER, as well as the presence of two hydroxyl groups (Harris et al. 2005), phytoestrogens exert their estrogenic activities by binding to ERs (Morito et al. 2001), thus activating the ER-dependent gene transcription, with a higher relative binding affinity for ER $\beta$ than ER $\alpha$ (Kuiper et al. 1998; Casanova et al. 1999). This relative selective binding of phytoestrogens to ER $\beta$ indicates that they may produce different effects from those exerted by estrogens, since estrogens bind to both ER $\alpha$ and ER $\beta$ with almost the same affinity (Morito et al. 2001), thus triggering distinct ER-mediated transcriptional events. On the other hand, some polyphenols, such as 8-prenylnaringenin (8-isoprene-4,5-7-hydroxy flavanone, isolated from the female flowers of Humulus lupulus), have been shown to preferentially bind to $\mathrm{ER} \alpha$ than to $\mathrm{ER} \beta$ and to promote osteoblast differentiation and inhibition of bone resorption with a stronger effect, compared to genistein and daidzein, at a dose of $10 \mu \mathrm{M}$ (Luo et al. 2014).

Besides the predominant effects of ER $\beta$, a wide range of structural forms of the ligand-receptor complex occur in generating a wider range of action for phytoestrogens, thus recruiting different co-activator or co-repressor proteins (Routledge et al. 2000). Furthermore, the potential hormonal effects of phytoestrogens on osteoblasts is pertinent with the different expression of the ER forms during the osteoblast differentiation stages, since ER $\beta$ is found to be greatly expressed during bone mineralization (Arts and Kuiper 1997). Binding of the ER with different compounds induces different conformational changes in the receptor.

Classical binding of estrogens to the ER in the cytosol, leads to a conformational change within the ER that promotes homodimerization, recruitment of the ER to the promoter region of transcription start sites, high affinity binding to specific cis-acting enhancers DNA response elements (ERE) located within the regulatory regions of target genes and recruitment of coactivators that stimulate gene transcription (O'Lone et al. 2004). In the case of genes whose promoters don't harbor EREs, ligand-bound ER can interact with transcription factor complexes like activator protein-1 (AP1) or specificity protein-1 (SP1), that tether the ER to the promoter, a process referred to as "non-ERE" or "transcription factor cross-talk" (Gustafsson 2003). Thus, phytoestrogens can act as pure agonists, as partial agonists or as pure antagonists. Different results, in literature, are given about agonistic or antagonistic activities of polyphenols, in fact coumestrol, apigenin, daidzein and genistein exhibit a strong agonistic activity for ERs at concentrations ranging from $10 \mu \mathrm{M}$ to $10 \mathrm{nM}$, while resveratrol, naringenin (a flavonoid found in Citrus medica), kaempferol and quercetin have been shown to have weak or even antagonistic activity for both ER $\alpha$ and ER $\beta$ (Miodini et al. 1999; Harris et al. 


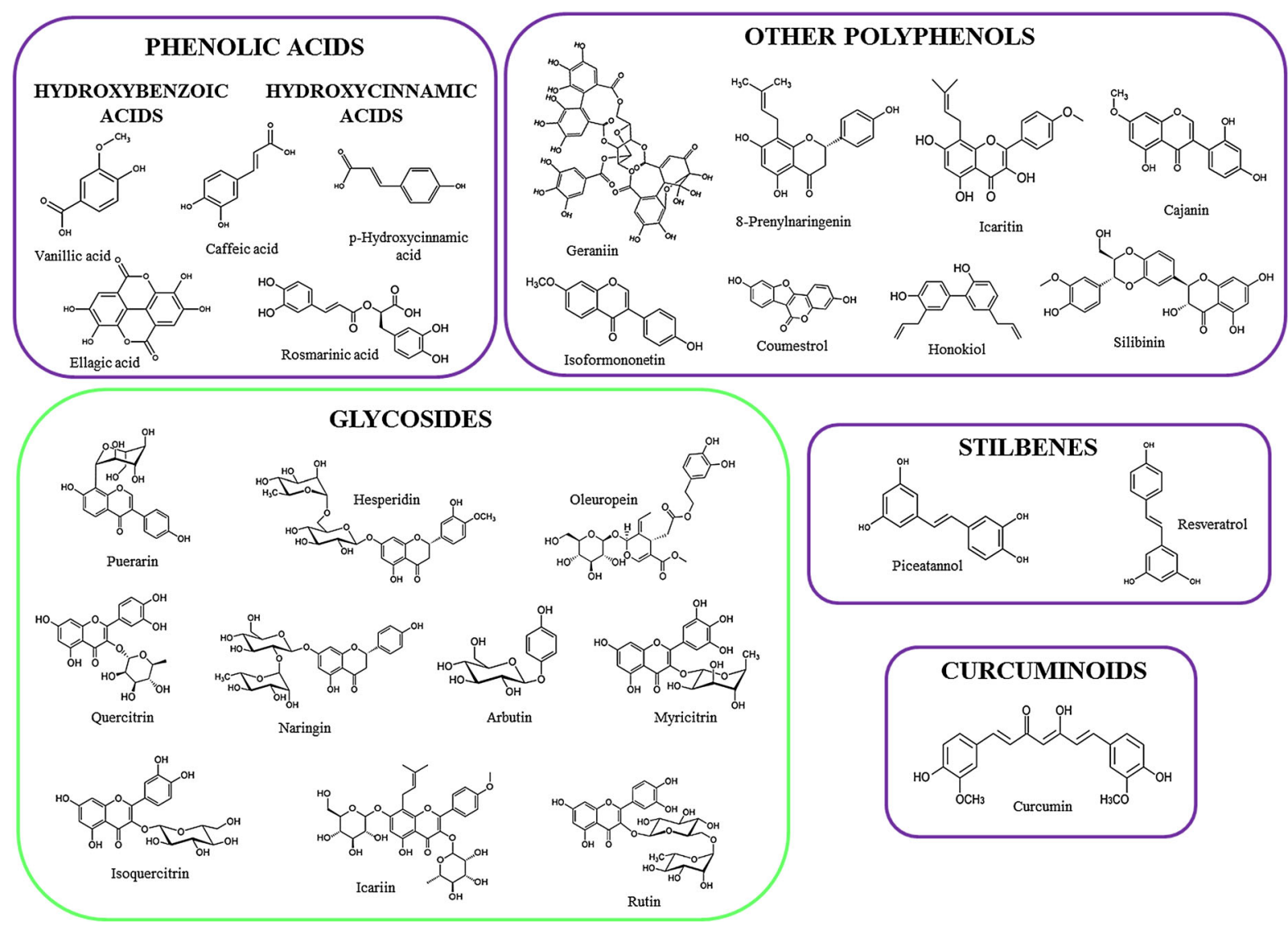

Fig. 2 Polyphenol classification. Principal classes of polyphenols and their relative most effective compounds (Rothwell et al. 2013)

2005; Tang et al. 2008b). Conversely, other authors found that quercetin mediates ERE-dependent transactivation with effects on stimulation of osteoblastic proliferation (Van Der Woude et al. 2005; Veprik et al. 2012).

Other phytoestrogens, following binding to the ER, have been observed to negatively target bone resorption through the classical ERE-mediated liganddependent pathway (Fig. 3). In fact, a possible interaction for quercetin and kaempferol with the ER, at concentrations of $0.1-10 \mu \mathrm{M}$, has been speculated on the basis of their inhibitory effects on bone resorption-although the estrogenic potency of kaempferol is greater than quercetin-significantly reversed by the use of the ER antagonist ICI 182780 (Wattel et al. 2003) and confirmed in a subsequent report showing, furthermore, that quercetin is able to act as selective ER modulator by upregulating ER $\beta$ and downregulating ER $\alpha$ expression (Rassi et al. 2005). Similarly, inhibition of osteoclastic bone resorption in rats and, conversely, stimulation of osteoblastic bone formation following a diet enriched with phlorizin (a flavonoid exclusively found in apple) $2.0 \times 10^{-4} \mathrm{~mol} /$ day and rutin $4.1 \times 10^{-3} \mathrm{~mol} / \mathrm{kg}$ have been postulated to be mediated through the ER (Horcajada-Molteni et al. 2000; Puel et al. 2005).

Apart from acting through EREs, phytoestrogens have been shown to interact, through the ERs, with other response elements, such as the antioxidant response element/electrophile responsive element (ARE/EpRE), thus inducing the transcription of the phase II detoxification enzymes (Fig. 3). Evidence for phytoestrogen modulation of ARE-regulated transcription is provided by Veprik et al., that report the involvement of the nuclear factor E2-related factor 2 (Nrf2)/ARE transcription system in the activation of estrogen signaling in two osteoblast-like cell lines (Veprik et al. 2012), while cyclic adenosine monophosphate (cAMP) response elements (CREs) have been shown to be targeted by soy isoflavones, 


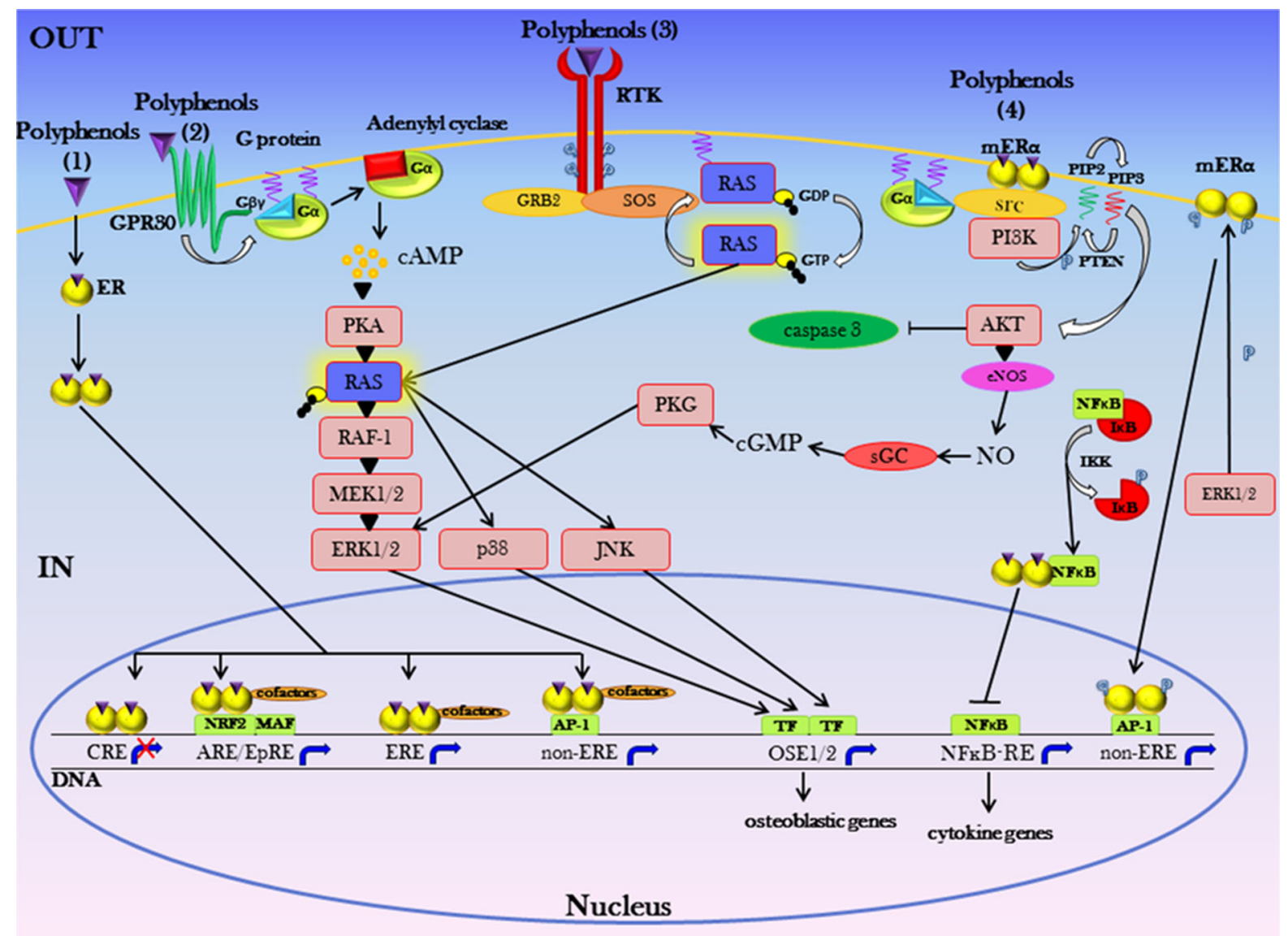

Fig. 3 Influence of polyphenols on bone metabolism through estrogen signaling. Binding of phenolic compounds to ERs leads to activation of the canonical and noncanonical estrogen pathways, with a crosstalk with MAPKs and PI3K/Akt signaling. GRB2 growth factor receptor-bound protein 2, SOS son of sevenless, $R T K$ receptor tyrosine kinase, GDP guanosine diphosphate, $O S E 1 / 2$ osteoblast-specific element $1 / 2, M A F$ MAF

which suppress CRE-mediated transcriptional activity through ERs and mRNA expression of genes that contain CRE/CRE-like elements in their promoter in osteoblastic cells (Tang et al. 2011).

Phytoestrogens not only target the classical ER pathway, but also the rapid non-genomic signaling, in a ligand-dependent or independent manner (Fig. 3). The "nongenomic" action differs from the genomic one, since it involves a series of rapid events deriving from the interaction between cell-surface ER forms that are linked to intracellular signal transduction proteins, such as the $\mathrm{G}$ protein-coupled receptor 30 (GPR30). These non-genomic events may be mediated protein, $G_{\alpha}$ G protein $\alpha$ subunit, $G_{\beta \gamma}$ G protein $\beta \gamma$ subunits. (1) Resveratrol, curcumin, daidzein, genistein, kaempferol, puerarin, coumestrol, apigenin, quercetin. (2) Vanillic acid, icariin, prunetin, resveratrol, daidzein, genistein, quercetin, kaempferol. (3) Daidzein, genistein, resveratrol, icariin, quercetin, kaempferol. (4) Resveratrol, genistein, daidzein, quercetin, rutin

by diverse main signaling cascades: phospholipase $\mathrm{C}$ (PLC)/PKC, Ras/Raf/MAPK, PI3K/AKT and cAMP/ protein kinase A (PKA) (Björnström and Sjöberg 2005).

Vanillic acid (VA), isolated from Sambucus williamsii, for example, differs from other phytoestrogens like genistein, because it does not bind to either $\mathrm{ER} \alpha$ or $\mathrm{ER} \beta$, nor induces ERE-dependent transcription. In fact, VA has been shown to upregulate the expression of osteoblastic differentiation markers, such as Runx2, osteocalcin (OCN) and osteoprotegerin (OPG), by activating the rapid nongenomic ER pathway at concentrations of $0.01 \mu \mathrm{M}$ 


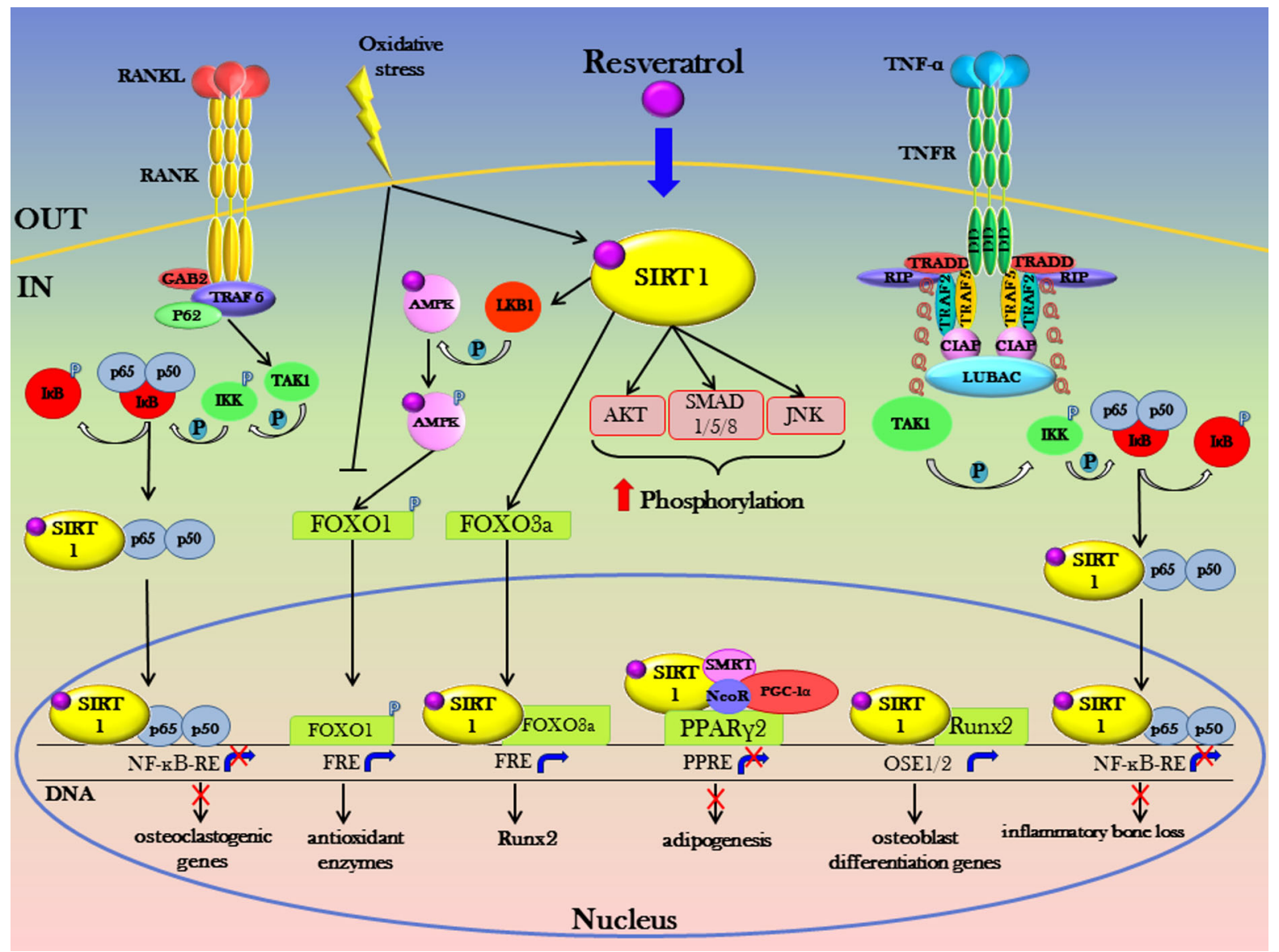

Fig. 4 SIRT1-mediated bone anabolic effects of resveratrol. The ability of resveratrol to bind to SIRT1 and to subsequently increase its enzymatic activity provides a reply aimed at enhancing the osteoblast differentiation process, through the parallel decrease of adipogenesis. Impairment of osteoclast differentiation and function is also achieved through decreasing the DNA binding activity of NFKB, thus inhibiting RANKL and TNF- $\alpha$-induced transcription of genes involved in

and $0.1 \mathrm{nM}$, through phosphorylation of MEK1/2, ERK1/2 and ER $\alpha$ (Xiao et al. 2014b). Also ipriflavone (7-isopropoxyisoflavon, isolated from Medicago sativa) has been shown not to bind to the ER, but to a unique steroid receptor superfamily binding site in the nucleus of pre-osteoblastic cells and not to induce ERE-dependent gene transcription (Petilli et al. 1995). Furthermore, icariin, the principal flavonoid glycoside found in Herba Epimedii, also acts like a phytoestrogen through the non-classical ER-dependent pathway (Xiao et al. 2014a), because its effects on osteoblast proliferation, differentiation and mineralization, at doses ranging from 5 to $40 \mu \mathrm{M}$, are reached by osteoclastogenesis. GAB2 GRB2-associated-binding protein 2, $T R A D D$ tumor necrosis factor receptor type 1-associated death domain, $R I P$ receptor-interacting protein kinases, CIAP cellular inhibitor of apoptosis, LUBAC linear ubiquitination assembly complex, $P G C-1 \alpha$ peroxisome proliferator-activated receptor gamma coactivator-1 alpha, PPRE PPAR response element, FRE FOXO response element, $Q$ ubiquitin, $P$ phosphorylation

activating AP-1 through the up-regulation of c-fos and c-jun via activation of extracellular signal-regulated kinase (ERK) and c-Jun N-terminal kinase (JNK) pathways (Song et al. 2013; Wu et al. 2015b). Thus, icariin could have therapeutic effects on osteoporosis (Zhang et al. 2009), by enhancing osteoblastic differentiation and suppressing osteoclastic differentiation (Chen et al. 2007; Huang et al. 2007; Hsieh et al. 2011).

G protein-coupled estrogen receptor 1 (GPER), also known as GPR30, is a member of the 7-transmembrane G protein-coupled receptor (GPCR) family, capable of mediating both transcriptional and 


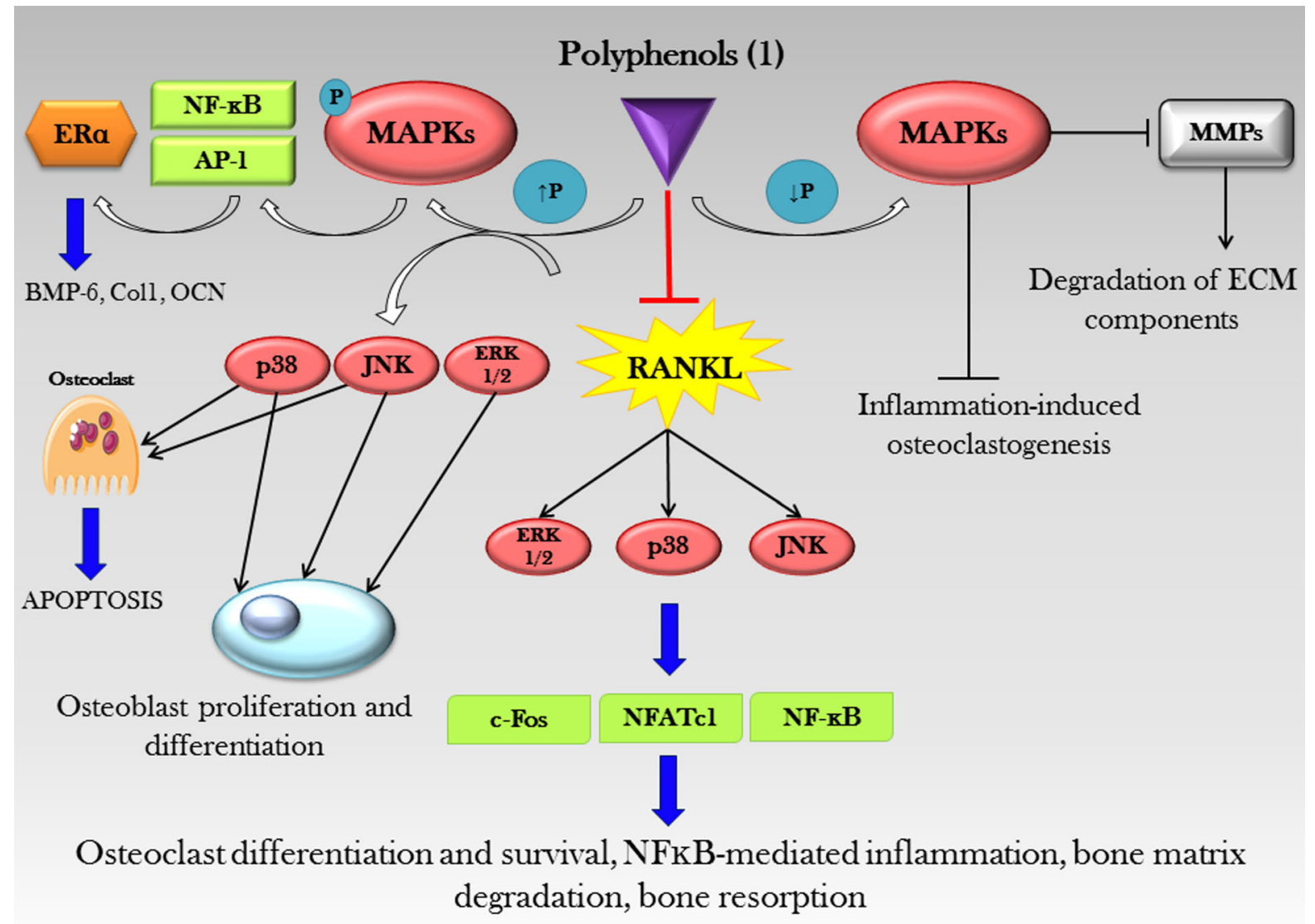

Fig. 5 Polyphenol beneficial effects on bone diseases are mediated through actions on the MAPKs cascade. Different effects are obtained on the basis of MAPKs phosphorylation state, in fact polyphenols are able to either increase or to decrease phosphorylation, thus determining osteoblast proliferation and differentiation and inhibition of inflammation-induced

nongenomic events in response to estrogen (Prossnitz et al. 2008). An example of a positively acting polyphenol on bone metabolism, through binding to the GPR30, is given by prunetin isoflavone (found in red clover and fruit of Prunus avium), which, at $0.01 \mu \mathrm{M}$, selectively binds to the GPR30, thus stimulating osteoblast proliferation and differentiation through the production of cAMP and through activating ERK/MAPK, as well as leading to expression of Runx2 in osteoblasts (Khan et al. 2015) (Fig. 3).

Given the evidence that the ER is expressed by mesenchymal stem cells (MSCs), osteoblasts and osteoclasts (Vidal et al. 1999; Windahl et al. 2000), it is clear that estrogen and estrogenic compounds osteoclastogenesis, respectively. (1) Geraniin, daidzein, genistein, quercetin, curcumin, caffeic acid, CADPE, furosin, coumestrol, EGCG, A-type proanthocyanidins, (2S)-2' methoxykurarinone, icariin, apigenin, cajanin, isoformononetin, HCA, ugonin $\mathrm{K}$, baicalein, quercitrin

exert pleiotropic effects on bone metabolism on the basis of which cell type they target.

First of all, phytoestrogens are capable of influencing MSCs, by enhancing osteogenic differentiation, while suppressing the adipogenic one via a nongenomic mechanism ER-mediated ( $\mathrm{Li}$ et al. 2005). In this context, supplementation of $1 \mu \mathrm{M}$ genistein has been reported to increase osteogenesis in human bone marrow stromal cells (hBMSCs) at day 18 of incubation, by acting on gene expression markers, such as Runx2 and alkaline phosphatase liver/bone/kidney (ALPL), involved in the early stages of differentiation of human primary MSCs (Heim et al. 2004). Ability of isoflavones to suppress adipogenic differentiation of adipose tissue-derived (AD) MSCs has also been 


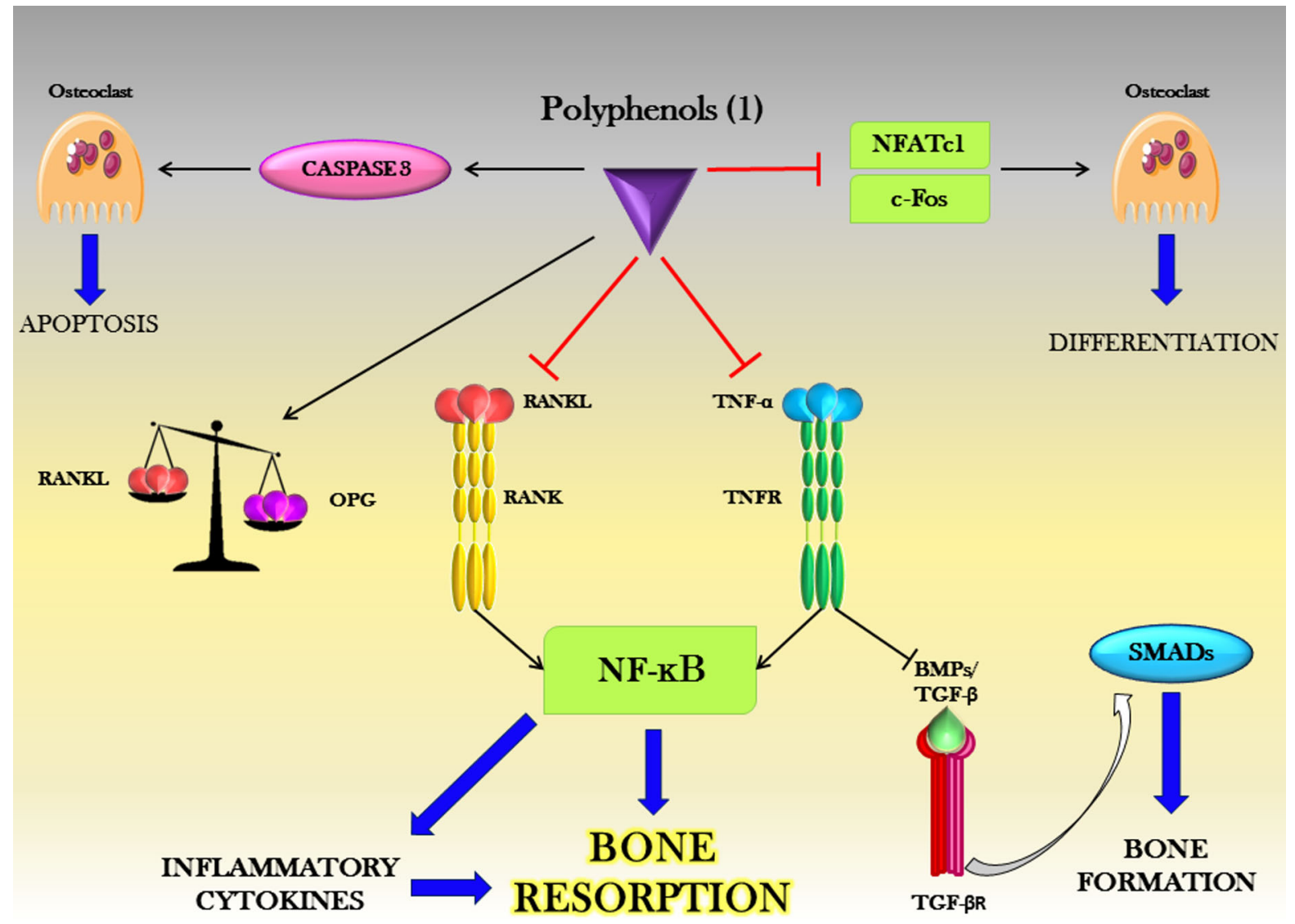

Fig. 6 Anti-inflammatory properties of polyphenols in controlling bone resorption. Inflammation-induced activation of $\mathrm{NF}-\kappa \mathrm{B}$ is inhibited by polyphenols, which are effective in triggering osteoclast apoptosis and inhibiting osteoclast differentiation. Thus, they play a role in shifting the RANKL/OPG ratio in favor of OPG. (1) HCA, curcumin, galangin, genistein,

investigated in the contest of $\mathrm{Wnt} / \beta$-catenin signaling using an estrogen antagonist. The results show that these phytoestrogens, at $0.01-100 \mu \mathrm{M}$, do inhibit ADMSCs differentiation in mature adipocytes through a stimulation of Wnt signaling mediated by both nongenomic and genomic ER-dependent pathways (Kim et al. 2010). These opposite effects on osteogenic and adipogenic differentiation are likely due to a different expression of the ER subtypes in the MSCs during the developmental stages, implying cell-specific differences in the estrogenic sensitivity. Indeed, all ERs already present in MSCs are up-regulated during osteogenesis, with the $\beta 5$ splice variant strongly expressed and, except for ER $\alpha$, downregulated during adipogenesis (Heim et al. 2004). Effects on MSCs proliferation have also been seen following treatment resveratrol, EA, geraniin, rutin, A-type pro-anthocyanidins, CADPE, delphinidin, fisetin, peonidin, honokiol, rosmarinic acid, arbutin, oleuropein, silibinin, luteolin, myricetin, EGCG, (+)-catechin, naringenin, apigenin, kaempferol, quercetin, quercitrin, formononetin, tyrosol

with resveratrol, which has been shown, at $1 \mu \mathrm{M}$, to directly stimulate cell proliferation, osteoblastic differentiation and osteogenic gene expression through induction of ER signaling and MAPK activation, with involvement of ERK1/2 and p38, playing a positive and a negative role on cell proliferation and osteoblast differentiation, respectively (Dai et al. 2007) (Fig. 3).

The role of polyphenols in bone anabolism is further supported by in vitro studies investigating the effects of isoflavones on osteoblast activity, showing increased protein synthesis, DNA content and alkaline phosphatase activity (Yamaguchi and Gao 1997); given that the presence of E2 caused a significant increase in protein content and alkaline phosphatase activity and that the anti-estrogen tamoxifen blocked the effects, the mechanism proposed by the authors 
partly involves the estrogen pathway (Yamaguchi and Gao 1997; Sugimoto and Yamaguchi 2000a, b; Yamaguchi and Sugimoto 2000). A study from Guo et al. (2012a) showed that kaempferol, at $50 \mu \mathrm{M}$, is able to stimulate osteogenic differentiation of cultured osteoblasts by the activation of ER $\alpha$ via a classical ER signaling pathway, while quercetin, at low concentrations $(1-10 \mu \mathrm{M})$ and curcumin and resveratrol at 2.5 and $10 \mu \mathrm{M}$, respectively, have been shown to stimulate cell proliferation (Van Der Woude et al. 2005; Veprik et al. 2012). Isoflavones such as daidzein and genistein, have been shown to stimulate osteoblast differentiation through enhancing Runx2 expression levels and bone morphogenetic protein (BMP)-2 signaling with a mechanism involving the ER (Jia et al. 2003; Dai et al. 2013; Hinenoya 2013). Increased Runx 2 expression, the master osteogenic transcription factor playing a major role in osteoblast maturation (Spilmont et al. 2013), is thus an obvious consequence of stimulation of osteoblastogenesis: ellagic acid (EA), for example, increases Runx2 expression by acting as a prebiotic in the intestine ( $\mathrm{Li}$ et al. 2015b), thus contributing to the enhancement of calcium $(\mathrm{Ca})$ absorption (Roberfroid et al. 2010) and pathways involving the ER (Papoutsi et al. 2005, 2008).

Osteoblastic activity has also been demonstrated to be stimulated by the flavonoids quercetin and kaempferol at $50 \mu \mathrm{M}$, which significantly increased ALP activity through activating ERK downstream of the ER (Prouillet et al. 2004), with involvement of a nongenomic mechanism and by the isoflavone daidzein, which, at $1 \mathrm{nM}$, increased the amount of the transcription factor RUNX2, ALP expression and the mineralization rate of osteoblasts via ER-dependent pathways (De Wilde et al. 2004). A direct stimulatory action on bone mineralization via the ER has been recognized as a resveratrol-mediated effect, which dose-dependently $(1 \mu \mathrm{M})$ increased ALP activity, suggesting an estrogen-like action for resveratrol (Mizutani et al. 1998). Increased ALP activity has also been observed following treatment with coumestrol $(1 \mu \mathrm{M})$, genistein and daidzein, with a higher estrogenic activity for coumestrol than genistein and daidzein (Kanno et al. 2004a). In vitro studies with human and animal osteoblasts or osteoblast-like cell lines have also been carried out to explore the action of polyphenols on bone formation, showing suppressed proliferation and parallel stimulatory effects on the differentiation of osteoblasts (Choi et al. 2001; Yoshida et al. 2011).

Estrogen and genistein have been also demonstrated to upregulate OPG through a direct interaction with the ER in human osteoblast cultures (Hofbauer and Khosla 1999; Viereck et al. 2002) and to induce OPG transcription through a DNA-binding independent nuclear mechanism (Roforth et al. 2014) and, in support of these data, a progressive up-regulation in the OPG:receptor activator of nuclear factor kappa-B ligand (RANKL) ratio during the osteoblast differentiation establishes a role for genistein in the maintenance of bone homeostasis, with a major impact on the relative balance between osteoblast and osteoclast number. Polyphenols from Drinaria fortunei and Pueraria mirifica, have been demonstrated to stimulate osteoblast proliferation, to increase OPG/RANKL ratio and to upregulate the expression of osteoblast differentiation markers, such as collagen type 1 (Col1), OCN and ALP, in an ER-dependent manner (Wang et al. 2011; Sheu et al. 2012; Wong et al. 2013; Tiyasatkulkovit et al. 2014).

Given that estrogen can enhance osteoblast activity also through a nitric oxide (NO)-dependent mechanism (O'Shaughnessy et al. 2000), in which NO-cyclic guanosine monophosphate (cGMP) pathway stimulates osteoblast replication and ALP activity (Mancini et al. 2000), the role of this pathway has been investigated in mediating the action of genistein on growth and osteoblastic differentiation of MSCs cultures (Pan et al. 2005). The results show that genistein, at $1 \mu \mathrm{M}$, stimulates proliferation and osteoblastic differentiation of MSCs via activation of the ER-dependent NO-cGMP pathway, by upregulating Runx2 gene expression (Fig. 3). In contrast to these anabolic effects, genistein supplemented to rat models at high doses $\left(1.85 \times 10^{-4} \mathrm{~mol} / \mathrm{kg}\right)$ causes adverse effects on bone cells (Li et al. 2012), probably via ER-independent mechanisms, whose results are in line with the reported genistein biphasic effect on the growth of breast cancer cells (Anderson et al. 1998). Stimulation of osteoblastic proliferation and differentiation via NO-cGMP signaling pathway has also been shown to be induced by resveratrol $(1 \mu \mathrm{M})$, which structurally resembles E2 and, thus, mimics E2 activity (Song et al. 2006).

Shortening of osteoblast lifespan is one of the hallmarks that, together with increased osteoclast activity and survival, contributes to the emergence of 
the osteoporotic disease (Manolagas 2000). In this respect, phytoestrogens have been demonstrated to prolong osteoblast lifespan in an estrogen-like manner, through inhibiting tumor necrosis factor- $\alpha$ (TNFa)-induced apoptosis (Suh et al. 2003).

The inhibitory effect of polyphenols on bone resorption has been widely studied, showing inhibition of osteoclast-like cell formation in mouse marrow cultures (Gao and Yamaguchi 1999a) and inhibitory effect on bone resorption induced by various boneresorbing factors (Yamaguchi and Gao 1998), through an estrogen-like mechanism.

Concerning apoptosis, different experimental evidence emerge from literature indicating anti-resorbing actions of polyphenols directly exerted on mature osteoclasts and their progenitors, through a molecular mechanism ER-mediated that involves activation of caspase-8 and caspase-3 (Rassi et al. 2002, 2005). Furthermore, the activation of ER signaling by genistein increased transforming growth factor- $\beta 1$ (TGF- $\beta 1$ ) expression during osteogenesis, especially in the final stages of osteoblast maturation (Heim et al. 2004), thereby contributing to osteoclast apoptosis (Hughes et al. 1996; Houde et al. 2009).

The anti-resorbing properties of flavonols are mainly mediated by ERs, through the inhibition of receptor activator of nuclear factor kappa-B (RANK) protein, thus directly targeting osteoclast progenitors. In this respect, unlike estrogen which does not alter the expression of RANK, but acts on c-jun activity to regulate the differentiation potential of osteoclast progenitors (Shevde et al. 2000), rutin, at $0.01 \mu \mathrm{M}$, has been shown to down-regulate RANK protein (Rassi et al. 2005).

On the other hand, daidzein, genistein and coumestrol, at $\mu \mathrm{M}$ concentrations, exert anti-osteoclastogenic effects through an ER-dependent mechanism that regulates the expression of genes involved in osteoclast formation, such as c-fos and nuclear factor of activated T-cells 1 (NFATc1) (Karieb and Fox 2011).

Polyphenols exert their anti-resorbing action by also regulating inflammatory cytokines responsible for bone resorption and, subsequently, degenerative bone diseases (Fig. 3). In fact, a large number of cytokines have been shown to regulate osteoclast formation and function, thus influencing their ability to resorb bone. As the most potent cytokine stimulator of bone resorption in vitro (Lorenzo et al. 1987), interleukin (IL)-1 possesses the ability to directly (Jimi et al.
1999) and indirectly (Hofbauer et al. 1999) act on osteoclasts, thus contributing to the development of chronic inflammatory diseases such as periodontitis. Genistein, with its tyrosine kinase inhibitory activity, has been shown to regulate, at $10 \mu \mathrm{M}$, the IL-1 $\beta$ induced activation of MAPKs in periodontal ligament cells (PDL) through a nongenomic mechanism involving the GPR30 (Luo et al. 2012). Conversely, Chen et al. (2002, 2003) described inhibition of IL-6 production and enhancement of OPG expression by genistein, as mediated through estrogen receptors and ERE-dependent pathways, thus regulating osteoclastogenesis. Direct stimulation of $\mathrm{ER} \alpha$ and $\operatorname{ER} \beta$ on osteoblasts by puerarin (daidzein 8-C-glycoside), the main isoflavone glycoside found in the Chinese herb radix of Pueraria lobata (Zhang et al. 2007), and genistein leads to increased OPG/RANKL ratio (Yamagishi et al. 2001) and decreased IL-6 levels, through an ERE-dependent direct genomic mechanism involving the ER $\beta$ and the ER $\alpha$ (Wang et al. 2014c). The work from Zhang et al. (2007) showed that these bone anabolic effects are mediated via activation of different signaling pathways cross-talking with the ER, such as the MAPKs and the PI3K/Akt (Zhang et al. 2007; Sheu et al. 2012; Wang et al. $2013 b$ ), following stimulation of the ER $\beta$ (Sheu et al. 2012) (Fig. 3). Soybean isoflavones can also inhibit secretion of TNF- $\alpha$-induced IL- 6 and prostaglandin E2 $\left(\mathrm{PGE}_{2}\right)$ from osteoblastic cells, suggesting an antiresorptive action of soy phytoestrogens (Suh et al. 2003). Furthermore, $\mathrm{PGE}_{2}$ production in osteoblasts is also inhibited by resveratrol, which suppresses proliferation of osteoclasts and stimulates mineralization (Morita et al. 1992).

Finally, given their antioxidant properties, polyphenols also counteract the deleterious effects of oxidative stress in osteoblastic cells, through different molecular mechanisms also involving the ER and the PI3K signaling pathways (Choi 2012).

Emerging evidence shows that a phytoestrogenrich diet provides an array of potent biological activities. Results, however, are contradictory (Adlercreutz 2002; Adlercreutz and Heinonen 2004), in fact phytoestrogen hormonal activity depends on different factors, such as the metabolism, the route of administration, the dosage, the developmental stage, the chemical structure and the endogenous estrogenic status. 


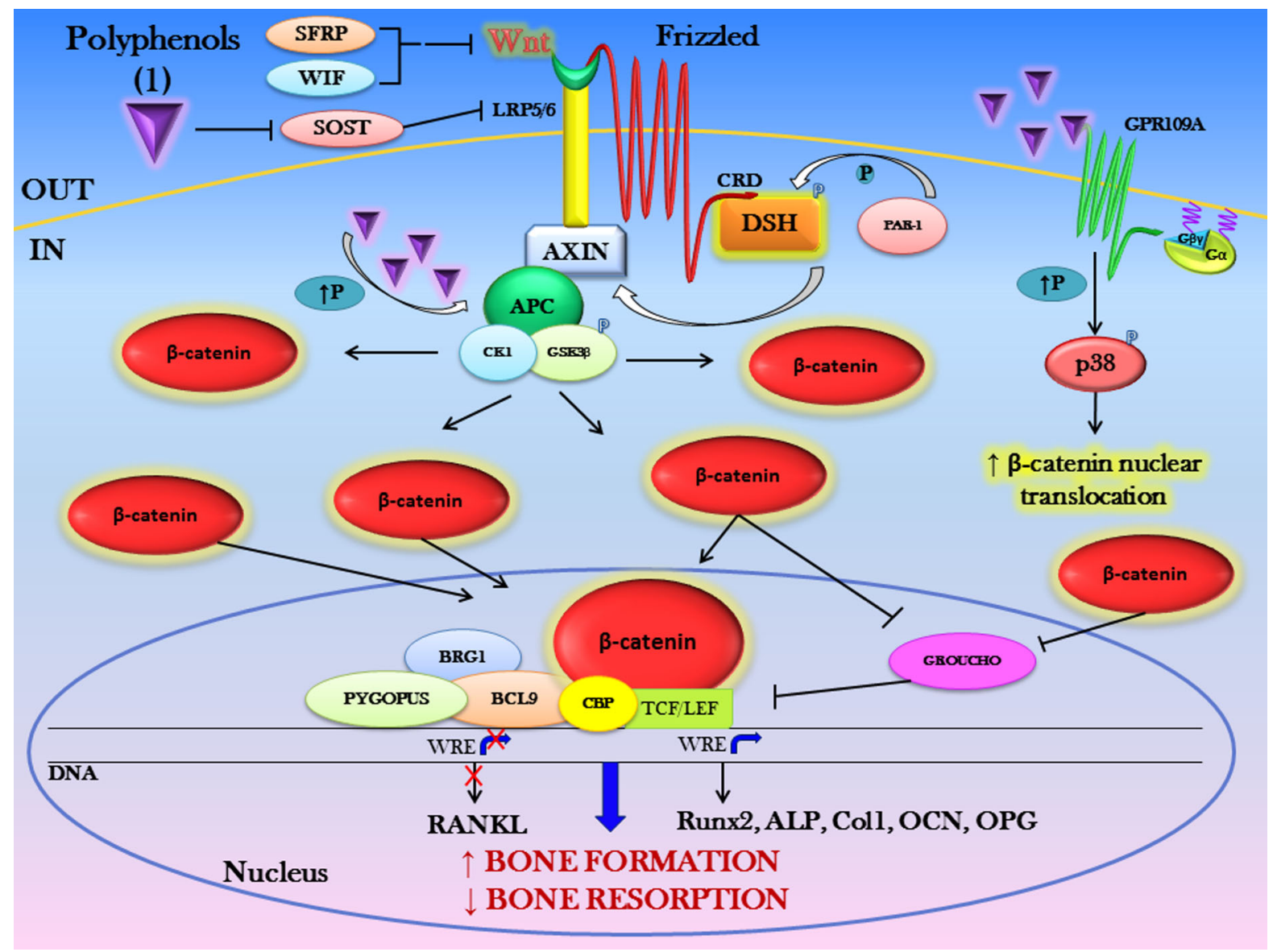

Fig. 7 The osteogenic Wnt/ $\beta$-catenin pathway and its interplay with polyphenols. Accumulation of $\beta$-catenin in the cytosol and its nuclear translocation are favored by phenolic compounds, which thus exert stimulatory effects on bone formation. Conversely, polyphenols inhibit bone resorption, through

Furthermore, because the potency of phytoestrogens is much lower than estradiol, estrogenic effects of phytoestrogens on bone may be of minimal impact, or even antagonistic in the face of endogenous estrogen levels.

\section{Sirt1 signaling pathway}

The sirtuins (silent information regulator 2-Sir2) are highly conserved nicotinamide adenine dinucleotide (NAD)-dependent enzymes that deacetylate residues of acetylated lysine, resulting in transcriptional silencing (Imai et al. 2000).

Sirtuin 1 (Sirt1) is a multifaceted class III histone deacetylase involved in a wide variety of cell decreasing RANKL expression and relieving SOST inhibitory action on Wnt receptor. SFRP secreted frizzled-related protein 1, WIF Wnt inhibitory factor $1, C R D$ cysteine rich domain, $C K 1$ casein kinase 1. (1) Baicalein, myricetin, orientin, luteolin, curcumin, EGCG, resveratrol, phenolic acids

processes, ranging from cancer to ageing, which has been conserved throughout evolution from yeast to human and is a crucial link between cell metabolism, longevity and stress response (Brooks and Gu 2009).

Several studies (Schneider-Stock et al. 2012) have been shown evidence for a role of polyphenols in epigenetic modifications, by altering DNA methylation and histone modifications, thus leading to gene activation or silencing. One of the most potent activators of Sirt1 is resveratrol, because of its ability to bind to a special binding site in Sirt1, which induces a conformational change in the protein, resulting in an increased enzymatic activity (Howitz et al. 2003). Given the reciprocal relationship between osteogenesis and adipogenesis in MSCs, Sirt1 activation by resveratrol at $50 \mu \mathrm{M}$ leads to decreased adipocyte 


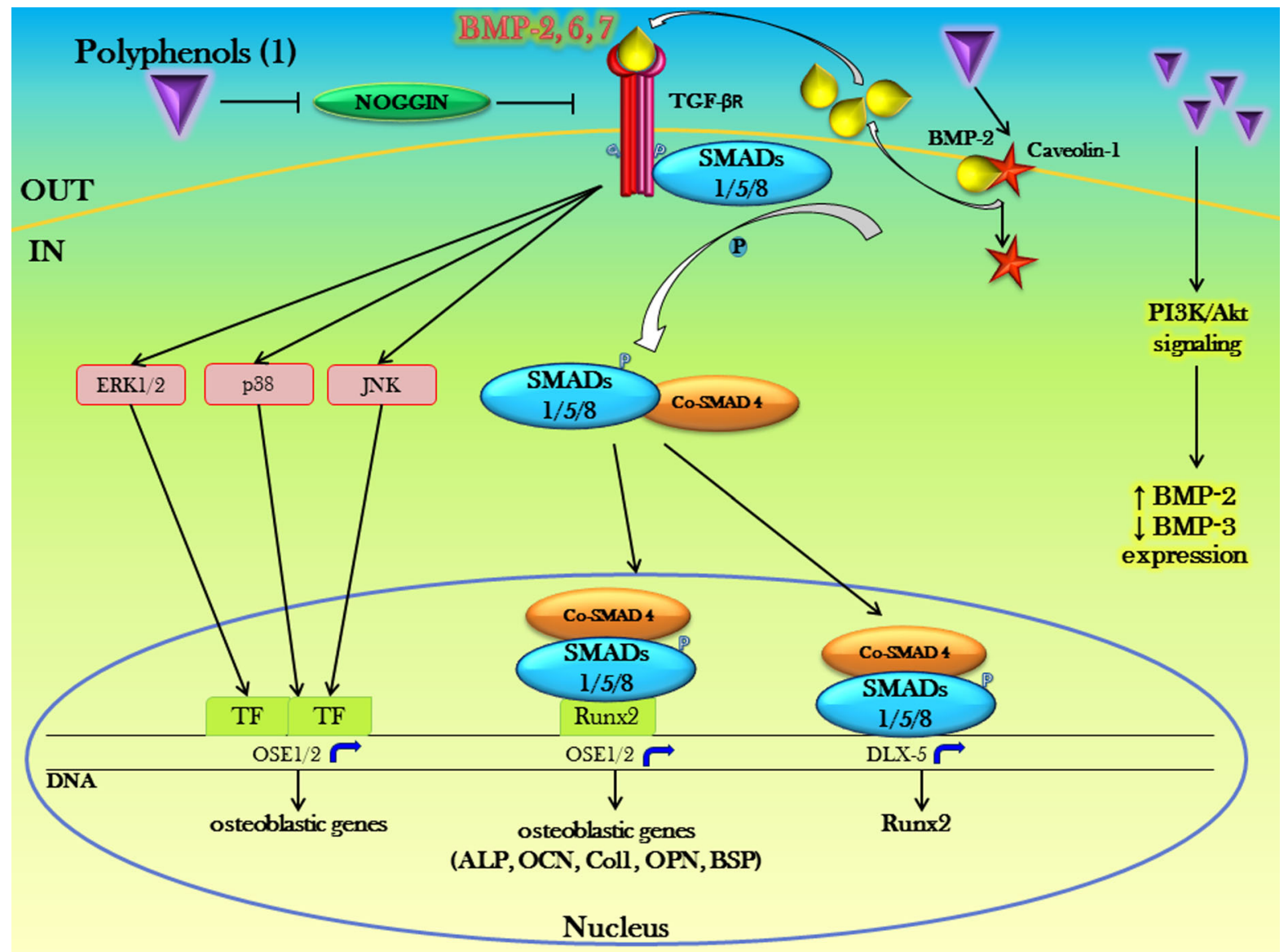

Fig. 8 Polyphenols counteract bone disease also through BMP signaling. BMP-2, BMP-6 and BMP-7 are induced by polyphenols to activate the SMAD cascade and, so, to express osteoblastic genes important in osteoblast differentiation and function. The parallel inhibition of NOGGIN and BMP-3

differentiation and increased osteoblast differentiation (Bäckesjö et al. 2008). The mechanism by which resveratrol inhibits adipogenesis and mediates differentiation of MSCs to osteoblasts appears to involve, on one hand, a Sirt1-dependent indirect inhibition of peroxisome proliferator-activated receptor gamma (PPAR $\gamma)$, through the interaction of Sirt1 with nuclear receptor co-repressor (NCoR) (Shakibaei et al. 2012) and, on the other, the direct activation of Runx2 (Tseng et al. 2011) (Fig. 4). Given that Sirt1 has no inherent DNA binding ability, its effects on osteogenic differentiation are mediated through Runx 2 transcription factor, by forming a Sirt1-Runx2 complex (Shakibaei et al. 2011), in which Sirt1 deacetylates Runx2, resulting in suppressed adipogenesis and expression further contributes to these osteoanabolic effects. $D L X-5$ distal-less homeobox 5. (1) EGCG, puerarin, icariin, hesperidin, imperatorin, bergapten, syringetin, resveratrol, myricetin, apigenin, silibinin, isoquercitrin, sylimarin, piceatannol, naringin, $\mathrm{CAFG}$, quercetin

activated osteogenesis (Shakibaei et al. 2012). These results were further confirmed by using immortalized human periodontal ligament cells, in which activation of Sirt1 by resveratrol, at $50 \mu \mathrm{M}$, increased mineralized nodule formation and upregulated the expression of mRNAs encoding osteoblastic markers (Lee et al. 2011b). Being resveratrol an agonist of Sirt1, its beneficial actions on osteoblastic differentiation are also achieved through production of Coll and osteopontin (OPN). The precise mechanism of this induction is represented by activation of SIRT1 and diminished expression of $\mathrm{pI \kappa \textrm {B }} \alpha$ and nuclear factor kappa-light-chain-enhancer of activated $\mathrm{B}$ cells (NF$\kappa \mathrm{B})$ subunit p65, thus promoting osteoblast differentiation (Feng et al. 2014) (Fig. 4). Moreover, 
resveratrol-mediated activation of Sirt1 enhanced phosphorylation of downstream kinases, reported to contribute to osteoblastic differentiation in bone cells and osteoblasts, such as PKB/Akt, Small Mother Against Decapentaplegic (SMAD)1/5/8, 5'-adenosine monophosphate protein kinase (AMPK) and MAPKs (Lee et al. 2011b). Resveratrol, at $5 \mu \mathrm{M}$, can also exert anti-osteoclastogenic effects via activating Sirt-1 pathway, in particular through inhibiting RANKLinduced NF- $\mathrm{KB}$ (Shakibaei et al. 2011), by reducing the levels of osteoclast activity markers, such as IL-6, TNF- $\alpha$ and tartrate-resistant acid phosphatase (TRAP)-5b and by contributing to maintaining a normal RANKL/OPG ratio (Zhao et al. 2015). Activation of Sirt1 pathway by resveratrol and the subsequent AMPK phosphorylation, repress the inflammatory responses mediated by the NF- $\kappa \mathrm{B} /$ MAPK pathway, while the enhanced expression of antioxidant enzymes following activation of the Nrf2/ antioxidant defense pathway leads to inducible nitric oxide synthase (iNOS) inhibition and, thus, to reduced nitrosative stress (Tamaki et al. 2014) (Fig. 4). Finally, resveratrol 2-50 $\mu \mathrm{M}$ also reverses the ironoverload-induced downregulation of Runx2, Col1 and OCN via Sirt1 activation, showing a potential in counteracting oxidative stress (Zhao et al. 2015).

Resveratrol also acts on bone architecture by promoting a proper bone remodeling, through reducing prostaglandin E1 (PGE1), prostaglandin D2 (PGD2 ), prostaglandin F $2 \alpha$ (PGF2 $\alpha$ ) and basic fibroblast growth factor 2 (FGF-2)-stimulated OPG production, through a mechanism involving SIRT1 activation and inhibition of Akt and MAPKs signaling (Kuroyanagi et al. 2014a, b, c; Yamamoto et al. 2015).

\section{Mapks cascade}

Transduction of extracellular signals to cellular responses is mediated by different information-processing circuits. These molecular circuits detect, amplify and integrate different external signals to generate molecular responses such as gene transcription and expression that translate to metabolic responses, which regulate cell proliferation, cell differentiation, metabolism, motility, survival and apoptosis (Zhang et al. 2002).

Mitogen-activated protein kinases are Ser/Thr protein kinases that transduce extracellular signals from membrane-bound activated tyrosine kinase receptors to the nucleus. The MAPKs pathway can be activated in most, if not all, of the vertebrate cells by a wide variety of receptor tyrosine kinases (TRKs), giving rise to multiple cross-talks with other signaling pathways thanks to the association with different scaffold proteins and to different docking motifs.

Several works (Ge et al. 2007; Ikeda et al. 2008; Matsuguchi et al. 2009; Thouverey and Caverzasio 2012; Lee et al. 2016) revealed that MAPKs are implicated in the regulation of bone mass, being mediators of osteoblast activity and osteoclast differentiation.

Activation of MAPKs signaling pathway by polyphenols has been demonstrated in different cellular systems, in a direct or indirect manner.

Their beneficial actions on bone metabolism are also achieved through molecular mechanisms targeting MAPKs pathway, which translate in regulation of osteoclast differentiation, bone resorption and promotion of osteoblast proliferation, differentiation and functions.

Polyphenols have been shown to negatively act on genes involved in RANKL-induced osteoclast differentiation, such as NFATc1 (Zhao et al. 2010b), c-fos (Grigoriadis et al. 1994), NF- $\mathrm{KB}$ and AP-1, through regulating ERK1/2, p38 and JNK MAPKs expression and phosphorylation (Kim et al. 2006a; Pang et al. 2006; Murakami et al. 2007; Tsai et al. 2008; Kim et al. 2008b, 2009, 2011b; Huh et al. 2013; Léotoing et al. 2013; Nepal et al. 2013; Sakai et al. 2013; Heo et al. 2014; Lee et al. 2014b, 2015) (Fig. 5).

Cross-talking with other molecular signaling pathways is also a common fact, in fact the increased phosphorylation of MAPKs induced by polyphenols such as genistein, also induces ER $\alpha$ gene expression, which stimulates osteoblast differentiation and maturation, by increasing BMP-6, Col1 and OCN gene levels (Liao et al. 2014) (Fig. 5).

Osteoprotective effects (Lu et al. 2015) by geraniin (the main polyphenolic component of Geranium thunbergii) at $\mathrm{nM}$ concentrations (He et al. 2013), daidzein and genistein are exerted through inhibitory actions on osteoclastogenesis and osteoclast functions, by employing mechanisms mediated via suppression of ERK and inhibition of NF- $\kappa \mathrm{B}$ activation, thus leading to impaired osteoclast formation and activity (Palacios et al. 2005; Xiao et al. 2015). Antagonizing action on osteoclast differentiation and, as a 
consequence, bone resorption is also reported by different works (Ozaki et al. 2000; Wattel et al. 2003; Bharti et al. 2004; Wattel et al. 2004; Woo et al. 2004; Yamaguchi et al. 2007; Siddiqui et al. 2011; Yamaguchi and Weitzmann 2011), in which quercetin and curcumin contribute to mitigate bone loss through a mechanism involving suppression of NF- $\mathrm{KB}$ and AP-1 (Wattel et al. 2004). Wu et al. (2012) found that treatment of ovariectomized mice with the phenolic compound caffeic acid 3,4-dihydroxy-phenethyl ester (CADPE) $3.5 \times 10^{-5} \mathrm{~mol} / \mathrm{kg}$ every 2 days inhibits NFATc1 expression, by targeting the MAPK/AP1 signaling pathway. Therefore, besides suppressing osteoclastogenesis, CADPE also impairs osteoclast activity through decreasing osteoclast-related marker genes, such as TRAP, cathepsin $\mathrm{K}$ and c-Src.

The same inhibitory effects are seen by following treatment with polyphenols, such as furosin, which targets the early stages of osteoclast differentiation through reducing the RANKL-induced phosphorylation of AP-1, p38 and JNK (Park et al. 2004), while coumestrol, at $10 \mu \mathrm{M}$, has been shown to have impact on late osteoclastic differentiation markers, such as matrix metalloproteinase (MMP)-9 and calcitonin receptor and the proposed mechanism includes decrease of ERK1/2 phosphorylation (Kanno et al. 2004b). Prevention of MMPs expression induced by Porphyromonas gingivalis in osteoclasts, has been shown to be also exerted by epigallocatechin gallate (EGCG) at $20 \mu \mathrm{M}$, maybe by blocking the MAPK signaling (Yun et al. 2004) (Fig. 5) and by A-type proanthocyanidins, which, at concentrations ranging from 10 to $50 \mathrm{mg} / \mathrm{l}$, do inhibit osteoclast differentiation (Tanabe et al. 2011), lipopolysaccharide (LPS)induced MMPs production and biofilm formation and modulate inflammatory responses to periodontopathogens, by inhibiting the phosphorylation of diverse signaling proteins, such as AP-1 and JNK (La et al. 2009a).

Several works report the anti-inflammatory effects of polyphenols, being exerted through targeting MAPKs pathway (Fig. 5): EGCG plays a role against inflammatory cytokines, which favor bone resorption, by inhibiting, at a dose of $30 \mu \mathrm{M}$, endothelin1 and platelet-derived growth factor BB-induced IL-6 synthesis, through diminishing the phosphorylation levels of MEK1/2 and Raf-1 at a point upstream of ERK1/2 MAPK (Tokuda et al. 2007a) and through downregulating the stress-activated protein kinase (SAPK)/
JNK pathway (Takai et al. 2008); (2S)-2'-Methoxykurarinone, a compound isolated from the root of Sophora flavescens, inhibits, at the dose of $20 \mu \mathrm{M}$, IL-1-induced differentiation of osteoclasts through the inhibition of p38 and JNK phosphorylation (Kim et al. 2014), while icariin, at nM concentrations, decreases $\mathrm{PGE}_{2}$ production by suppressing activation of $\mathrm{p} 38$ and JNK pathways (Hsieh et al. 2011).

Triggering apoptosis in osteoclasts is also an event that contributes to modulating bone resorption, in fact EGCG has been shown to induce osteoclast apoptosis by decreasing RANKL-induced JNK activation (Lin et al. 2009; Lee et al. 2010a; Jin et al. 2011), while quercetin, at $50 \mu \mathrm{M}$, upregulates B-cell lymphoma 2 (Bcl-2)-associated $\mathrm{X}$ (Bax) protein expression, via a mechanism involving p38 and JNK MAPKs (Guo et al. 2012c) (Fig. 5).

Promotion of bone anabolism is also achieved through actions aimed at enhancing proliferation, differentiation and mineralization of osteoblasts.

In this respect, polyphenols like icariin and apigenin have shown induction of MSCs proliferation through modulating phosphorylation of ERK, p38 and JNK MAPKs (Qin et al. 2015; Zhang et al. 2015), while cajanin and isoformononetin, both found in Butea monosperma extract, at concentrations ranging from $\mathrm{nM}$ to $\mathrm{pM}$, do stimulate osteoblast activity, proliferation and differentiation through activating MEK-ERK signaling pathways (Bhargavan et al. 2009).

p-Hydroxycinnamic acid (HCA), at concentrations of 0.01 and $0.1 \mu \mathrm{M}$, has been demonstrated to have anabolic effects on bone cells, which are carried out through stimulation of osteoblastic cell number, increase in calcium content, alkaline phosphatase activity and DNA content in vitro (Lai and Yamaguchi 2006a, b, 2008a, b).

Catechins are able to stimulate osteoblast differentiation and bone formation through regulating the ERK1/2 (Natsume et al. 2009), the p38 (Byun et al. 2014) and the SAPK/JNK (Tokuda et al. 2007b) MAPKs.

The pro-anabolic effects of HCA are also exerted through suppression of insulin-stimulated adipogenesis in pre-adipocytes and then favoring osteoblast differentiation, through a mechanism involving MAPK/ERK signaling (Yamaguchi et al. 2013).

Ugonin K (a flavonoid isolated from the roots of Helminthostachys zeylanica) and genistein are able to 
induce osteoblast differentiation through up-regulating the expression of Runx 2 and Osx, via a mechanism involving phosphorylation of ERK1/2 and p38 MAPKs (Liao et al. 2007; Lee et al. 2011a).

Furthermore, genistein was reported to promote osteoblast differentiation and mineralization in vitro through suppressing DNA-binding of NF- $\kappa \mathrm{B}$ (Kim et al. 2005) and LPS-induced activation of NF- $\kappa B$ (Hämäläinen et al. 2007), although Yamaguchi and Weitzmann (2009a) found a significant increase in $\mathrm{NF}-\kappa \mathrm{B}$ activity and even no antagonistic effects on TNF- $\alpha$-induced NF- $\kappa B$ promoter activity, suggesting that the observed differentiation effect on osteoblastic cells is not mediated through suppressing NF- $\kappa B$. Baicalein at $10 \mu \mathrm{M}$ has been demonstrated to control expression of specific osteoblastic genes, such as OCN, OPN and Col1 through regulating the activation of NF- $\kappa \mathrm{B}$ and AP-1 transcription factors via MAPK signaling at the early and the late stages of osteoblast differentiation, respectively (Kim et al. 2008a).

Hydroxyflavones have been displayed ability to stimulate osteoblastic differentiation and in increasing ALP activity via ERK and JNK signaling activation (Lai et al. 2014).

Polyphenols also favor osteogenesis through acting on mechanisms of regulation, such as phosphatases, which control different signaling pathways. For example, catechin, at $1 \mu \mathrm{M}$, has been seen to stimulate protein phosphatase 2A (PP2A), which regulates ERK activity by dephosphorylating it (Wei et al. 2011).

Quercetin, at $10 \mu \mathrm{M}$, promotes osteoblast differentiation through stimulating the expression of TGF- $\beta 1$, BMP-2 and Runx2, via activation of ERK1/2, p38 and JNK MAPKs (Li et al. 2015a) (Fig. 5). However, quercetin is a flavonoid whose effects are both concentration and cell type dependent. Thus, different and, sometimes, opposite effects can be seen depending on which experimental model is used (Zhou et al. 2015): induction of apoptosis (Son et al. 2006; Nam et al. 2008), through activation of ERK-induced caspases (Nam et al. 2008) and JNK-mediated mechanisms (Son et al. 2008); inhibition of proliferation, differentiation, migration and mineralization in vitro (Notoya et al. 2004; Nam et al. 2008; Yamaguchi and Weitzmann 2011); increased alkaline phosphatase (Prouillet et al. 2004) and other marker proteins of osteoblastic cells (Kim et al. 2006b); stimulation of bone calcification (Yamaguchi et al. 2007).
Furthermore, quercetin, at doses ranging from 5 to $20 \mu \mathrm{M}$, is less efficient than kaempferol, at the same concentrations, in regulating the RANKL-induced expression of c-fos, which is required for osteoclast differentiation (Pang et al. 2006), while opposite results show an osteoblast protection effect against TNF- $\alpha$-induced apoptotic cell death and prevention of $\mathrm{H}_{2} \mathrm{O}_{2}$-related cell death (Nam et al. 2008) through an ERK-dependent mechanism. Besides stimulation of proliferation and osteogenic differentiation, quercetin and quercitrin also exert angiogenetic effects, partially mediated through ERK and p38 MAPKs (Choi 2012; Zhou et al. 2015). Similarly to quercetin, curcumin has been demonstrated to dose-dependently induce apoptosis $(12.5-25 \mu \mathrm{M})$ and necrosis $(50-200 \mu \mathrm{M})$ in osteoblasts (Chan et al. 2006) by increasing reactive oxygen species (ROS) and decreasing adenosine triphosphate (ATP) levels, while on the other hand it has been demonstrated to decrease the rate of apoptosis dexamethasone-induced, by up-regulating the expression level of ERK1/2 (Chen et al. 2016).

Although HCAs have been shown to counteract some deleterious effects on skeletal system, caffeic acid may also impair bone mechanical properties (Folwarczna et al. 2009; Zych et al. 2010), showing how phenolic acids differently regulate bone. Concerning these different results, a deeper investigation on rats treated with phenolic acids led to dosedependent differential effects: high doses $\left(2.77 \times 10^{-4} \mathrm{~mol} / \mathrm{kg} /\right.$ day caffeic acid, $2.82 \times 10^{-4}$ $\mathrm{mol} / \mathrm{kg} /$ day chlorogenic acid) do favor bone anabolism, while low doses $\left(2.77 \times 10^{-5} \mathrm{~mol} / \mathrm{kg} /\right.$ day caffeic acid) do impair it (Folwarczna et al. 2015). Possible mechanisms of action have been speculated, based on general findings that identify polyphenolpromoted bone growth via $338 \mathrm{MAPK} / \beta$-catenin Wnt canonical signaling (Chen et al. 2010).

The protective antioxidant properties of polyphenols have been shown to be mediated through increased phosphorylation of ERK1/2 and pNrf2, superoxide dismutase 1 (SOD-1) and heme oxygenase 1 (HO-1) protein levels (Braun et al. 2011; Choi 2012). Quercitrin glycoside counteracts the deleterious effects of oxidative stress in osteoblastic cells, through different molecular mechanisms also involving p38 pathway (Choi 2012). 


\section{Inflammatory response pathway}

Inflammation is the process by which the immune system responds to infections and injuries, thus enabling the removal of harmful stimuli and the healing of damaged tissues, aimed at restoring the host homeostasis. It is a complex series of events that includes its initiation, regulation and resolution, with a variety of forms triggered by different stimuli and numerous cross-talking molecular mechanisms (Abbas et al. 2012).

Several studies have investigated the anti-inflammatory and immunomodulatory activity of polyphenols, showing their interaction with a wide spectrum of molecular targets central to the inflammatory signaling, thereby exerting inhibitory effects on the production of inflammatory mediators and antioxidant detoxifying actions (González-Gallego et al. 2010).

Different polyphenols exert their osteoprotective effects through suppressing RANKL-induced NF- $\kappa B$, thus affecting osteoclast differentiation and bone remodeling (Fig. 6).

Examples are given by polyphenols such as HCA, which exert inhibitory effects on osteoclastic cells formation induced by various osteoclastogenic factors (Lai and Yamaguchi 2006b, 2007), by functioning as natural NF- $\mathrm{NB}$ antagonists, since they block the binding of RANKL to its receptor RANK and thus relieving the inhibitory action of TNF- $\alpha$ on the proanabolic SMAD pathway (Yamaguchi and Weitzmann 2009b; Yamaguchi 2012) (Fig. 6). Inhibition of RANKL has also been shown by treatment of human osteosarcoma cells (Lin et al. 2014) with Punica granatum fruit extract and in primary BMSCs (Oh et al. 2008) and osteoclast precursors (Huh et al. 2013) with curcumin and galangin (a flavonol found in Alpinia officinarum), thus inhibiting osteoclast formation. In an in vivo study involving women in postmenopause, intake of genistein downregulated RANKL expression and secretion, thus decreased RANKL/OPG ratio (Marini et al. 2008). In addition, dried plum polyphenols, at the doses of 5 and $10 \mathrm{mg} / 1$, also act on bone resorption, by down-regulating RANKL expression and by directly suppressing osteoclast differentiation and activity via lowering TNF- $\alpha$ and NO production (Bu et al. 2009). Contrasting results show involvement of resveratrol on RANKL production, in fact Boissy (Boissy et al. 2005) and Shakibaei (Shakibaei et al. 2011) suggest reduction of RANKL levels at 100 and $5 \mu \mathrm{M}$, respectively, while in the study from Casarin and al. (Casarin et al. 2014), the daily administration of $4.4 \times 10^{-5} \mathrm{~mol} / \mathrm{kg}$ resveratrol had no significant effect on the reduction of RANKL.

Although EA has been shown to reduce NF- $\kappa B$ in macrophage cells (Spilmont et al. 2013), different results demonstrated that the effect of EA could be NF- $\kappa B$-independent (Rogerio and Favarin 2013), as it does not reduce NF- $\kappa \mathrm{B}$ activation during the peak of inflammation. Geraniin and rutin have been shown to have osteoprotective effects ( $\mathrm{Lu}$ et al. 2015) by exerting inhibitory actions on osteoclastogenesis and osteoclast functions (He et al. 2013), through mechanisms mediated via suppression of diverse signaling pathways, including NF- $\kappa \mathrm{B}$ and TNF- $\alpha$ (Pan et al. 2000; Kyung et al. 2008), while A-type proanthocyanidins do inhibit osteoclast differentiation (Tanabe et al. 2011), LPS-induced MMPs production and biofilm formation and modulate inflammatory responses to periodontopathogens, by negatively regulating the DNA-binding activity of NF- $\mathrm{KB}$ p65 (La et al. 2009a).

CADPE is a specific inhibitor of NF- $\kappa \mathrm{B}$ induced by different inflammatory agents, such as TNF and $\mathrm{H}_{2} \mathrm{O}_{2}$ (Natarajan et al. 1996), shown to have a beneficial effect on bone healing, following an inflammatory reaction induced by in vitro irradiation (Linard et al. 2004). One of the molecular mechanisms proposed to explain CADPE inhibitory activities is represented by its ability to covalently modify sulfhydryl groups of the NF- $\kappa$ B subunits, thus affecting NF- $\kappa B$ binding to DNA (Natarajan et al. 1996; Marquez 2003), without influencing I $\kappa \mathrm{B}$ degradation. Furthermore, NF- $\kappa \mathrm{B}$ is crucial for the early stages of RANKL-induced osteoclastogenesis and treatment of macrophages and osteoclasts with $10 \mu \mathrm{M}$ CADPE, showed inhibition of NF- $\kappa \mathrm{B}$ activation and apoptosis and downregulation of the osteoclastogenesis-related genes NFATc1 (Marquez 2003) and c-fos (Ha et al. 2009), thus making this polyphenol a useful compound for the treatment of osteolytic bone diseases (Ang et al. 2009) (Fig. 6). Also delphinidin and fisetin have potent inhibitory effects on bone resorption, with the involvement of NF- $\mathrm{BB}$ pathway, by downregulating c-fos and NFATc1 (Choi et al. 2012; Léotoing et al. 2013; Moriwaki et al. 2014). Conversely, peonidin, an anthocyanin from Vaccinium macrocarpon, has been shown to have no influence on osteoclast 
differentiation (Moriwaki et al. 2014), demonstrating a structure-related different mechanism of action on the skeletal system.

Honokiol, one of the major active ingredients of Magnolia extract, is reported to inhibit osteoclast differentiation in a dose-dependent manner $(0.1-100 \mu \mathrm{M})$ through a mechanism involving suppression of $\mathrm{TNF} \alpha$-induced $\mathrm{NF}-\mathrm{\kappa B}$ activation, by inhibiting p65 nuclear translocation and by intensifying I $\kappa \mathrm{B}$ stabilization and alleviation of the repressive action of TNF $\alpha$ on SMAD signaling (Yamaguchi 2011).

Rosmarinic acid, arbutin, oleuropein (isolated from Olea europaea olive oil) and polyphenols from Punica granatum fruit peel extract are able to inhibit bone resorption by blocking mRNA expression of osteoclast marker genes, such as MMP-9, cathepsin-K, calmodulin, C-C chemokine receptor type 2 (CCR2), calcitonin receptor and TRAP, via downregulating NF- $\kappa B$, hence also NFATc1, thus affecting osteoclast activity and differentiation at an early stage (Hsu et al. 2011; Santiago-Mora et al. 2011; Omori et al. 2015; Spilmont et al. 2015). Silibinin, the major active constituent of the natural compound silymarin (the isomeric mixture of flavonolignans extracted from Silybum marianum), inhibits osteoclastogenesis by negatively targeting multiple osteoclast specific signaling molecules, in particular NFATc1 and its related downstream genes, such as TRAP, cathepsin $\mathrm{K}$ and osteoclast-associated immunoglobulin-like receptor (OSCAR). In parallel, it inhibited RANKL-induced DNA binding of NF- $\mathrm{KB}$ and AP-1 (Kim et al. 2009; Kavitha et al. 2014).

Luteolin has been characterized as a natural compound, whose properties have inhibitory effect upon osteoclast resorptive activity, some indicating, as possible target, osteoclast differentiation with inhibition of RANKL-induced signaling pathway and inhibition of the expression of NFATc1 gene (Lee et al. 2009; Kim et al. 2011a; Shin et al. 2012), while some others do not (Crasto et al. 2013). The same situation has been seen following treatment, on osteoclast precursors and mature osteoclasts, with $10-30 \mathrm{mg} / \mathrm{l}$ dried plum (DP) polyphenols which, on one hand, exert their benefic actions on bone metabolism by decreasing, at osteoclastogenesis through a mechanism involving NFATc1 and through suppression of inflammatory mediators, such as NO and TNF- $\alpha$ and, on the other hand, it elevates TNF- $\alpha$ levels in macrophages. It is, therefore, clear that the different effects, probably due to the different types and concentrations of phenolic compounds, seen in the two cell lineages are cell-type dependent $(\mathrm{Bu}$ et al. 2008).

Fisetin's action against bone resorption has been seen to be primarily elicited on osteoclastogenesis, at $10 \mu \mathrm{M}$, by inhibiting NFATc1 and c-Src, as well as AP-1/c-fos (Sakai et al. 2013).

Curcumin has been extensively studied because of its ability, at doses ranging from 40 to $60 \mu \mathrm{M}$, to inhibit NF- $\kappa \mathrm{B}$ activation (Bharti and Donato 2003; Guimarães et al. 2011) and AP-1 activation induced by inflammatory stimuli, such as IL-1 $\beta$, TNF- $\alpha$ (Aggarwal 1995) and RANKL (Bharti et al. 2004), by keeping the NF- $\kappa \mathrm{B} / \mathrm{I} \kappa \mathrm{B}$ complex inactivated in the cytoplasm (Jobin et al. 1999; Bharti and Donato 2003; von Metzler et al. 2009), thus suppressing subsequent transcription of pro-inflammatory genes, such as TNF$\alpha$, IL-6 (Zhou et al. 2013), cyclooxygenase 2 (COX2), vascular endothelial growth factor (VEGF) (Csaki et al. 2009) and iNOS (Chowdhury et al. 2008) and contributing to inhibition of MMPs synthesis (Kumar et al. 2012). This anti-inflammatory property of curcumin has also effect on osteoclastogenesis, in which cytokine production is associated with regulation of osteoclast formation and function. In this regard, curcumin has been indeed shown to induce apoptosis in osteoclasts, which possible mechanism has been hypothesized to be correlated with inhibition of NF-אB (Hall et al. 1995; Ozaki et al. 1997) and by decreasing RANKL expression (Zhou et al. 2013), although Hie et al. (2009). showed osteoclastogenesis to be inhibited through suppressing expression of c-fos and c-jun, rather than RANK, in vivo.

A combination of genistein $(1 \mu \mathrm{M})$ and zinc $(10 \mu \mathrm{M})$ has been shown to stimulate osteoclast apoptosis through a mechanism involving caspase-3 activation and to suppress osteoclastogenesis through downregulating NFATc1 expression (Uchiyama and Yamaguchi 2007a), while in osteoblastic cells their combination (10 and $100 \mu \mathrm{M}$, respectively) resulted in enhanced mineralization through enhancement of protein synthesis, by activating aminoacyl-tRNA synthase (Uchiyama and Yamaguchi 2007b). Myricetin, at $10 \mu \mathrm{M}$, has been demonstrated to inhibit inflammatory cytokine-mediated apoptosis of osteoblasts, by preventing Fas upregulation and by increasing the expression of the antiapoptotic FLICE (FADD- 
like IL-1 $\beta$-converting enzyme)-inhibitory protein (FLIP) (Kuo 2005). Myricetin action is also elicited through suppressing the MAPK signaling pathways (Ko 2012; Wu et al. 2015a), as well as NF- $\mathrm{BB}$, thus inhibiting RANKL-induced osteoclastogenesis ( $\mathrm{Wu}$ et al. 2015a).

Besides their primary role in osteogenesis, catechins are also implicated in diminishing bone resorption: EGCG, in fact, increases osteoclast apoptosis by stimulating the DNA damage response and caspase-3 and by decreasing RANKL-induced NF- $\kappa \mathrm{B}$ activation (Lin et al. 2009; Lee et al. 2010a; Jin et al. 2011). Catechins, at 40-60 mg/l, have also been demonstrated to induce apoptosis in osteosarcoma cells, by suppressing I $\mathrm{KB}$ kinase (IKK) activation and by increasing phosphorylation of I $\mathrm{B}-\alpha$, thus inhibiting NF- $\kappa B$ (Hafeez et al. 2006). The consequence is that the ratio $\mathrm{Bax} / \mathrm{Bcl}-2$ shifts towards apoptosis.

The osteoanabolic effects of $(+)$-catechin have also been demonstrated by the increase of survival and activity of osteoblasts. Such inhibition of apoptotic cell death in osteoblastic cells may result from the decrease in production of TNF- $\alpha$ and IL- 6 , thus increasing survival and ALP activity at a dose of $10 \mu \mathrm{M}$ (Choi and Hwang 2003). Catechins, at $30 \mu \mathrm{M}$, have also been shown to be involved in the suppression of bone resorption, through acting on osteoblasts, by inhibiting the synthesis of genes associated with bone resorption, such as RANKL, COX-2, microsomal prostaglandin $\mathrm{E}$ synthase (mPGES)-1 and mPGES-2 (Tominari et al. 2015).

Given that NF- $\kappa$ B plays a pivotal role by coordinating the induction of a wide range of genes encoding pro-inflammatory cytokines [e.g., IL-1, IL-2, IL-6, and tumor necrosis factor receptor (TNFR)], chemokines (e.g., IL-8, macrophage inflammatory protein (MIP)$1 \mathrm{R}$, and monocyte chemotactic protein (MCP)-1, adhesion molecules [e.g., intercellular adhesion molecule (ICAM), vascular cell adhesion molecule (VCAM), and E-selectin], acute-phase proteins (e.g., COX-2, iNOS, etc.), it is very likely that the molecular mechanism implicated by polyphenols in attenuating inflammation is represented by NF- $\kappa \mathrm{B}$ inhibition.

In fact, several studies (Kohyama et al. 1997; Pan et al. 2000; Bertelli et al. 2002; Maiuri et al. 2005; Puel et al. 2006; De Stefano et al. 2007; Puel et al. 2008; Su et al. 2015) report the ability of phenolic compounds to be effective in inhibiting inflammatory cytokines involved in the acute phase of inflammation, but also in enhancing anti-inflammatory cytokines, such as IL10 (Comalada et al. 2006), targeting macrophagic cells and osteoblasts.

Catechins, naringenin and apigenin also target osteoclastogenic cytokines, as they downregulate IL1, IL-23, MCP-1, MCP-3, regulated on activation, normal $\mathrm{T}$ cell expressed and secreted (RANTES) and IL-6, as well as RANKL expression (Bandyopadhyay et al. 2006; La et al. 2009b), through inhibiting NF- $\mathrm{\kappa B}$ activation (Ishida et al. 2007; Nakamura et al. 2010) and, so, contributing to impairing osteoclastogenesis (Lee et al. 2010a). On the contrary, EGCG, in the range between 0.05 and $0.1 \mathrm{~mol} / \mathrm{l}$, has been seen to enhance IL-1 stimulated IL-6 release by osteoblastic

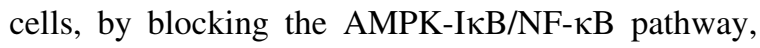
thus having a role in bone remodeling mediation, being IL-6, in addition to a potent bone resorptive cytokine, also an osteotropic factor that modulates bone remodeling (Kuroyanagi et al. 2013).

Naringenin molecular mechanism of action has been investigated and the results show that it diminishes NF- $\kappa$ B expression (Tsai et al. 1999; Kanno et al. 2006; Ang et al. 2011), it inhibits RANKL-induced p38 signaling and NFATc1 transcriptional activity, thus suppressing the expression of inflammatory genes, such as iNOS, COX-2, TNF- $\alpha$ and IL-6, regulators of osteoclastogenesis and osteoclast differentiation (Wang et al. 2014a). Estrogen receptorindependent actions on osteoblast, such as inhibition of TNF- $\alpha$-induced secretion of IL- 6 and MCP-1, have been shown to be exerted by kaempferol, at $10 \mu \mathrm{M}$, through avoiding nuclear translocation of NF- $\kappa \mathrm{B}$ (Pang et al. 2006).

A reduced expression of inflammatory molecules, such as IL-1 $\beta$, TNF- $\alpha$ and IL-17, following quercetin treatment $\left(3.3 \times 10^{-4} \mathrm{~mol} / \mathrm{kg}\right)$, has been shown to also negatively affect RANKL expression and downregulation of the adhesion molecule ICAM-1 in a mouse periodontitis model (Napimoga et al. 2013). Green tea polyphenols decrease inflammatory mediators such as COX-2, TNF- $\alpha$ (Shen et al. 2010), IL- $1 \alpha$, IL-2, IL-4, IL-10, granulocyte-macrophage colonystimulating factor (GM-CSF) and interferon $\gamma$ (IFN $\gamma$ ) (Shen et al. 2012), while quercitrin has also been demonstrated to exert anti-resorbing effects thanks to its anti-inflammatory properties in human gingival fibroblasts, by reducing IL-6 and MMP-1 expression (Gómez-Florit et al. 2014, 2015), responsible for induction of bone resorption and extracellular matrix 
(ECM) degradation, respectively (Gómez-Florit et al. 2014). Formononetin is able, at the concentration range $1-10 \mu \mathrm{M}$, to inhibit osteoclast differentiation by downregulating RANKL-induced production of cytokines and chemokines through suppressing phosphorylation of the NF- $\kappa \mathrm{B}$ subunit p65 and I $\kappa \mathrm{B} \alpha$ degradation, as well as downregulating Akt and MAPKs, thus negatively affecting c-fos and NFATc1 expression (Huh et al. 2014).

Moreover, apigenin is also able to inhibit IFN $\gamma$ stimulated chemokine (C-X-C motif) ligand (CXCL)9 and CXCL-10 secretion, as well as secretion of leptin, thus negatively regulating osteoclastogenesis (Bandyopadhyay et al. 2006; Goto et al. 2015).

\section{Redox signaling pathway}

Oxidative stress is a disequilibrium between the production of reactive oxygen species and antioxidant defenses, which may lead to tissue injury (Halliwell 1994). Free radicals are the byproducts of many metabolic pathways, from reactions involved in photosynthesis and respiration, but also in response to external electromagnetic stimuli. Namely, any chemical species that contains unpaired electrons is defined as free radical. Examples include ROS and reactive nitrogen species (RNS). Thanks to their potent antioxidant properties, polyphenols, besides negatively targeting inflammatory cytokines, do exert inhibition of bone resorption by also enhancing the levels of the antioxidant defense system, raised against ROS and other free radicals, therefore making them promising molecules to be employed in oxidative stress situations, such as after tooth extraction (Al-Obaidi et al. 2014a, b).

EA, together with other polyphenols, has been found to exert a preventive action on bone loss, by acting on oxidative stress biomarkers (Sellappan and Akoh 2002).

As an antioxidant, curcumin $5 \mu \mathrm{M}$ does prevent production of ROS- which are responsible for activation of NF- $\mathrm{KB}$ - by regulating expression of genes implicated in RANKL-induced osteoclast differentiation. Therefore, by suppressing NF- $\kappa \mathrm{B}$ signaling, curcumin indirectly and negatively acts on NFATc1 gene expression, thus resulting in inhibition of the osteoclast differentiation process (Moon et al. 2012). Moreover, thanks to its ROS scavenger activity, curcumin is able to dose dependently $(0.5-4 \mu \mathrm{M})$ up-regulate the content of antioxidant enzymes such as glutathione peroxidase (Gpx)-1, in the osteoclast, thus modulating ROS levels (Kim et al. 2011b). Curcumin, at $10 \mu \mathrm{M}$, is also an inducer of HO-1 expression, which contributes to give increased resistance to oxidative stress and plays an important role for bone marrow stem cell differentiation in the osteoblastic lineage ( $\mathrm{Gu}$ et al. 2012). Contrasting results show, however, the lack of inhibition of bone resorption in different works (Guimarães et al. 2011, 2012). Moreover, treatment of MG-63 osteoblastic cells with curcumin 20-30 $\mu \mathrm{M}$ (Moran et al. 2012) elicits inhibition of proliferation, accordingly to a study (Notoya et al. 2006) in which the presented results show that curcumin $5 \mu \mathrm{M}$ inhibited the proliferation and metabolism of osteoblasts via suppression of the activation of AP-1.

Thanks to their ROS scavenging activity, also icaritin (a flavonoid isolated from Epimedium pubescens) and phloredzin exert an inhibitory effect on bone resorption by reducing superoxide generation in osteoclasts (Huang et al. 2007), through decreasing $\mathrm{PGE}_{2}$ production by inhibiting $\mathrm{COX}-2$ and hypoxiainducible factor 1-alpha (HIF-1 $\alpha$ ) pathways (Puel et al. 2005; Hsieh et al. 2011). Quercetin and quercitrin also inhibit osteoclastogenesis through downregulating COX-2 expression (Guo et al. 2012c) and NO synthase (Gómez-Florit et al. 2015), given that NFATc1 is a transcription factor (TF) responsible for the translation of many genes, including cytokines, cell surface receptors and enzymes such as COX2.

Genistein antioxidant properties are important in controlling ROS generation and, thus, in protecting the disruption of the mitochondrial electron transport chain system by downregulating NADPH oxidase (Nox)-1 expression in a dose-dependent manner $(1-10 \mu \mathrm{M})$, as well as Nox-1 activation via TNF receptor associated factor (TRAF)-6/cSrc/PI3K signaling pathway in RANKL-mediated osteoclast differentiation (Lee et al. 2014a). Furthermore, this scavenging effect is also demonstrated by the upregulation of Nrf2, a nuclear factor that contributes to the enhanced production of antioxidant enzymes such as SOD-1 and HO-1 (Lee et al. 2014a). Furthermore, also fisetin, at $10 \mu \mathrm{M}$, suppresses RANKL-induced ROS formation by enhancing the expression of various Nrf2-mediated oxidative stress-response enzymes (Sakai et al. 2013). 
Resveratrol, thanks to its antioxidant properties, is able to restore enzymes of the antioxidant defense system, such as catalase (CAT), SOD and glutathione peroxidase (GPx) in a dose-dependent manner (10, 30, $90 \mu \mathrm{M})$, by restoring the normal levels of forkhead box $\mathrm{O}$ (FoxO)-1 and by inhibiting the phosphorylation of p66shc (Zhao et al. 2015). Furthermore, DP bone anabolic effects elicited following administration of $25 \%$ (w/w) in C57BL/6 mice for 4 or 12 weeks, also include enhancement of glutathione peroxidase, suggesting the involvement of antioxidant mechanisms (Smith et al. 2014).

Moreover, myricitrin, a glycoside from myricetin, is able, at $1-10 \mu \mathrm{M}$, to inhibit bone-resorbing cytokines production under oxidative conditions, showing protective effects against osteoblast cytotoxicity, thanks to its antioxidant properties (Huang et al. 2014). The authors suggest a molecular mechanism to explain these protective effects, involving FoxO signaling in osteoblasts.

Being EGCG an iron ion chelator, its reductive action on $\mathrm{Fe}$ (III) is involved in osteoclast apoptosis catalyzed through the Fenton reaction, which leads to production of hydroxyl radicals-potent reactive oxygen species-responsible for a direct cleavage of DNA and caspase-3 activation in osteoclasts (Islam et al. 2000; Nakagawa et al. 2002; Yun et al. 2007) (Fig. 6). Thus, reduction of oxidative stress by catechins promotes osteogenic effects, by inhibiting osteoclastogenesis and bone resorption (Zeng et al. 2014).

Protective antioxidant actions on osteoblastic cells are exerted by apigenin flavone $1 \mu \mathrm{M}$, with positive antioxidant actions on osteoblast differentiation, survival and function, through enhancing the cell survival-related molecular pathways PI3K, Akt and ERK2 and through upregulating the expression of the antioxidant enzymes SOD-1, SOD-2 and GPx (Jung 2014). Conversely, reports show that apigenin does not exhibit antioxidant effects on osteoblastic cells and that, instead, it both inhibits osteoblastogenesis and osteoclastogenesis (Hagiwara et al. 2011; Goto et al. 2015). Proanthocyanidins, instead, exert a significant osteoblast protection by ameliorating the $\mathrm{H}_{2} \mathrm{O}_{2}$-induced mitochondrial dysfunction effect at $1 \mu \mathrm{M}$, by inhibiting their apoptosis through suppressing the activation of p53 signaling (Zhang et al. 2014).

\section{PI3K/Akt signaling pathway}

Several tyrosine kinases, such as the insulin receptor and cytokine receptors, take part in the promotion of cell survival and proliferation, through activating the phosphoinositide pathway. Once activated, these receptors recruit the PI3K enzyme, which directly activated kinase is the PKB, also named Akt.

Among the several TFs activated by the PI3K/Akt pathway, NF- $\kappa \mathrm{B}$, FoxOs and cAMP response element binding protein (CREB) have been shown to have a role in regulating osteogenic pathways implicated in osteoblast differentiation. In particular, Akt activation also affects FoxO3, Runx2, Osx and activating transcription factor (Atf)-4, which are directly implicated in bone development and bone cell functions.

Cross-talk with other osteogenic signaling pathways, such as Wnt, BMP and NO/cGMP can also occur, thus contributing to enhance or maintain bone development (Guntur and Rosen 2011).

Therefore, it is not surprising that targeting of PI3K/Akt pathway by polyphenols leads to controlling of a series of mechanisms involved in cell survival, growth and proliferation and, concerning bone system, induction of osteoblast proliferation and differentiation, while inhibition of osteoclast proliferation and differentiation, resulting in an osteoanabolic effect.

Promotion of osteogenic differentiation of BMSCs by icariin is reached via enhancing activation of the PI3K-Akt-endothelial NOS (eNOS)-NO-soluble guanylyl cyclase (sGC)-cGMP-dependent protein kinase (PKG) signaling pathway, through phosphorylation of Akt at $10 \mu \mathrm{M}$ (Zhai et al. 2014), showing an interplay between PI3K and NO pathways, the latter being an important regulator of bone formation and resorption (Saura et al. 2010).

Osteoblastic differentiation via activation of Akt signaling has also been displayed by treatment of preosteoblasts with hydroxyflavones $20 \mu \mathrm{M}$, which action is focused on the stimulation and the increase of ALP activity (Lai et al. 2014). In addition to stimulating osteoblastic differentiation, cajanin $1.0 \times 10^{-5}$ $\mu \mathrm{M}$ also promotes osteoblast proliferation and activity, through activating the Akt signaling pathway (Bhargavan et al. 2009). Protection of osteoblasts from apoptosis, by inhibiting p53 and by increasing Akt phosphorylation is another effect exerted by the quercetin analogue 6-C- $\beta$-D-glucopyranosyl-(2S,3S)- 
(+)-3', $4^{\prime}, 5,7$-tetrahydroxyflavanol (GTDF), isolated from Ulmus wallichiana (Khan et al. 2013).

In addition, EGCG significantly attenuates, in a dose-dependent manner $(10-30 \mu \mathrm{M})$, the phosphorylation rate of Akt in osteoblasts induced by sphingosine 1-phosphate, thus inhibiting heat shock protein (HSP)-27 (Natsume et al. 2009), reported to be involved in the balance between differentiation and apoptosis (Leonardi et al. 2004). Another mechanism of action, exerted by naringin $0.01 \mu \mathrm{M}$, aimed at promoting bone cell proliferation, includes the recruitment of Akt, thus facilitating phosphorylation and stabilization of $\beta$-catenin (Wang et al. 2015).

On the other hand, inhibition of RANKL and IL-1induced osteoclast differentiation, through the inhibition of Akt phosphorylation, has also been reported following treatment with (2S)-2'-Methoxykurarinone prenylflavonoid (Kim et al. 2014).

\section{AMPK signaling pathway}

The AMPK is a signaling protein that has originally evolved to act as a sensor of energy status in mammals, being a heterotrimeric complex activated by increases in AMP:ATP ratio, which reflects dangerous metabolic stresses. AMPK activation is allosterically achieved following binding of AMP, while pharmacological activators, such as plant-derived products, which include resveratrol $(12.5-50 \mu \mathrm{M})$ (Baur et al. 2006), berberine (Lee et al. 2006), genistein and EGCG (Hwang et al. 2005) have been shown to induce AMPK activation through an indirect mechanism, by increasing cellular AMP levels.

Besides limiting energy spending, it also plays a crucial role in growth inhibition and in blocking the cell cycle. In fact, in conditions where nutrients are scarce, AMPK acts as a metabolic checkpoint by inhibiting cellular growth, via suppression of the mammalian target of rapamycin complex (mTORC)-1 signaling (Mihaylova and Shaw 2012).

AMPK is ubiquitously expressed, but its function and regulation in bone tissue are poorly understood. However, finding out that energy metabolism affects bone remodeling, suggested that a cross-talk between these two systems exists (Confavreux et al. 2009).

First of all, adipocytes and osteoblasts share a common progenitor, that is the MSC and second, several interactions between adipocyte-derived hormones, such as leptin and adiponectin, and bone have been described (Pino et al. 2012). Furthermore, not only direct actions of these hormones on bone cells occur, but also indirect actions, through acting on receptors in the central nervous system. Several in vitro studies (Kanazawa et al. 2007, 2008, 2009; Quinn et al. 2010) show how modulation of AMPK affects bone cell differentiation and function, in particular activation of AMPK has been demonstrated to be inhibitory for osteoclast differentiation (Lee et al. 2010b), while AMPK activation in osteoblasts has been shown to be important for bone nodule formation and maintenance of bone mass (Shah et al. 2010).

Evidence for AMPK activation by polyphenols are primarily given in the field of ameliorating the negative effects of a high fat rate, via an indirect mechanism of AMPK activation, which involves either PPAR $\gamma$ or Sirt1, thus switching the adipogenic pathway towards the osteogenic one (Hwang et al. 2005; Yamashita et al. 2006; Zang et al. 2006).

Naringin, the major flavonoid glycoside in Citrus paradisi, induces bone development through recruiting, at a concentration of $0.01 \mu \mathrm{M}$, AMPK in osteoblasts, thus facilitating phosphorylation of $\beta$ catenin at Ser-552 (Wang et al. 2015), showing that a cross-talk between AMPK and Wnt/ $\beta$-catenin pathways exists (Zhao et al. 2010a).

Moreover, activation of AMPK in osteoclast precursors by resveratrol and EGCG, suppresses osteoclast formation and bone resorption without stimulating RANKL-RANK signaling (Lee et al. 2010b; Zhou et al. 2014).

\section{Wnt/ß-catenin signaling pathway}

The evolutionarily-conserved Wnt extracellular signaling pathway is a complex network, containing numerous components, implicated in different developmental processes, such as embryogenesis and adult tissue homeostasis, but also in mitogenic stimulation, cell fate determination and differentiation (Soltanoff et al. 2009). Wnt ligands are cysteine-rich proteins with distinct effects on different cellular events and, in bone, they control chondrogenesis, osteoblastogenesis and osteoclastogenesis (Monroe et al. 2012).

Several polyphenols have been shown to target Wnt pathway in bone, with evident stimulatory effects of osteoblast differentiation (Chen et al. 2010; Guo et al. 
2012b) and inhibition of osteoclast differentiation and function (Guo et al. 2012b) (Fig. 7).

Among them, myricetin $20 \mu \mathrm{M}$ has been demonstrated to activate the $\mathrm{Wnt} / \beta$-catenin pathway by increasing $\beta$-catenin expression levels and TCF/LEFdriven downstream genes (Ying et al. 2014) and Luteolin $5 \mu \mathrm{M}$ and its glycoside orientin $20 \mu \mathrm{M}$ have been shown to reduce sclerostin (SOST) levels, inhibitor of lipoprotein receptor-related protein (LRP). Hence, this reduction of SOST does favour the Wnt canonical pathway, involved in osteoblast differentiation (Nash et al. 2014). The effects of curcumin on bone are also elicited through signaling pathways known to be involved in the growth, development and maintenance of bone tissue, such as the $\mathrm{Wnt} / \beta$-catenin pathway. Concerning this, contrasting results show both curcumin-dependent Wnt/ $\beta$ catenin activation (Chen et al. 2014a; Tiwari et al. 2014, 2015; Yang et al. 2015) and suppression (Cui et al. 2013; He et al. 2014) in different cell types, while experimental data show effective curcumin-induced restoration of $\mathrm{Wnt} / \beta$-catenin signal in glucocorticoidtreated osteoblastic cells. Modulation of Wnt signaling has been reported to be also elicited by EGCG $25 \mu \mathrm{M}$, which increases ALP activity through activating $\beta$ catenin (Mount et al. 2006).

Phenolic acids, commonly found in blueberries, are able to increase osteoblastogenesis in mice fed with a dose of $5 \mathrm{mg} / \mathrm{kg} / \mathrm{day}$, through activating the niacin receptor GPR109A, which leads to increased phosphorylation of p38 MAPK, then to activation of Osx, Runx2 and Wnt signaling cascade (Chen and Lazarenko 2014) (Fig. 7), while treatment of SpragueDawley rats with resveratrol $2.0 \times 10^{-3} \mathrm{~mol} / \mathrm{kg} / \mathrm{day}$ also leads to the $\mathrm{Wnt} / \beta$-catenin pathway restoration, to the enhancement of IGF-1 mRNA levels and to suppression of the PPAR $\gamma$ signaling (Wang et al. 2013a), thus inhibiting adipogenesis and enhancing osteoblastogenesis. Inhibition of adipogenesis in favor of osteogenesis is also achieved by resveratrol $10 \mu \mathrm{M}$, through upregulation of the $\mathrm{Wnt} / \beta$-catenin pathway and activation of Sirt1 (Zhou et al. 2009), which is a PPAR $\gamma$ inhibitor.

\section{TGF-ק/BMP signaling pathway}

BMPs are a group of growth factors that belong to the TGF- $\beta$ superfamily. Their multiple roles vary from regulation of bone induction, maintenance and repair, to the determination of non-osteogenic embryological developmental processes and to the maintenance of adult tissue homeostasis (Chen et al. 2004).

Involvement of the BMP signaling in polyphenolmediated bone anabolism has been largely investigated and several evidence show increase of new bone growth through the enhancement of the BMP-2 promoter activity and BMP-2 mRNA and protein expression (Zhang et al. 2012; Lin et al. 2014) (Fig. 8).

EGCG, in particular, has been shown to be a proosteogenic agent for the treatment of osteoporosis, thanks to its positive actions on osteoblast functions, on osteogenic differentiation and on mesenchymal stem cell proliferation, through the up-regulation of BMP-2 and Runx2 expression at $5 \mu \mathrm{M}$ (Jin et al. 2014). In vitro studies show puerarin and icariininduced BMP-2/SMAD and NO synthesis which, respectively, increase osteoblast survival, through suppressing caspase- 3 activity, and positively control osteoblast differentiation and proliferation, through regulating Runx2 expression (Zhao et al. 2008; Hsieh et al. 2010; Sheu et al. 2012).

Hesperidin, the glycoside of hesperetin (a flavonone found in citrus fruit), is able to upregulate the expression of mineralization genes, such as OCN and OPN, by both stimulating BMP pathway and downregulating Noggin signaling, thus also enhancing Runx2 and Osx expression. Moreover, c-jun and c-fos upregulation and, consequently, AP-1 positive modulation following hesperidin treatment does suggest a possible cross-talk with other signaling pathways, such as Wnt, Hedgehog and MAPKs, implicated in osteoblast differentiation (Trzeciakiewicz et al. 2010a, b). The two furocoumarins imperatorin and bergapten, the first one isolated from Urena lobata, the second one from Citrus bergamia and syringetin, from red grape, induce osteoblast differentiation and maturation through enhancing BMP-2 expression via p-38 and ERK1/2 MAPKs (Tang et al. 2008a; Hsu et al. 2009) (Fig. 8).

Given that the osteoblast lineage is a primary source for VEGF production and that VEGF plays a critical role in coupling of angiogenesis and bone remodeling, it can be postulated that resveratrol increases bone formation also through the regulation of angiogenesis. In fact, it attenuates BMP-4 and TGF$\beta$-stimulated VEGF synthesis through suppression of the activation of p70-S6 kinase and through inhibiting 
p44/p42 MAPK and SAPK/JNK in osteoblasts, this inhibitory effect being mediated through SIRT1 activation (Kondo et al. 2014; Kuroyanagi et al. 2015).

Myricetin has been demonstrated to be beneficial in stimulating osteoblast activity and differentiation thanks to its ability to increase BMP-2 production and phosphorylation of SMAD1/5/8, as well as the subsequent p38 activity, thus inducing bone matrix gene expression and ALP activity in osteoblasts (Guicheux et al. 2003; Hsu et al. 2007). Apigenin at 5 and $10 \mu \mathrm{M}$ (positively regulates osteoblast differentiation markers, through upregulating BMP-6 (Bandyopadhyay et al. 2006) and other osteoblast differentiation genes, such as ALP, OCN, OPN, bone sialoprotein (BSP), Osx and Col1 (Jung 2014). Silibinin can promote osteoblast differentiation through activating BMP signaling and, thus, SMADs phosphorylation and subsequent Runx2 signaling activation. In response to these osteogenic effects, different osteogenic markers, such as ALP, Col1 and OCN are stimulated (Kim et al. 2012b; Ying et al. 2013).

Also isoquercitrin $1 \mu \mathrm{M}$ has been proved to be involved in osteoblastic differentiation, thanks to its ability to induce BMP-2 and, subsequently, Runx2 and ATF-6 genes to target the OCN gene (Wang et al. 2014b). Osteoblast proliferation by silymarin $10 \mu \mathrm{M}$ has been shown by the enhancement of collagen secretion, OCN transcription and BMP pathway, which have been proved to be related to an increase of SMAD1/5/8 phosphorylation and Runx 2 expression (Kim et al. 2012a).

Resveratrol $1 \mu \mathrm{M}$ was found to induce osteogenic BMP-2 and to reduce anti-osteogenic BMP-3, thus stimulating osteoblast differentiation and maintaining the phenotype of mature osteoblasts ( $\mathrm{Su}$ et al. 2007); resveratrol also increases OPN, BMP-2 and BMP-7, while no stimulation of BMP-6 has been observed; other resveratrol structurally-related polyphenols, like piceatannol, have instead shown the only stimulation of BMP-2 release (Gruber et al. 2003). In fact, piceatannol $1 \mu \mathrm{M}$ increases ALP activity, OCN production and Col1 synthesis, by up-regulating BMP-2 expression both at transcriptional and translational levels, thus improving bone anabolism (Chang et al. 2006).

It has also been postulated that naringin, at $3 \mu \mathrm{M}$, can act through cross-talk with other signaling pathways, such as the PI3K/Akt, c-fos/c-jun and AP-1 pathways to induce osteogenic BMP-2 expression and to reduce anti-osteogenic BMP-3 (Wu et al. 2008) (Fig. 8).

Caviunin $\quad 7-O$-[ $\beta$-D-apiofuranosyl-(1-6)- $\beta$-D-glucopyranoside] (CAFG) is a non-estrogenic flavonoid glucoside extracted from leaves of Dalbergia sissoo, that has been proved to triggers, in ovariectomized mice fed with $1.5 \times 10^{-6} \mathrm{~mol} / \mathrm{kg} /$ day, BMP-2-canonical $\mathrm{Wnt} / \beta$-catenin signaling in osteoblasts and that results in the stimulation of osteoblast differentiation and mineralization (Kushwaha et al. 2014), in fact, although BMP-2 signaling components are distinct from the known $\mathrm{Wnt} / \beta$-catenin signal transduction pathway, they may stimulate processes that cooperate with activated $\beta$-catenin to promote osteoblast differentiation (Kushwaha et al. 2014).

Conversely, quercetin has been shown to negatively modulate TGF- $\beta$-induced or BMP-2-induced SMAD activation (Phan et al. 2004; Yamaguchi and Weitzmann 2011), thus adding further confusion about quercetin's action on bone formation.

Moreover, although quercetin has been shown to suppress TNF- $\alpha$ (Zhang et al. 1996) basal and TNF- $\alpha$ induced NF- $\kappa \mathrm{B}$ activation (Yamaguchi and Weitzmann 2011), it exerts the same inhibitory effect both on osteoclastogenesis and osteoblastogenesis, failing to alleviate the suppressive action of TNF- $\alpha$ on BMP2 -induced or TGF- $\beta$-induced SMAD activation (Yamaguchi and Weitzmann 2011).

\section{Calcium signaling pathway}

Calcium ion $\left(\mathrm{Ca}^{2+}\right)$ is particularly important in maintaining cell homeostasis, as it participates in many cellular activities.

Thanks to its peculiar distribution, it differs from other ion functions in that its very low levels in cell cytosol enable it to act as a second messenger playing a crucial role in regulating cytosolic $\mathrm{Ca}^{2+}$-dependent enzymes (Ghibelli et al. 2010). Because of the presence of a large number of $\mathrm{Ca}^{2+}$ binding sites in the cytosol, $\mathrm{Ca}^{2+}$ ions are continuously buffered and, then, their movements are constantly controlled; consequently, calcium elevations can arise in specific cell zones and spread to others in a slow manner.

Calcium signal in bone is important in the regulation of osteoclast differentiation, bone resorption and gene transcription. In fact, binding of RANKL to RANK leads to production of inositol trisphosphate 
$\left(\mathrm{IP}_{3}\right)$, that binds to and activates the IP3 receptor $\left(\mathrm{IP}_{3} \mathrm{R}\right)$, resulting in calcium release from the ER. In osteoclasts, not only signals from internal stores exist, but also signals derived from calcium entering across the plasma membrane and these cytosolic calcium oscillations are essential for the osteoclastogenesis RANKL-dependent.

The calcium released leads to activation of downstream effector proteins, such as calmodulin kinases and calcineurin. Calcineurin phosphatase dephosphorylates and, thus, activates, NFATc1 that translocates to the nucleus where it initiates the transcription of several osteoclast specific genes, such as cathepsin K, TRAP and calcitonin receptor (Hwang and Putney 2011). Concerning osteoblasts, studies report a cell sensitivity to high extracellular calcium concentrations, in that they may affect the proliferation and differentiation of osteoblasts (Farley et al. 1994; Honda et al. 1995; Eklou-Kalonji et al. 1998).

Polyphenols like resveratrol have been shown to regulate different cellular processes, by acting as ligand for transmembrane proteins, like voltage-gated calcium channels and plasma membrane calcium ATPase (Sareen et al. 2007; Sulaiman et al. 2010), but also through regulating intracellular calcium channels (Dobrydneva et al. 1999; Buluc and Demirel-Yilmaz 2006; Dobrydneva et al. 2010; McCalley et al. 2014).

The protective actions of polyphenols on bone metabolism via modulating the calcium signaling are mainly achieved through repression of bone resorption, with osteoclastogenic genes as primary targets (Yamaguchi and Sugimoto 2000; Wu et al. 2012).

A suppressive effect on bone resorption by genistein $(1-10 \mu \mathrm{M})$ is mainly exerted through acting on osteoclast proliferation, via induction of apoptosis, through a mechanism $\mathrm{Ca}^{2+}$-mediated (Gao and Yamaguchi 1999b), while a repressive action on osteoclast functions by genistein $50 \mu \mathrm{M}$ has been shown to be achieved through inhibiting inward rectifier $\mathrm{K}^{+}$channels - which, in osteoclasts, are important to maintain the $\mathrm{H}^{+}$transport to bone surface (Sims and Dixon 1989) — thus inducing membrane depolarization and causing $\left[\mathrm{Ca}^{2+}\right]_{\mathrm{i}}$ elevation (Okamoto et al. 2001).

\section{Discussion}

Behind all the above discussed shared molecular mechanisms implied in polyphenol bone protection, it is of extreme importance to take into account how these polyvalent phytochemicals interact, influence and/or interfere with different parallel signaling pathways. One of the main properties characterizing polyphenols and, as such, the most extensively studied, is represented by their ability to exert antiinflammatory actions by negatively regulating the inflammation pathway and, especially, its crucial NF$\kappa \mathrm{B}$ TF.

Because NF- $\kappa \mathrm{B}$ gives rise to signals implicated in varied transcriptional programs with broad physiological and medical effects such as immunological response, development (Hayden and Ghosh 2004; Oeckinghaus and Ghosh 2009), survival, apoptosis and cell growth (Guttridge et al. 1999), polyphenol effects on this signaling pathway also reflect downstream of NF- $\kappa B$, thanks to different crosstalks. In fact, cooperative interactions with other TFs or receptor molecules are responsible for integration of $\mathrm{NF}-\kappa \mathrm{B}$ functions with other cell-signaling pathways, thanks to different specific binding sites in the molecule itself, or on the promoters of the target genes (Perkins 2007). The estrogen receptor, in fact, may interact via protein-protein interactions with NF$\kappa \mathrm{B}$, resulting in modulation of the binding of NF- $\kappa \mathrm{B}$ to $\mathrm{NF}-\kappa \mathrm{B}$ response elements, thus regulating NF- $\kappa \mathrm{B}-$ dependent gene transcription in a cell-type-specific manner and has important implications in the inflammatory processes.

For example, estrogen downregulates IL-6 production indirectly, by binding to NF- $\mathrm{BB}$ and thus reducing the IL-6 promoter activity (Stein and Yang 1995).

Polyphenol ability to reduce and/or suppress inflammation, also reflects on a new field of interest that is the osteo-immune-oncology, because there is a link between immunology, bone metabolism and tumorigenesis.

In this field, NF- $\kappa \mathrm{B}$ is also investigated in oncogenesis, because of its ability to regulate genes involved in proliferation and apoptosis processes, with elevation of its levels in some types of cancers (Sovak et al. 1997; Reuther et al. 1998). In view of this, estrogen has been shown to inhibit different tumorigenic cell line growth, by binding to NF-kB (Pratt et al. 2003). 
Other evidence of interaction between estrogen and other pathways is available in literature; for example, reciprocal effects between $\mathrm{Wnt} / \beta$-catenin and estrogen are showed by their synergistic regulation of osteogenic differentiation (Gao et al. 2013), while, between estrogen and TGF- $\beta$, different levels of crosstalking are present, including estrogen induction of TGF- $\beta$ gene expression, which results in the activation of the Smad signaling pathway and, so, in a synergistic regulation of bone metabolism (Hawse and Subramaniam 2008).

Inflammation is also linked to the development of different chronic diseases, from heart diseases, to obesity, diabetes and osteoporosis, and, furthermore, given that osteoblasts and adipocytes derive from the same MSC compartment, polyphenol action on switching differentiation towards osteoblastogenesis, rather than adipogenesis, makes these molecules a promising tool to treat metabolic dysfunctions (Ginaldi and De Martinis 2016).

Negative regulation of NF- $\kappa \mathrm{B}$ by Wnt signal is also achieved through the physical interaction between $\beta$ catenin and $\mathrm{NF}-\kappa \mathrm{B}$, that results in a minor DNA binding activity and, thus, in diminished NF- $\kappa \mathrm{B}-$ related gene expression. Overexpression of $\beta$-catenin in osteoblasts, for example, leads to inhibition of NF$\kappa \mathrm{B}$, showing a molecular connection between $\mathrm{Wnt} / \beta$ catenin-mediated bone formation and NF- $\kappa \mathrm{B}-$ mediated inflammation (Die et al. 2012). Given the ability of Wnt signaling to stimulate or suppress NF- $\kappa \mathrm{B}$ pathway, opposite properties of anti-inflammation and pro-inflammation are of evidence, even if most of the results show a prevalence of the anti-inflammatory actions (Ma and Hottiger 2016).

Depending on the cellular context, these types of crosstalk can have effect of antagonism or synergism; for example, regarding BMP/Wnt relationship, the osteoblast precursor is maintained in a proliferation status by Wnt, while BMP does stimulate it to undergo the maturation stage, showing antagonism between these two pathways at a distinct developmental stage. In the subsequent developmental stages, a synergism can be observed, when the signals begin to function cooperatively (Itasaki and Hoppler 2010). However, an increment of the Wnt signal could lead to cancer initiation and progression, being $\beta$-catenin involved in carcinogenesis, especially in colorectal cancer. If it is true that many beneficial actions of polyphenols on bone metabolism are also achieved by enhancement of the Wnt signaling, it is also true that some polyphenol effects on cancer prevention are achieved by negatively targeting Wnt signaling (Amado et al. 2011). These opposite effects could be explained by the different types of polyphenols involved and, most importantly, by the doses. In fact, as already extensively reported in the previous paragraphs, different toxicity effects can be observed, for a specific polyphenol, at high $(\mathrm{mmol} / \mathrm{L})$ or low-doses $(\mu$ or nmol/L) (Williamson and Manach 2005), thus showing a dualistic phytochemical nature (Martin 2009).

By taking these observations into account, it is clear that the present understanding of how phytochemicals act on a specific biological system is still far from an effective and reproducible application in vivo.

This consideration is also supported by the observation that some polyphenols differ from others in terms of bioavailability and bioactivity.

Despite their structure diversity, they share common different properties, which are responsible for the even more growing interest in researchers and society. These multiple features, which include anti-inflammation, anti-oxidation and anti-aging, contribute to the prevention of human diseases and, specifically for the above analyzed bone system context, to the protection against bone diseases, in so far as they also include anti-resorption and pro-osteogenesis.

The many different possible chemical structures are also made more complex by the binding of sugars, such as glucose, galactose, rhamnose, xylose, rutinose, arabinopyranose and arabinofuranose to form more stable glycosylated derivatives to be stored in vacuoles and chloroplasts and by esterification with lipids and organic acids. Hence, these aspects represent an important key point that determines the degree of polyphenol bioavailability and absorption: in fact, in the small intestine, enzymes such as glycosylases are able to metabolize the glycosylated forms to aglycones, while only specific strains of the gut microbiota in the colon, are able to break the esterification bond and to generate active metabolites (Marín et al. 2015).

Besides polyphenol metabolism, other aspects to be considered are the subsequent modifications carried out by enterocytes, such as methylation, sulfation and glucuronidation, representing a detoxification mechanism by which the organism prepares the molecule to be excreted. Before polyphenols are taken to tissues or excreted through bile, urine or faeces, conjugation, mainly in the liver, with other carrier molecules or 
interaction with other types of polyphenols is also possible, thus increasing the factors to take into account when considering polyphenol bioavailability.

So, it is also important to investigate whether the extensive modifications which take place in the host organism, do also affect polyphenol activity, that can be different from the one that has been observed in the original sources and to notice that aglycones, the presumed active forms of polyphenols, are generally absent in plasma, although with some exceptions (D'Archivio et al. 2007).

That's why, when considering in vivo delivery, techniques aimed at improving absorption and bioavailability should be well chosen and designed. For example, by targeting the gut bacteria genome with mutagenesis techniques to generate new and improved strains, could allow them to be more efficient in metabolizing polyphenols or to produce new or more active metabolites, while increasing the lipophilicity by combination of polyphenols with other molecules and the addiction of lipophilic groups reduces the hydrogen bonding potential. In this field, phytosomes with unique vehicle properties that arise from the complexation of a phospholipid with a phytochemical, exhibit better pharmacokinetic and pharmacodynamic profiles than free phytochemical compounds (Jain et al. 2010). Another way to improve bioavailability, involves structural changes aimed at increasing the plasma half-life (clearance) of compounds, the involvement of a vector molecule, which is directly conjugated with the polyphenol and which has affinity for a relative receptor on the target tissue, or the development of micro or nano-carriers such as microspheres, nanoparticles, microemultions and so on (Khushnud and Mousa 2013).

Regarding the engineering of delivery systems and devices, nanotechnologies, which are getting researchers more and more interested in, could represent a promising approach, as they involve the tailoring of materials at atomic level, in view of obtaining unique properties suitable for a wide variety of applications (Gleiter 2000).

Nanomedicine is a new field of treatments based on nanosystems able to enhance drugs delivery, drugs specific targeting and drugs half-life, thanks to their properties of passive accumulation in specific tissues, stability, specificity and biocompatibility. So, given the relative high clearance of polyphenols and their low stability, a nanotechnological approach aimed at increasing the phytochemical circulation in the bloodstream could represent a way to be investigated (Tabrez and Priyadarshini 2013). Furthermore, nanotechnologies specificity could be improved by creating targeted nanoparticle systems, particularly useful when the phytochemical delivery is to be obtained via topical or parenteral delivery, rather than by the classical enteral delivery. For example, considering the transdermal administration of a drug, its penetration often finds difficulties due to skin anatomy, with different routes of penetration; so, the employ of nanoparticles provide a number of advantages, including increased xenobiotic solubility and, thus, permeation, reduced toxicity, as the first-pass hepatic metabolism is avoided and high affinity for cellular membranes, due to nanoparticles surface properties (Uchechi et al. 2014).

\section{Conclusion}

In the past few decades, accumulating data have shown potential beneficial effects of polyphenols on human health.

In particular, thanks to their multiple beneficial properties, which can modulate different signaling pathways, polyphenols are able to target the diverse bone cellular compartments, thus exerting a noticeable bone protection (Đudarić et al. 2015).

However, despite these findings, care must be taken when considering dietary intake of polyphenols, because they can act in a double manner, being dependent on many other associated factors, such as bioavailability, diet or dosage (Martin 2009) and, therefore, the need to develop tests aimed at establishing the right dose to ensure safety and the low risk of adverse effects is even more crucial.

Furthermore, besides dosage, also the form of the phenolic compound is of note, in fact it influences its bioavailability, together with the presence of intestinal microflora and gut enzymes.

So, biomedical applications of these natural compounds are severely hindered by their low bioavailability, rapid metabolism, and often by unfavorable physico-chemical properties, e.g. a generally low water solubility, as well as still insufficient scientific data derived from preclinical and clinical studies.

Given the Directive 2001/83/EC of the European Parliament and of the Council of 6 November 2001 on 
the Community code, relating to medicinal products for human use, at article 1, first subparagraph, the term "medicinal product" is established as "any substance or combination of substances presented as having properties for treating or preventing disease in human beings; or any substance or combination of substances which may be used in or administered to human beings either with a view to restoring, correcting or modifying physiological functions by exerting a pharmacological, immunological or metabolic action, or to making a medical diagnosis" (EC 2001).

The main purpose of the standards concerning production, distribution and intended use of medicinal products, is to ensure the protection of public health and to enable the competent authorities to make decisions on the basis of uniform tests and by reference to uniform criteria, by contributing to prevent differences of view.

Although polyphenols have been shown to possess effective biological properties in the prevention, treatment and mitigation of different bone diseases, they cannot be defined as "active pharmaceutical ingredient" (API) and they are not regulated by technical dossiers involved in the definition of "medicinal products".

Not less important, they have not yet been shown to represent a definitive cure for bone diseases.

Aiming at reducing the differences by setting them against the evolution of science, it is concluded that properties and intended use of medicinal products are diversified not only on the basis of already existing scientific data, but also by the appropriate understanding of the existing legislation.

Therefore, thanks to their beneficial osteoanabolic effects, polyphenols could be used as adjuvants in the prevention, treatment and mitigation of the osteoporotic disease, with a strict control of the dosages at which their health benefits and lack of adverse effects have been shown.

Consequently, more in vivo tests should be necessary to determine, at first, which types of intervention on molecules do improve their bioavailability, then which doses are better useful to get the desired effects, by also taking into account the toxicity aspect. Furthermore, in a medical devices context, it is important to evaluate how polyphenols combined with medical devices do act and eventually modify their properties in the different pathways, following a sterilization process, for example, or the all necessary steps aimed at ensuring an excellent result of quality control also in the post marketing activity.

Acknowledgements Dr. Giorgio Iviglia for assistance in preparation of the manuscript and Dr. Erica Lodi for assistance in civil Law.

Open Access This article is distributed under the terms of the Creative Commons Attribution 4.0 International License (http:// creativecommons.org/licenses/by/4.0/), which permits unrestricted use, distribution, and reproduction in any medium, provided you give appropriate credit to the original author(s) and the source, provide a link to the Creative Commons license, and indicate if changes were made.

\section{References}

Abbas AK, Lichtman AH, Pillai S (2012) Basic immunology: functions and disorders of the immune system. 4th edn. Saunders, Philadelphia

Adlercreutz H (2002) Phyto-oestrogens and cancer. Lancet Oncol 3:364-373

Adlercreutz H, Heinonen S (2004) Phytoestrogens, cancer and coronary heart disease. BioFactors 22:229-236

Aggarwal BB (1995) Activation of transcription factor NFkappaB is suppressed by curcumin (diferuloylmethane). J Biol Chem 270:24995-25000. doi:10.1074/jbc.270.42. 24995

Al-Obaidi MMJ, Al-Bayaty FH, Al Batran R et al (2014a) Protective effect of ellagic acid on healing alveolar bone after tooth extraction in rat-a histological and immunohistochemical study. Arch Oral Biol 59:987-999. doi:10. 1016/j.archoralbio.2014.06.001

Al-Obaidi MMJ, Al-Bayaty FH, Al Batran R, Hussaini J, Khor $\mathrm{GH}$ et al (2014b) Impact of ellagic acid in bone formation after tooth extraction: an experimental study on diabetic rats. Sci World J. doi:10.1155/2014/908098

Amado NG, Fonseca BF, Cerqueira DM et al (2011) Flavonoids: potential $\mathrm{Wnt} /$ beta-catenin signaling modulators in cancer. Life Sci 89:545-554

Anderson JJ, Ambrose WW, Garner SC (1998) Biphasic effects of genistein on bone tissue in the ovariectomized, lactating rat model. Proc Soc Exp Biol Med 217:345-350

Ang ESM, Pavlos NJ, Chai LY et al (2009) Caffeic acid phenethyl ester, an active component of honeybee propolis attenuates osteoclastogenesis and bone resorption via the suppression of RANKL-induced NF-kappaB and NFAT activity. J Cell Physiol 221:642-649. doi:10.1002/jcp. 21898

Ang ESM, Yang X, Chen H et al (2011) Naringin abrogates osteoclastogenesis and bone resorption via the inhibition of RANKL-induced NF- $\kappa B$ and ERK activation. FEBS Lett 585:2755-2762. doi:10.1016/j.febslet.2011.07.046

Arts J, Kuiper GG (1997) Differential expression of extrogen receptors alfa and beta mRNA during differentiation of human osteoblast SV-HFO cells. Endocr Soc 138:5067-5070 
Bäckesjö C-M, Li Y, Lindgren U, Haldosén L-A (2008) Activation of sirt 1 decreases adipocyte formation during osteoblast differentiation of mesenchymal stem cells. J Bone Miner Res 21:993-1002. doi:10.1159/000151744

Bandyopadhyay S, Lion JM, Mentaverri R et al (2006) Attenuation of osteoclastogenesis and osteoclast function by apigenin. Biochem Pharmacol 72:184-197. doi:10.1016/j. bcp. 2006.04 .018

Baur JA, Pearson KJ, Price NL et al (2006) Resveratrol improves health and survival of mice on a high-calorie diet. Nature 444:337-342. doi:10.1038/nature05354

Bertelli AAE, Migliori M, Panichi V et al (2002) Oxidative stress and inflammatory reaction modulation by white wine. Ann NY Acad Sci 957:295-301. doi:10.1111/j.17496632.2002.tb02929.x

Bhargavan B, Gautam AK, Singh D et al (2009) Methoxylated isoflavones, cajanin and isoformononetin, have non-estrogenic bone forming effect via differential mitogen activated protein kinase (MAPK) signaling. J Cell Biochem 108:388-399. doi:10.1002/jcb.22264

Bharti A, Donato N (2003) Curcumin (diferuloylmethane) down-regulates the constitutive activation of nuclear factor- $-\kappa \mathrm{B}$ and $\mathrm{I} \kappa \mathrm{B} \alpha$ kinase in human multiple myeloma cells, leading to suppression of proliferation and induction of apoptosis. Blood 101:1053-1062. doi:10.1182/blood2002-05-1320.Supported

Bharti AC, Takada Y, Aggarwal BB (2004) Curcumin (diferuloylmethane) inhibits receptor activator of NF- $\kappa \mathrm{B}$ ligandinduced $\mathrm{NF}-\kappa \mathrm{B}$ activation in osteoclast precursors and suppresses osteoclastogenesis. J Immunol 172:5940-5947. doi:10.4049/jimmunol.172.10.5940

Björnström L, Sjöberg M (2005) Mechanisms of estrogen receptor signaling: convergence of genomic and nongenomic actions on target genes. Mol Endocrinol 19:833-842. doi:10.1210/me.2004-0486

Bodet C, Chandad F, Grenier D (2007) Cranberry components inhibit interleukin-6, interleukin-8, and prostaglandin E production by lipopolysaccharide-activated gingival fibroblasts. Eur J Oral Sci 115:64-70. doi:10.1111/j.16000722.2007.00415.x

Boissy P, Andersen TL, Abdallah BM et al (2005) Resveratrol inhibits myeloma cell growth, prevents osteoclast formation, and promotes osteoblast differentiation. Cancer Res 65:9943-9952. doi:10.1158/0008-5472.CAN-05-0651

Bonewald LF (2011) The amazing osteocyte. J Bone Miner Res 26:229-238. doi:10.1002/jbmr.320

Braun KF, Ehnert S, Freude T et al (2011) Quercetin protects primary human osteoblasts exposed to cigarette smoke through activation of the antioxidative enzymes HO-1 and SOD-1. Sci World J 11:2348-2357. doi:10.1100/2011/ 471426

$\mathrm{Bu}$ SY, Lerner M, Stoecker BJ et al (2008) Dried plum polyphenols inhibit osteoclastogenesis by downregulating NFATc1 and inflammatory mediators. Calcif Tissue Int 82:475-488. doi:10.1007/s00223-008-9139-0

Bu SY, Hunt TS, Smith BJ (2009) Dried plum polyphenols attenuate the detrimental effects of TNF- $\alpha$ on osteoblast function coincident with up-regulation of Runx2, Osterix and IGF-I. J Nutr Biochem 20:35-44. doi:10.1016/j. jnutbio.2007.11.012
Buluc M, Demirel-Yilmaz E (2006) Resveratrol decreases calcium sensitivity of vascular smooth muscle and enhances cytosolic calcium increase in endothelium. Vasc Pharmacol 44:231-237. doi:10.1016/j.vph.2005.12.003

Byun MR, Sung MK, Kim AR et al (2014) (-)-Epicatechin gallate (ECG) stimulates osteoblast differentiation via Runt-related transcription factor 2 (RUNX2) and transcriptional coactivator with PDZ-binding motif (TAZ)mediated transcriptional activation. J Biol Chem 289:9926-9935. doi:10.1074/jbc.M113.522870

Callaway DA, Jiang JX (2015) Reactive oxygen species and oxidative stress in osteoclastogenesis, skeletal aging and bone diseases. J Bone Miner Metab. doi:10.1007/s00774015-0656-4

Casanova M, You L, Gaido KW et al (1999) Developmental effects of dietary phytoestrogens in Sprague-Dawley rats and interactions of genistein and daidzein with rat estrogen receptors $\alpha$ and $\beta$ in vitro. Toxicol Sci 51:236-244. doi:10. 1093/toxsci/51.2.236

Casarin RC, Casati MZ, Pimentel SP et al (2014) Resveratrol improves bone repair by modulation of bone morphogenetic proteins and osteopontin gene expression in rats. Int J Oral Maxillofac Surg 43:900-906. doi:10.1016/j.ijom. 2014.01.009

Cauley J (2015) Estrogen and bone health in men and women. Steroids 99:11-15. doi:10.1016/j.steroids.2014.12.010

Chan WH, Wu HY, Chang WH (2006) Dosage effects of curcumin on cell death types in a human osteoblast cell line. Food Chem Toxicol 44:1362-1371. doi:10.1016/j.fct. 2006.03.001

Chang J, Jeong H (2015) Discovery of novel drug targets and their functions using phenotypic screening of natural products. J Ind Microbiol Biotechnol 43:221-231. doi:10. 1007/s10295-015-1681-y

Chang JK, Hsu YL, Teng IC, Kuo PL (2006) Piceatannol stimulates osteoblast differentiation that may be mediated by increased bone morphogenetic protein-2 production. Eur J Pharmacol 551:1-9. doi:10.1016/j.ejphar.2006.08. 073

Chen J-R, Lazarenko OP (2014) Diet-derived phenolic acids regulate osteoblast and adipocyte lineage commitment and differentiation in young mice. $J$ Bone Miner Res 29:1043-1053. doi:10.1002/jbmr.2234

Chen XW, Garner SC, Anderson JJB (2002) Isoflavones regulate interleukin-6 and osteoprotegerin synthesis during osteoblast cell differentiation via an estrogen-receptordependent pathway. Biochem Biophys Res Commun 295:417-422. doi:10.1016/S0006-291X(02)00667-8

Chen X, Garner SC, Quarles LD, Anderson JJB (2003) Effects of genistein on expression of bone markers during MC3T3E1 osteoblastic cell differentiation. J Nutr Biochem 14:342-349. doi:10.1016/S0955-2863(03)00056-1

Chen D, Zhao M, Mundy GR (2004) Bone morphogenetic proteins. Growth Factors 22:233-241. doi:10.1080/ 08977190412331279890

Chen KM, Ge BF, Liu XY et al (2007) Icariin inhibits the osteoclast formation induced by RANKL and macrophagecolony stimulating factor in mouse bone marrow culture. Pharmazie 62:388-391. doi:10.1691/ph.2007.5.6682

Chen J-R, Lazarenko OP, Wu X et al (2010) Dietary-induced serum phenolic acids promote bone growth via $\mathrm{p} 38 \mathrm{MAPK} /$ 
$\beta$-catenin canonical Wnt signaling. J Bone Miner Res 25:2399-2411. doi:10.1002/jbmr.137

Chen F, Wang H, Xiang X et al (2014a) Curcumin increased the differentiation rate of neurons in neural stem cells via wnt signaling in vitro study. J Surg Res 192:298-304. doi:10. 1016/j.jss.2014.06.026

Chen X, Li Y, Lin Q et al (2014b) Tea polyphenols induced apoptosis of breast cancer cells by suppressing the expression of Survivin. Sci Rep 4:4416. doi:10.1038/ srep04416

Chen Z, Xue J, Shen T et al (2016) Curcumin alleviates glucocorticoid-induced osteoporosis by protecting osteoblasts from apoptosis in vivo and in vitro. Clin Exp Pharmacol Physiol 43:268-276. doi:10.1111/1440-1681.12513

Choi EM (2012) Protective effect of quercitrin against hydrogen peroxide-induced dysfunction in osteoblastic MC3T3-E1 cells. Exp Toxicol Pathol 64:211-216. doi:10.1016/j.tiv. 2011.06.004

Choi E-M, Hwang J-K (2003) Effects of (+)-catechin on the function of osteoblastic cells. Biol Pharm Bull 26:523-526

Choi EM, Suh KS, Kim YS et al (2001) Soybean ethanol extract increases the function of osteoblastic MC3T3-E1 cells. Phytochemistry 56:733-739

Choi SW, Son YJ, Yun JM, Kim SH (2012) Fisetin inhibits osteoclast differentiation via downregulation of p38 and c-Fos-NFATc1 signaling pathways. Evidence Based Complement Altern Med. doi:10.1155/2012/810563

Chowdhury TT, Salter DM, Bader DL, Lee DA (2008) Signal transduction pathways involving p38 MAPK, JNK, NFkB and AP-1 influences the response of chondrocytes cultured in agarose constructs to IL-1 $\beta$ and dynamic compression. Inflamm Res 57:306-313. doi:10.1007/s00011-007-7126y

Comalada M, Ballester I, Bailón E et al (2006) Inhibition of proinflammatory markers in primary bone marrow-derived mouse macrophages by naturally occurring flavonoids: analysis of the structure-activity relationship. Biochem Pharmacol 72:1010-1021. doi:10.1016/j.bcp.2006.07.016

Confavreux CB, Levine RL, Karsenty G (2009) A paradigm of integrative physiology, the crosstalk between bone and energy metabolisms. Mol Cell Endocrinol 310:21-29. doi:10.1016/j.mce.2009.04.004

Cos P, Apers S (2003) Phytoestrogens: recent developments. Planta Med 69:589-599

Crasto GJ, Kartner N, Yao Y et al (2013) Luteolin inhibition of V-ATPase a3-d2 interaction decreases osteoclast resorptive activity. J Cell Biochem 114:929-941. doi:10.1002/ jcb. 24434

Crozier A, Jaganath IB, Clifford MN (2009) Dietary phenolics: chemistry, bioavailability and effects on health. Nat Prod Rep 26:1001-1043. doi:10.1039/b802662a

Csaki C, Mobasheri A, Shakibaei M (2009) Synergistic chondroprotective effects of curcumin and resveratrol in human articular chondrocytes: inhibition of IL-1beta-induced NFkappaB-mediated inflammation and apoptosis. Arthritis Res Ther 11:R165. doi:10.1186/ar2850

Cui L, Jia X, Zhou Q et al (2013) Curcumin affects beta-catenin pathway in hepatic stellate cell in vitro and in vivo. J Pharm Pharmacol 66:1615-1622. doi:10.1111/jphp.12283
D’Archivio M, Filesi C, Di Benedetto R et al (2007) Polyphenols, dietary sources and bioavailability. Ann Ist Super Sanita 43:348-361

Dai Z, Li Y, Quarles LD et al (2007) Resveratrol enhances proliferation and osteoblastic differentiation in human mesenchymal stem cells via ER-dependent ERK1/2 activation. Phytomedicine 14:806-814. doi:10.1016/j. phymed.2007.04.003

Dai J, Li Y, Zhou H et al (2013) Genistein promotion of osteogenic differentiation through BMP2/SMAD5/ RUNX2 signaling. Int J Biol Sci 9:1089-1098. doi:10. 7150/ijbs. 7367

De Stefano D, Maiuri MC, Simeon V et al (2007) Lycopene, quercetin and tyrosol prevent macrophage activation induced by gliadin and IFN- $\gamma$. Eur $\mathbf{J}$ Pharmacol 566:192-199. doi:10.1016/j.ejphar.2007.03.051

De Wilde A, Lieberherr M, Colin C, Pointillart A (2004) A low dose of daidzein acts as an ERbeta-selective agonist in trabecular osteoblasts of young female piglets. J Cell Physiol 200:253-262. doi:10.1002/jcp.20008

Die L, Yan P, Jun Jiang Z et al (2012) Glycogen synthase kinase3 beta inhibitor suppresses Porphyromonas gingivalis lipopolysaccharide-induced CD40 expression by inhibiting nuclear factor-kappa B activation in mouse osteoblasts. Mol Immunol 52:38-49. doi:10.1016/j.molimm.2012.04. 005

Dobrydneva Y, Williams RL, Blackmore PF (1999) transResveratrol inhibits calcium influx in thrombin-stimulated human platelets. Br J Pharmacol 128:149-157. doi:10. 1038/sj.bjp.0702749

Dobrydneva Y, Williams RL, Blackmore PF (2010) Diethylstilbestrol and other nonsteroidal estrogens: novel class of store-operated calcium channel modulators. J Cardiovasc Pharmacol 55:522-530. doi:10.1097/FJC. 0b013e3181d64b33

Dragan S, Andrica F, Serban M-C, Timar R (2015) Polyphenolsrich natural products for treatment of diabetes. Curr Med Chem 22:14-22

Đudarić L, Fužinac-Smojver A, Muhvić D, Giacometti J (2015) The role of polyphenols on bone metabolism in osteoporosis. Food Res Int 77:290-298. doi:10.1016/j.foodres. 2015.10.017

Ebrahimi A, Schluesener H (2012) Natural polyphenols against neurodegenerative disorders: potentials and pitfalls. Ageing Res Rev 11:329-345

EC (2001) DIRECTIVE 2001/83/EC OF THE EUROPEAN PARLIAMENT AND OF THE COUNCIL of 6 November 2001 on the Community code relating to medicinal products for human use. Off J Eur Communities L 311:1-188

Eklou-Kalonji E, Denis I, Lieberherr M, Pointillart A (1998) Effects of extracellular calcium on the proliferation and differentiation of porcine osteoblasts in vitro. Cell Tissue Res 292:163-171. doi:10.1007/s004410051046

Farha MA, Brown ED (2016) Strategies for target identification of antimicrobial natural products. Nat Prod Rep. doi:10. 1039/C5NP00127G

Farley JR, Hall SL, Tanner MA, Wergedal JE (1994) Specific activity of skeletal alkaline phosphatase in human osteoblast-line cells regulated by phosphate, phosphate esters, and phosphate analogs and release of alkaline phosphatase 
activity inversely regulated by calcium. J Bone Miner Res 9:497-508. doi:10.1002/jbmr.5650090409

Feng J, Liu S, Ma S et al (2014) Protective effects of resveratrol on postmenopausal osteoporosis: regulation of SIRT1-NF$\mathrm{kB}$ signaling pathway. Acta Biochim Biophys Sin 46:1024-1033. doi:10.1093/abbs/gmu103.Advance

Folwarczna J, Zych M, Burczyk J et al (2009) Effects of natural phenolic acids on the skeletal system of ovariectomized rats. Planta Med 75:1567-1572. doi:10.1055/s-00291185904

Folwarczna J, Pytlik M, Zych M et al (2015) Effects of caffeic and chlorogenic acids on the rat skeletal system. Eur Rev Med Pharmacol Sci 19:682-693. doi:10.1016/j.bone.2012. 02.495

Gao YH, Yamaguchi M (1999a) Inhibitory effect of genistein on osteoclast-like cell formation in mouse marrow cultures. Biochem Pharmacol 58:767-772

Gao YH, Yamaguchi M (1999b) Suppressive effect of Genistein on rat bone osteoclasts: apoptosis is induced through $\mathrm{Ca}^{2+}$ signaling. Biol Pharm Bull 22:805-809

Gao Y, Huang E, Zhang H et al (2013) Crosstalk between Wnt/ $\beta$-catenin and estrogen receptor signaling synergistically promotes osteogenic differentiation of mesenchymal progenitor cells. PLoS ONE 8:e82436. doi:10.1371/journal. pone. 0082436

Ge C, Xiao G, Jiang D, Franceschi RT (2007) Critical role of the extracellular signal-regulated kinase-MAPK pathway in osteoblast differentiation and skeletal development. J Cell Biol 176:709-718. doi:10.1083/jcb.200610046

Ghibelli L, Cerella C, Diederich M (2010) The dual role of calcium as messenger and stressor in cell damage, death, and survival. Int J Cell Biol. doi:10.1155/2010/546163

Ginaldi L, De Martinis M (2016) Osteoimmunology and beyond. Curr Med Chem. doi:10.2174/ 0929867323666160907

Gleiter H (2000) Nanostructured materials: basic concepts and microstructure. Acta Mater 48:1-29. doi:10.1016/S13596454(99)00285-2

Gómez-Florit M, Monjo M, Ramis JM (2014) Identification of quercitrin as potential therapeutic agent for periodontal applications. J Periodontol 85:966-974. doi:10.1902/jop. 2014.130438

Gómez-Florit M, Monjo M, Ramis JM (2015) Quercitrin for periodontal regeneration: effects on human gingival fibroblasts and mesenchymal stem cells. Sci Rep. doi:10. 1038/srep16593

González-Gallego J, García-Mediavilla MV, Sánchez-Campos S, Tuñón MJ (2010) Fruit polyphenols, immunity and inflammation. Br J Nutr 104(Suppl):S15-S27. doi:10. 1017/S0007114510003910

Gosden JR, Middleton PG, Rout D (1986) Localization of the human oestrogen receptor gene to chromosome $6 \mathrm{q} 24 \rightarrow \mathrm{q} 27$ by in situ hybridization. Cytogenet Cell Genet 43:218-220

Goto T, Hagiwara K, Shirai N et al (2015) Apigenin inhibits osteoblastogenesis and osteoclastogenesis and prevents bone loss in ovariectomized mice. Cytotechnology 67:357-365. doi:10.1007/s10616-014-9694-3

Grigoriadis AE, Wang Z, Cecchini MG et al (1994) c-Fos: a key regulator of osteoclast-macrophage lineage determination and bone remodeling. Science 266:443-448
Gruber R, Graninger W, Bobacz K et al (2003) BMP-6-induced osteogenic differentiation of mesenchymal cell lines is not modulated by sex steroids and resveratrol. Cytokine 23:133-137. doi:10.1016/S1043-4666(03)00223-0

Gu Q, Cai Y, Huang C et al (2012) Curcumin increases rat mesenchymal stem cell osteoblast differentiation but inhibits adipocyte differentiation. Pharmacogn Mag 8:202-208. doi:10.4103/0973-1296.99285

Guicheux J, Lemonnier J, Ghayor C et al (2003) Activation of p38 mitogen-activated protein kinase and c-Jun-NH2-terminal kinase by BMP-2 and their implication in the stimulation of osteoblastic cell differentiation. J Bone Miner Res 18:2060-2068. doi:10.1359/jbmr.2003.18.11.2060

Guimarães MR, Coimbra LS, De Aquino SG et al (2011) Potent anti-inflammatory effects of systemically administered curcumin modulate periodontal disease in vivo. J Periodontal Res 46:269-279. doi:10.1111/j.1600-0765.2010. 01342.x

Guimarães MR, de Aquino SG, Coimbra LS et al (2012) Curcumin modulates the immune response associated with LPS-induced periodontal disease in rats. Innate Immun 18:155-163. doi:10.1177/1753425910392935

Guntur AR, Rosen CJ (2011) The skeleton: a multi-functional complex organ. New insights into osteoblasts and their role in bone formation: the central role of PI3Kinase. J Endocrinol 211:123-130. doi:10.1530/JOE-11-0175

Guo AJ, Choi RC, Zheng KY et al (2012a) Kaempferol as a flavonoid induces osteoblastic differentiation via estrogen receptor signaling. Chin Med 7:10. doi:10.1186/17498546-7-10

Guo AJY, Choi AWHC, Chen VP et al (2012b) Baicalin, a flavone, induces the differentiation of cultured osteoblasts: an action via the $\mathrm{Wnt} / \beta$-catenin signaling pathway. J Biol Chem 286:27882. doi:10.1093/ndt/gfr716

Guo C, Hou G, Li X et al (2012c) Quercetin triggers apoptosis of lipopolysaccharide (LPS)-induced osteoclasts and inhibits bone resorption in RAW264.7 cells. Cell Physiol Biochem 30:123-136

Gustafsson J-A (2003) What pharmacologists can learn from recent advances in estrogen signalling. Trends Pharmacol Sci 24:479-485. doi:10.1016/S0165-6147(03)00229-3

Guttridge DC, Albanese C, Reuther JY et al (1999) NF-kappaB controls cell growth and differentiation through transcriptional regulation of cyclin D1. Mol Cell Biol 19:5785-5799. doi:10.1128/MCB.19.8.5785

Ha J, Choi H-S, Lee Y et al (2009) Caffeic acid phenethyl ester inhibits osteoclastogenesis by suppressing NF kappaB and downregulating NFATc1 and c-Fos. Int Immunopharmacol 9:774-780. doi:10.1016/j.intimp.2009.03.001

Hafeez BB, Ahmed S, Wang N et al (2006) Green tea polyphenols-induced apoptosis in human osteosarcoma SAOS-2 cells involves a caspase-dependent mechanism with downregulation of nuclear factor-kappaB. Toxicol Appl Pharmacol 216:11-19. doi:10.1016/j.taap.2006.03. 013

Hagiwara K, Goto T, Araki M et al (2011) Olive polyphenol hydroxytyrosol prevents bone loss. Eur J Pharmacol 662:78-84. doi:10.1016/j.ejphar.2011.04.023

Hall TJ, Schaeublin M, Jeker H et al (1995) The role of reactive oxygen intermediates in osteoclastic bone resorption. Biochem Biophys Res Commun 207:280-287 
Halliwell B (1994) Free radicals, antioxidants, and human disease: curiosity, cause, or consequence? Lancet 344:721-724

Hämäläinen M, Nieminen R, Vuorela P et al (2007) Anti-inflammatory effects of flavonoids: genistein, kaempferol, quercetin, and daidzein inhibit STAT-1 and NF- $\kappa$ B activations, whereas flavone, isorhamnetin, naringenin, and pelargonidin inhibit only NF- $\kappa \mathrm{B}$ activation along with their inhibitory effect on i. Mediat Inflamm. doi:10.1155/2007/ 45673

Harris DM, Besselink E, Henning SM et al (2005) Phytoestrogens induce differential estrogen receptor alpha- or betamediated responses in transfected breast cancer cells. Exp Biol Med (Maywood) 230:558-568

Hawse JR, Subramaniam M (2008) Estrogen-TGF $\beta$ cross-talk in bone and other cell types: role of TIEG, Runx2, and other transcription factors. J Cell Biochem 103:383-392. doi:10. $1002 / j \mathrm{cb} .21425$

Hayden MS, Ghosh S (2004) Signaling to NF-kB. Genes Dev 18:2195-2224. doi:10.1101/gad.1228704.bone

He B, Hu M, Li S-D et al (2013) Effects of geraniin on osteoclastic bone resorption and matrix metalloproteinase-9 expression. Bioorg Med Chem Lett 23:630-634. doi:10. 1016/j.bmcl.2012.12.005

He M, Li Y, Zhang L et al (2014) Curcumin suppresses cell proliferation through inhibition of the $\mathrm{Wnt} / \beta$-catenin signaling pathway in medulloblastoma. Oncol Rep 32:173-180. doi:10.3892/or.2014.3206

Heim M, Frank O, Kampmann G et al (2004) The phytoestrogen genistein enhances osteogenesis and represses adipogenic differentiation of human primary bone marrow stromal cells. Endocrinology 145:848-859. doi:10.1210/en.20031014

Henrotin Y, Lambert C, Couchourel D et al (2011) Nutraceuticals: do they represent a new era in the management of osteoarthritis? A narrative review from the lessons taken with five products. Osteoarthr Cartil 19:1-21. doi:10.1016/ j.joca.2010.10.017

Heo DN, Ko W-K, Moon H-J et al (2014) Inhibition of osteoclast differentiation by gold nanoparticles functionalized with cyclodextrin curcumin complexes. ACS Nano 8:12049-12062. doi:10.1021/nn504329u

Hie M, Yamazaki M, Tsukamoto I (2009) Curcumin suppresses increased bone resorption by inhibiting osteoclastogenesis in rats with streptozotocin-induced diabetes. Eur J Pharmacol 621:1-9. doi:10.1016/j.ejphar.2009.08.025

Hinenoya H (2013) Genistein affects osteoblastic MC3T3-E1 cells both through estrogen receptor and BMP-Smad signaling pathways. Kawasaki Med J 39:21-31

Hofbauer LC, Khosla S (1999) Estrogen stimulates gene expression and protein production of osteoprotegerin in human osteoblastic cells. Endocrinology 138:4367-4370

Hofbauer LC, Lacey DL, Dunstan CR et al (1999) Interleukin1 beta and tumor necrosis factor-alfa, but not interleukin-6, stimulate osteoprotegerin ligand gene expression in human osteoblastic cells. Bone 25:255-259. doi:10.1016/S87563282(99)00162-3

Honda Y, Fitzsimmons RJ, Baylink DJ, Mohan S (1995) Effects of extracellular calcium on insulin-like growth factor II in human bone cells. J Bone Min Res 10:1660-1665
Horcajada-Molteni MN, Crespy V, Coxam V et al (2000) Rutin inhibits ovariectomy-induced osteopenia in rats. J Bone Miner Res 15:2251-2258. doi:10.1359/jbmr.2000.15.11. 2251

Houde N, Chamoux E, Bisson M, Roux S (2009) Transforming Growth Factor-Beta1 (TGF-Beta 1) induces human osteoclast apoptosis by up-regulating Bim. J Biol Chem 284:23397-23404. doi:10.1074/jbc.M109.019372

Howitz K, Bitterman J, Cohen H (2003) Small molecule activators of sirtuins extend Saccharomyces cerevisiae lifespan. Nature 425:191-196. doi:10.1038/nature01965.1

Hsieh T-P, Sheu S-Y, Sun J-S et al (2010) Icariin isolated from Epimedium pubescens regulates osteoblasts anabolism through BMP-2, SMAD4, and Cbfa1 expression. Phytomedicine 17:414-423. doi:10.1016/j.phymed.2009.08. 007

Hsieh T-P, Sheu S-Y, Sun J-S, Chen M-H (2011) Icariin inhibits osteoclast differentiation and bone resorption by suppression of MAPKs/NF- $\kappa$ B regulated HIF- $1 \alpha$ and PGE2 synthesis. Phytomedicine 18:176-185. doi:10.1016/j.phymed. 2010.04.003

Hsu Y-LL, Chang J-KK, Tsai C-HH et al (2007) Myricetin induces human osteoblast differentiation through bone morphogenetic protein-2/p38 mitogen-activated protein kinase pathway. Biochem Pharmacol 73:504-514. doi:10. 1016/j.bcp.2006.10.020

Hsu Y-L, Liang H-L, Hung C-H, Kuo P-L (2009) Syringetin, a flavonoid derivative in grape and wine, induces human osteoblast differentiation through bone morphogenetic protein-2/extracellular signal-regulated kinase $1 / 2$ pathway. Mol Nutr Food Res 53:1452-1461. doi:10.1002/mnfr. 200800483

Hsu YC, Cheng CP, Chang DM (2011) Plectranthus amboinicus attenuates inflammatory bone erosion in mice with collagen-induced arthritis by downregulation of RANKL-induced NFATc1 expression. J Rheumatol 38:1844-1857. doi:10.3899/jrheum.101223

Huang J, Yuan L, Wang X et al (2007) Icaritin and its glycosides enhance osteoblastic, but suppress osteoclastic, differentiation and activity in vitro. Life Sci 81:832-840. doi:10. 1016/j.1fs.2007.07.015

Huang Q, Gao B, Wang L et al (2014) Protective effects of myricitrin against osteoporosis via reducing reactive oxygen species and bone-resorbing cytokines. Toxicol Appl Pharmacol 280:550-560. doi:10.1016/j.taap.2014.08.004

Hughes DE, Dai A, Tiffee JC et al (1996) Estrogen promotes apoptosis of murine osteoclasts mediated by TGF-beta. Nat Med 2:1132-1136. doi:10.1038/nm1096-1132

Huh J-E, Jung I-T, Choi J et al (2013) The natural flavonoid galangin inhibits osteoclastic bone destruction and osteoclastogenesis by suppressing NF- $\kappa \mathrm{B}$ in collagen-induced arthritis and bone marrow-derived macrophages. Eur $\mathrm{J}$ Pharmacol 698:57-66. doi:10.1016/j.ejphar.2012.08.013

Huh J-E, Lee WI, Kang JW et al (2014) Formononetin attenuates osteoclastogenesis via suppressing the RANKL-induced activation of NF- $\mathrm{\kappa B}$, c-Fos, and nuclear factor of activated T-Cells cytoplasmic 1 signaling pathway. J Nat Prod 77:2423-2431. doi:10.1021/np500417d

Hwang SY, Putney JW (2011) Calcium signaling in osteoclasts. Biochim Biophys Acta Mol Cell Res 1813:979-983. doi:10.1016/j.bbamcr.2010.11.002 
Hwang JT, Park IJ, Shin JI et al (2005) Genistein, EGCG, and capsaicin inhibit adipocyte differentiation process via activating AMP-activated protein kinase. Biochem Biophys Res Commun 338:694-699. doi:10.1016/j.bbrc. 2005. 09.195

Ikeda F, Matsubara T, Tsurukai T et al (2008) JNK/c-Jun signaling mediates an anti-apoptotic effect of RANKL in osteoclasts. J Bone Miner Res 23:907-914. doi:10.1359/ jbmr.080211

Imai S, Armstrong CM, Kaeberlein M, Guarente L (2000) Transcriptional silencing and longevity protein Sir2 is an NAD-dependent histone deacetylase. Nature 403:795-800. doi: $10.1038 / 35001622$

Ishida I, Kohda C, Yanagawa Y et al (2007) Epigallocatechin gallate suppresses expression of receptor activator of NFkappaB ligand (RANKL) in Staphylococcus aureus infection in osteoblast-like NRG cells. J Med Microbiol 56:1042-1046. doi:10.1099/jmm.0.47029-0

Islam S, Islam N, Kermode T et al (2000) Involvement of caspase-3 in epigallocatechin-3-gallate-mediated apoptosis of human chondrosarcoma cells. Biochem Biophys Res Commun 270:793-797. doi:10.1006/bbrc.2000.2536

Itasaki N, Hoppler S (2010) Crosstalk between Wnt and bone morphogenic protein signaling: a turbulent relationship. Dev Dyn 239:16-33. doi:10.1002/dvdy.22009

Jain N, Gupta BP, Thakur N et al (2010) Phytosome: a novel drug delivery system for herbal medicine. Int J Pharm Sci Drug Res 2:224-228

Jia TL, Wang HZ, Xie LP et al (2003) Daidzein enhances osteoblast growth that may be mediated by increased bone morphogenetic protein (BMP) production. Biochem Pharmacol 65:709-715. doi:10.1016/S0006-2952(02)01585-X

Jimi E, Nakamura I, Duong LT et al (1999) Interleukin 1 induces multinucleation and bone-resorbing activity of osteoclasts in the absence of osteoblasts/stromal cells. Exp Cell Res 247:84-93. doi:10.1006/excr.1998.4320

Jin S, Park JY, Hong JM et al (2011) Inhibitory effect of (-)epigallocatechin gallate on titanium particle-induced TNF$\alpha$ release and in vivo osteolysis. Exp Mol Med 43:411-418. doi:10.3858/emm.2011.43.7.045

Jin $\mathrm{P}, \mathrm{Wu} \mathrm{H}, \mathrm{Xu} \mathrm{G}$ et al (2014) Epigallocatechin-3-gallate (EGCG) as a pro-osteogenic agent to enhance osteogenic differentiation of mesenchymal stem cells from human bone marrow: an in vitro study. Cell Tissue Res 356:381-390. doi:10.1007/s00441-014-1797-9

Jobin C, Bradham CA, Russo MP et al (1999) Curcumin blocks cytokine-mediated NF-kB activation and proinflammatory gene expression by inhibiting inhibitory factor I-kB kinase activity. J Immunol 163:3474-3483

Jung W-W (2014) Protective effect of apigenin against oxidative stress-induced damage in osteoblastic cells. Int J Mol Med 33:1327-1334. doi:10.3892/ijmm.2014.1666

Kanazawa I, Yamaguchi T, Yano S et al (2007) Adiponectin and AMP kinase activator stimulate proliferation, differentiation, and mineralization of osteoblastic MC3T3-E1 cells. BMC Cell Biol 8:51. doi:10.1186/1471-2121-8-51

Kanazawa I, Yamaguchi T, Yano S et al (2008) Metformin enhances the differentiation and mineralization of osteoblastic MC3T3-E1 cells via AMP kinase activation as well as eNOS and BMP-2 expression. Biochem Biophys
Res Commun 375:414-419. doi:10.1016/j.bbrc.2008.08. 034

Kanazawa I, Yamaguchi T, Yano S et al (2009) Activation of AMP kinase and inhibition of Rho kinase induce the mineralization of osteoblastic MC3T3-E1 cells through endothelial NOS and BMP-2 expression. Am J Physiol Endocrinol Metab 296:E139-E146. doi:10.1152/ajpendo. 90677.2008

Kanno S, Hirano S, Kayama F (2004a) Effects of phytoestrogens and environmental estrogens on osteoblastic differentiation in MC3T3-E1 cells. Toxicology 196:137-145. doi:10. 1016/j.tox.2003.12.002

Kanno S, Hirano S, Kayama F (2004b) Effects of the phytoestrogen coumestrol on RANK-ligand-induced differentiation of osteoclasts. Toxicology 203:211-220. doi:10.1016/ j.tox.2004.06.015

Kanno SI, Shouji A, Tomizawa A et al (2006) Inhibitory effect of naringin on lipopolysaccharide (LPS)-induced endotoxin shock in mice and nitric oxide production in RAW 264.7 macrophages. Life Sci 78:673-681. doi:10.1016/j. lfs.2005.04.051

Karieb S, Fox SW (2011) Phytoestrogens directly inhibit TNF$\alpha$-induced bone resorption in RAW264.7 cells by suppressing c-fos-induced NFATc1 expression. J Cell Biochem 112:476-487. doi:10.1002/jcb.22935

Kavitha CV, Deep G, Gangar SC et al (2014) Silibinin inhibits prostate cancer cells- and RANKL-induced osteoclastogenesis by targeting NFATc1, NF- $\mathrm{KB}$, and AP-1 activation in RAW264.7 cells. Mol Carcinog 53:169-180. doi:10. 1002/mc. 21959

Kern M, Pahlke G, Balavenkatraman KK et al (2007) Apple polyphenols affect protein kinase $\mathrm{C}$ activity and the onset of apoptosis in human colon carcinoma cells. J Agric Food Chem 55:4999-5006. doi:10.1021/jf063158x

Khan MP, Mishra JS, Sharan K et al (2013) A novel flavonoid C-glucoside from Ulmus wallichiana preserves bone mineral density, microarchitecture and biomechanical properties in the presence of glucocorticoid by promoting osteoblast survival: a comparative study with human parathyroid hormone. Phytomedicine 20:1256-1266. doi:10.1016/j.phymed.2013.07.007

Khan K, Pal S, Yadav M et al (2015) Prunetin signals via G-protein-coupled receptor, GPR30 (GPER1): stimulation of adenylyl cyclase and cAMP-mediated activation of MAPK signaling induces Runx 2 expression in osteoblasts to promote bone regeneration. J Nutr Biochem 30:1-11. doi:10.1016/j.jnutbio.2015.07.021

Khlebnikov AI, Schepetkin IA, Domina NG et al (2007) Improved quantitative structure-activity relationship models to predict antioxidant activity of flavonoids in chemical, enzymatic, and cellular systems. Bioorganic Med Chem 15:1749-1770. doi:10.1016/j.bmc.2006.11.037

Khosla S, Oursler MJ, Monroe DG (2012) Estrogen and the skeleton. Trends Endocrinol Metab 23:576-581. doi:10. 1016/j.tem.2012.03.008

Khushnud T, Mousa SA (2013) Potential role of naturally derived polyphenols and their nanotechnology delivery in cancer. Mol Biotechnol 55:78-86. doi:10.1007/s12033012-9623-7

Kim AR, Cho JY, Zou Y et al (2005) Flavonoids differentially modulate nitric oxide production pathways in 
lipopolysaccharide-activated RAW264.7 cells. Arch Pharm Res 28:297-304. doi:10.1007/BF02977796

Kim JY, Jung KJ, Choi JS, Chung HY (2006a) Modulation of the age-related nuclear factor- $\kappa \mathrm{B}(\mathrm{NF}-\kappa \mathrm{B})$ pathway by hesperetin. Aging Cell 5:401-411. doi:10.1111/j.14749726.2006.00233.x

Kim YJ, Bae YC, Suh KT, Jung JS (2006b) Quercetin, a flavonoid, inhibits proliferation and increases osteogenic differentiation in human adipose stromal cells. Biochem Pharmacol 72:1268-1278. doi:10.1016/j.bcp.2006.08.021

Kim JM, Lee SU, Kim YS et al (2008a) Baicalein stimulates osteoblast differentiation via coordinating activation of MAP kinases and transcription factors. J Cell Biochem 104:1906-1917. doi:10.1002/jcb.21760

Kim MH, Ryu SY, Bae MA et al (2008b) Baicalein inhibits osteoclast differentiation and induces mature osteoclast apoptosis. Food Chem Toxicol 46:3375-3382. doi:10. 1016/j.fct.2008.08.016

Kim JH, Kim K, Jin HM et al (2009) Silibinin inhibits osteoclast differentiation mediated by TNF family members. Mol Cells 28:201-207. doi:10.1007/s10059-009-0123-y

Kim M-H, Park J-S, Seo M-S et al (2010) Genistein and daidzein repress adipogenic differentiation of human adipose tissuederived mesenchymal stem cells via Wnt/ $\beta$-catenin signalling or lipolysis. Cell Prolif 43:594-605. doi:10.1111/j. 1365-2184.2010.00709.x

Kim T-H, Jung JW, Ha BG et al (2011a) The effects of luteolin on osteoclast differentiation, function in vitro and ovariectomy-induced bone loss. J Nutr Biochem 22:8-15. doi:10.1016/j.jnutbio.2009.11.002

Kim WK, Ke K, Sul OJ et al (2011b) Curcumin protects against ovariectomy-induced bone loss and decreases osteoclastogenesis. J Cell Biochem 112:3159-3166. doi:10.1002/ jcb. 23242

Kim J-L, Park S-H, Jeong D et al (2012a) Osteogenic activity of silymarin through enhancement of alkaline phosphatase and osteocalcin in osteoblasts and tibia-fractured mice. Exp Biol Med (Maywood) 237:417-428. doi:10.1258/ebm. 2011.011376

Kim JL, Kang SW, Kang MK et al (2012b) Osteoblastogenesis and osteoprotection enhanced by flavonolignan silibinin in osteoblasts and osteoclasts. J Cell Biochem 113:247-259. doi: $10.1002 /$ jcb. 23351

Kim J-Y, Kim JY, Kim JJ et al (2014) (2S)-2'-Methoxykurarinone inhibits osteoclastogenesis and bone resorption through down-regulation of RANKL signaling. Biol Pharm Bull 37:255-261

Ko SY (2012) Myricetin suppresses LPS-induced MMP expression in human gingival fibroblasts and inhibits osteoclastogenesis by downregulating NFATc1 in RANKL-induced RAW 264.7 cells. Arch Oral Biol 57:1623-1632. doi:10.1016/j.archoralbio.2012.06.012

Kohyama N, Nagata T, Fujimoto S, Sekiya K (1997) Inhibition of arachidonate lipoxygenase activities by 2-(3,4-dihydroxyphenyl)ethanol, a phenolic compound from olives. Yakugaku Zasshi 117:415-434. doi:10.1248/cpb.37.3229

Kondo A, Otsuka T, Kuroyanagi G et al (2014) Resveratrol inhibits BMP-4-stimulated VEGF synthesis in osteoblasts: suppression of S6 kinase. Int J Mol Med 33:1013-1018. doi:10.3892/ijmm.2014.1626
Kousteni S, Han L, Chen J-R et al (2003) Kinase-mediated regulation of common transcription factors accounts for the bone-protective effects of sex steroids. J Clin Invest 111:1651-1664. doi:10.1172/JCI17261

Kuiper GG, Lemmen JG, Carlsson B et al (1998) Interaction of estrogenic chemicals and pytoestrogens with estrogen receptor beta. Endocrinology 139:4252-4263. doi:10. 1210/endo.139.10.6216

Kumar D, Kumar M, Saravanan C, Singh SK (2012) Curcumin: a potential candidate for matrix metalloproteinase inhibitors. Expert Opin Ther Targets 16:959-972. doi:10.1517/ 14728222.2012.710603

Kuo P-L (2005) Myricetin inhibits the induction of anti-Fas IgM-, tumor necrosis factor-alpha- and interleukin-1betamediated apoptosis by Fas pathway inhibition in human osteoblastic cell line MG-63. Life Sci 77:2964-2976. doi:10.1016/j.lfs.2005.05.026

Kuroyanagi G, Otsuka T, Kondo A et al (2013) (-)-Epigallocatechin gallate amplifies interleukin-1-stimulated interleukin-6 synthesis in osteoblast-like MC3T3-E1 cells. Biochimie 95:1933-1938. doi:10.1016/j.biochi.2013.07. 001

Kuroyanagi G, Mizutani J, Kondo A et al (2014a) Suppression by resveratrol of prostaglandin D2-stimulated osteoprotegerin synthesis in osteoblasts. Prostaglandins Leukot Essent Fatty Acids 91:73-80. doi:10.1016/j.plefa.2014.04. 003

Kuroyanagi G, Otsuka T, Yamamoto N et al (2014b) Downregulation by resveratrol of basic fibroblast growth factorstimulated osteoprotegerin synthesis through suppression of Akt in osteoblasts. Int J Mol Sci 15:17886-17900. doi:10.3390/ijms151017886

Kuroyanagi G, Tokuda H, Matsushima-Nishiwaki R et al (2014c) Resveratrol suppresses prostaglandin F2 $\alpha$-induced osteoprotegerin synthesis in osteoblasts: inhibition of the MAP kinase signaling. Arch Biochem Biophys 542:39-45. doi:10.1016/j.abb.2013.12.002

Kuroyanagi G, Otsuka T, Yamamoto N, Nishiwaki RIEM (2015) Resveratrol suppresses TGF- $\beta$-induced VEGF synthesis in osteoblasts: inhibition of the p44/p42 MAPK and SAPK/JNK pathways. Exp Ther Med. doi:10.3892/ etm.2015.2389

Kushwaha P, Khedgikar V, Gautam J et al (2014) A novel therapeutic approach with Caviunin-based isoflavonoid that en routes bone marrow cells to bone formation via BMP2/Wnt- $\beta$-catenin signaling. Cell Death Dis 5:e142216. doi:10.1038/cddis.2014.350

Kyung TW, Lee JE, Shin HH, Choi HS (2008) Rutin inhibits osteoclast formation by decreasing reactive oxygen species and TNF-alpha by inhibiting activation of NF-kappaB. Exp Mol Med 40:52-58. doi:10.3858/emm.2008.40.1.52

La VD, Howell AB, Grenier D (2009a) Cranberry proanthocyanidins inhibit MMP production and activity. J Dent Res 88:627-632. doi:10.1177/0022034509339487

La VD, Tanabe S, Grenier D (2009b) Naringenin inhibits human osteoclastogenesis and osteoclastic bone resorption. J Periodontal Res 44:193-198. doi:10.1111/j.1600-0765.2008. 01107.x

Lai YL, Yamaguchi M (2006a) Oral administration of phytocomponent p-hydroxycinnamic acid has anabolic effects 
on bone calcification in femoral tissues of rats in vivo. J Heal Sci 52:308-312. doi:10.1248/jhs.52.308

Lai YL, Yamaguchi M (2006b) Phytocomponent p-hydroxycinnamic acid stimulates bone formation and inhibits bone resorption in rat femoral tissues in vitro. Mol Cell Biochem 292:45-52. doi:10.1007/s11010-006-9175-x

Lai YL, Yamaguchi M (2007) Phytocomponent p-hydroxycinnamic acid inhibits osteoclast-like cell formation in mouse bone marrow cultures. Int J Mol Med 19:123-128

Lai C-H, Wu Y-W, Yeh S-D et al (2014) Effects of 6-hydroxyflavone on osteoblast differentiation in MC3T3-E1 cells. Evid Based Complement Altern Med 2014:924560. doi:10. 1155/2014/924560

Larsen C, Dashwood RH, Bisson WH (2010) Tea catechins as inhibitors of receptor tyrosine kinases: mechanistic insights and human relevance. Pharmacol Res 62:457-464. doi:10. 1016/j.phrs.2010.07.010

Lee YS, Kim WS, Kim KH et al (2006) Berberine, a natural plant product, activates AMP-activated protein kinase with beneficial metabolic effects in diabetic and insulin-resistant states. Diabetes 55:2256-2264. doi:10.2337/db060006

Lee J-W, Ahn J-Y, Hasegawa S-I et al (2009) Inhibitory effect of luteolin on osteoclast differentiation and function. Cytotechnology 61:125-134. doi:10.1007/s10616-0109253-5

Lee JH, Jin H, Shim HE et al (2010a) Epigallocatechin-3-gallate inhibits osteoclastogenesis by down-regulating c-Fos expression and suppressing the nuclear factor-kappaB signal. Mol Pharmacol 77:17-25. doi:10.1124/mol.109. 057877

Lee YS, Kim YS, Lee SY et al (2010b) AMP kinase acts as a negative regulator of RANKL in the differentiation of osteoclasts. Bone 47:926-937. doi:10.1016/j.bone.2010. 08.001

Lee CH, Huang YL, Liao JF, Chiou WF (2011a) Ugonin K promotes osteoblastic differentiation and mineralization by activation of p38 MAPK- and ERK-mediated expression of Runx2 and osterix. Eur J Pharmacol 668:383-389. doi:10. 1016/j.ejphar.2011.06.059

Lee Y-M, Shin S-I, Shin K-S et al (2011b) The role of sirtuin 1 in osteoblastic differentiation in human periodontal ligament cells. J Periodontal Res 46:712-721. doi:10.1111/j.16000765.2011.01394.x

Lee SH, Kim JK, Jang HD (2014a) Genistein inhibits osteoclastic differentiation of RAW 264.7 cells via regulation of ROS production and scavenging. Int $\mathrm{J}$ Mol Sci 15:10605-10621. doi:10.3390/ijms150610605

Lee WS, Lee EG, Sung MS, Yoo WH (2014b) Kaempferol inhibits IL-1 $\beta$-stimulated, RANKL-mediated osteoclastogenesis via downregulation of MAPKs, c-Fos, and NFATc1. Inflammation 37:1221-1230. doi:10.1007/ s10753-014-9849-6

Lee J, Noh ALSM, Zheng T et al (2015) Eriodicyol inhibits osteoclast differentiation and ovariectomy-induced bone loss in vivo. Exp Cell Res. doi:10.1016/j.yexcr.2015.10. 001

Lee K, Chung YH, Ahn H et al (2016) Selective regulation of MAPK signaling mediates RANKL-dependent osteoclast differentiation. Int J Biol Sci 12:235-245. doi:10.7150/ijbs. 13814
Leonardi R, Barbato E, Paganelli C, Lo Muzio L (2004) Immunolocalization of heat shock protein 27 in developing jaw bones and tooth germs of human fetuses. Calcif Tissue Int 75:509-516. doi:10.1007/s00223-004-0077-1

Léotoing L, Wauquier F, Guicheux J et al (2013) The polyphenol Fisetin protects bone by repressing NF- $\kappa \mathrm{B}$ and MKP-1-dependent signaling pathways in osteoclasts. PLoS ONE 8:1-14. doi:10.1371/journal.pone.0068388

Li X, Zhang J, Sui S, Yang M (2005) Effect of daidzin, genistin, and glycitin on osteogenic and adipogenic differentiation of bone marrow stromal cells and adipocytic transdifferentiation of osteoblasts. Acta Pharmacol Sin 26:1081-1086. doi:10.1111/j.1745-7254.2005.00161.x

Li Y, Xing X, Wang H et al (2012) Dose-dependent effects of genistein on bone homeostasis in rats' mandibular subchondral bone. Acta Pharmacol Sin 33:66-74. doi:10. 1038/aps.2011.136

Li Y, Wang J, Chen G et al (2015a) Quercetin promotes the osteogenic differentiation of rat mesenchymal stem cells via mitogen-activated protein kinase signaling. Exp Ther Med. doi:10.3892/etm.2015.2388

Li Z, Summanen PH, Komoriya T et al (2015b) Pomegranate ellagitannins stimulate growth of gut bacteria in vitro: implications for prebiotic and metabolic effects. Anaerobe 34:164-168. doi:10.1016/j.anaerobe.2015.05.012

Liao Q-C, Xiao Z-S, Qin Y-F, Zhou H-H (2007) Genistein stimulates osteoblastic differentiation via p38 MAPK-Cbfa1 pathway in bone marrow culture. Acta Pharmacol Sin 28:1597-1602. doi:10.1111/j.1745-7254.2007.00632.x

Liao M-H, Tai Y-T, Cherng Y-G et al (2014) Genistein induces oestrogen receptor- $\alpha$ gene expression in osteoblasts through the activation of mitogen-activated protein kina$\mathrm{ses} / \mathrm{NF}-\kappa \mathrm{B} /$ activator protein-1 and promotes cell mineralisation. $\mathrm{Br} \mathrm{J}$ Nutr 111:55-63. doi:10.1017/ S0007114513002043

Lin J-K (2002) Cancer chemoprevention by tea polyphenols through modulating signal transduction pathways. Arch Pharm Res 25:561-571

Lin RW, Chen CH, Wang YH et al (2009) (-)-Epigallocatechin gallate inhibition of osteoclastic differentiation via NFkappaB. Biochem Biophys Res Commun 379:1033-1037. doi:10.1016/j.bbrc.2009.01.007

Lin Y, Murray MA, Garrett IR et al (2014) A targeted approach for evaluating preclinical activity of botanical extracts for support of bone health. J Nutr Sci 3:e13. doi:10.1017/jns. 2014.5

Linard C, Marquette C, Mathieu J et al (2004) Acute induction of inflammatory cytokine expression after $\gamma$-irradiation in the rat: effect of an NF- $\mathrm{NB}$ inhibitor. Int J Radiat Oncol Biol Phys 58:427-434. doi:10.1016/j.ijrobp.2003.09.039

Loke WM, Proudfoot JM, Hodgson JM et al (2010) Specific dietary polyphenols attenuate atherosclerosis in apolipoprotein e-knockout mice by alleviating inflammation and endothelial dysfunction. Arterioscler Thromb Vasc Biol 30:749-757. doi:10.1161/ATVBAHA.109. 199687

Lorenzo JA, Sousa SL, Alander C et al (1987) Comparison of the bone-resorbing activity in the supernatants from phytohemagglutinin-stimulated human peripheral blood mononuclear cells with that of cytokines through the use of 
an antiserum to interleukin 1. Endocrinology 121:1164-1170

Lu Y, He B, Zhang X et al (2015) Osteoprotective effect of geraniin against ovariectomy-induced bone loss in rats. Bioorg Med Chem Lett 25:673-679. doi:10.1016/j.bmcl. 2014.11.081

Luo LJ, Liu F, Lin ZK et al (2012) Genistein regulates the IL-1 beta induced activation of MAPKs in human periodontal ligament cells through $\mathrm{G}$ protein-coupled receptor 30 . Arch Biochem Biophys 522:9-16. doi:10.1016/j.abb.2012.04. 007

Luo D, Kang L, Ma Y et al (2014) Effects and mechanisms of 8-prenylnaringenin on osteoblast MC3T3-E1 and osteoclast-like cells RAW264.7. Food Sci Nutr 2:341-350. doi:10.1002/fsn3.109

Ma B, Hottiger MO (2016) Crosstalk between wnt/ $\beta$-catenin and NF- $\kappa \mathrm{B}$ signaling pathway during inflammation. Front Immunol. doi:10.3389/fimmu.2016.00378

Maiuri MC, De Stefano D, Di Meglio P et al (2005) Hydroxytyrosol, a phenolic compound from virgin olive oil, prevents macrophage activation. Naunyn Schmiedebergs Arch Pharmacol 371:457-465. doi:10.1007/s00210-0051078-y

Mancini L, Moradi-Bidhendi N, Becherini L et al (2000) The biphasic effects of nitric oxide in primary rat osteoblasts are cGMP dependent. Biochem Biophys Res Commun 274:477-481. doi:10.1006/bbrc.2000.3164

Manolagas SC (2000) Birth and death of bone cells: basic regulatory mechanisms and implications for the pathogenesis and treatment of osteoporosis. Endocr Rev 21:115-137

Marín L, Miguélez EM, Villar CJ, Lombó F (2015) Bioavailability of dietary polyphenols and gut microbiota metabolism: antimicrobial properties. Biomed Res Int. doi:10. 1155/2015/905215

Marini H, Minutoli L, Polito F et al (2008) OPG and sRANKL serum concentrations in osteopenic, postmenopausal women after 2-year genistein administration. J Bone Miner Res 23:715-720. doi:10.1359/jbmr.080201

Marquez N (2003) Caffeic acid phenethyl ester inhibits T-cell activation by targeting both nuclear factor of activated T-cells and NF-kB transcription factors. J Pharmacol Exp Ther 308:993-1001. doi:10.1124/jpet.103.060673. expression

Martin KR (2009) Polyphenols as dietary supplements: a double-edged sword. Nutr Diet Suppl. doi:10.2147/NDS. S6422

Matsuguchi T, Chiba N, Bandow K et al (2009) JNK activity is essential for Atf4 expression and late-stage osteoblast differentiation. J Bone Miner Res 24:398-410. doi:10. 1359/jbmr.081107

McCalley AE, Kaja S, Payne AJ, Koulen P (2014) Resveratrol and calcium signaling: molecular mechanisms and clinical relevance. Molecules 19:7327-7340

McKinney JD, Richard A, Waller C et al (2000) The practice of structure activity relationships (SAR) in toxicology. Toxicol Sci 56:8-17. doi:10.1093/toxsci/56.1.8

Mihaylova MM, Shaw RJ (2012) The AMP-activated protein kinase (AMPK) signaling pathway coordinates cell growth, autophagy, \& metabolism. Nat Cell Biol 13:1016-1023. doi: $10.1038 /$ ncb2329
Miodini P, Fioravanti L, Di Fronzo G, Cappelletti V (1999) The two phyto-oestrogens genistein and quercetin exert different effects on oestrogen receptor function. Br J Cancer 80:1150-1155. doi:10.1038/sj.bjc.6690479

Mizutani K, Ikeda K, Kawai Y, Yamori Y (1998) Resveratrol stimulates the proliferation and differentiation of osteoblastic MC3T3-E1 cells. Biochem Biophys Res Commun 253:859-863. doi:10.1006/bbrc.1998.9870

Monroe DG, McGee-Lawrence ME, Oursler MJ, Westendorf JJ (2012) Update on Wnt signaling in bone cell biology and bone disease. Gene 492:1-18. doi:10.1016/j.gene.2011.10. 044

Moon HJ, Ko WK, Han SW et al (2012) Antioxidants, like coenzyme Q10, selenite, and curcumin, inhibited osteoclast differentiation by suppressing reactive oxygen species generation. Biochem Biophys Res Commun 418:247-253. doi:10.1016/j.bbrc.2012.01.005

Moran JM, Roncero-Martin R, Rodriguez-Velasco FJ et al (2012) Effects of curcumin on the proliferation and mineralization of human osteoblast-like cells: implications of nitric oxide. Int J Mol Sci 13:16104-16118. doi:10.3390/ ijms131216104

Morita I, Sakaguchi K, Kurachi T, Murota S (1992) Ipriflavone inhibits murine osteoclast formation in vitro. Calcif Tissue Int 51:87-90

Morito K, Hirose T, Kinjo J et al (2001) Interaction of phytoestrogens with estrogen receptors alpha and beta. Biol Pharm Bull 24:351-356. doi:10.1248/bpb.24.351

Moriwaki S, Suzuki K, Muramatsu M et al (2014) Delphinidin, one of the major anthocyanidins, prevents bone loss through the inhibition of excessive osteoclastogenesis in osteoporosis model mice. PLoS ONE 9:e97177. doi:10. 1371/journal.pone.0097177

Mount JG, Muzylak M, Allen S et al (2006) Evidence that the canonical Wnt signalling pathway regulates deer antler regeneration. Dev Dyn 235:1390-1399. doi:10.1002/dvdy. 20742

Moutsatsou P (2007) The spectrum of phytoestrogens in nature: our knowledge is expanding. Hormones (Athens) 6:173-193

Murakami A, Song M, Katsumata S-I et al (2007) Citrus nobiletin suppresses bone loss in ovariectomized ddY mice and collagen-induced arthritis in DBA/1 $\mathrm{J}$ mice: possible involvement of receptor activator of NF-kappaB ligand (RANKL)-induced osteoclastogenesis regulation. BioFactors 30:179-192. doi:10.1002/biof.5520300305

Nakagawa H, Wachi M, Woo J-T et al (2002) Fenton reaction is primarily involved in a mechanism of (-)-epigallocatechin-3-gallate to induce osteoclastic cell death. Biochem Biophys Res Commun 292:94-101. doi:10.1006/bbrc. 2002.6622

Nakamura H, Ukai T, Yoshimura A et al (2010) Green tea catechin inhibits lipopolysaccharide-induced bone resorption in vivo. J Periodontal Res 45:23-30. doi:10.1111/j. 1600-0765.2008.01198.x

Nam TW, Il YC, Kim HT et al (2008) The flavonoid quercetin induces apoptosis and inhibits migration through a MAPKdependent mechanism in osteoblasts. J Bone Miner Metab 26:551-560. doi:10.1007/s00774-008-0864-2

Napimoga MH, Clemente-Napimoga JT, Macedo CG et al (2013) Quercetin inhibits inflammatory bone resorption in 
a mouse periodontitis model. J Nat Prod 76:2316-2321. doi:10.1021/np400691n

Nash LA, Sullivan PJ, Peters SJ, Ward WE (2014) Rooibos flavonoids, orientin and luteolin, stimulate mineralization in human osteoblasts through the Wnt pathway. Mol Nutr Food Res. doi:10.1002/mnfr.201400592

Natarajan K, Singh S, Burke TR et al (1996) Caffeic acid phenethyl ester is a potent and specific inhibitor of activation of nuclear transcription factor NF-kappa B. Proc Natl Acad Sci 93:9090-9095. doi:10.1073/pnas.93.17.9090

Natsume H, Adachi S, Takai S et al (2009) (-)-Epigallocatechin gallate attenuates the induction of HSP27 stimulated by sphingosine 1-phosphate via suppression of phosphatidylinositol 3-kinase/Akt pathway in osteoblasts. Int J Mol Med 24:197-203. doi:10.3892/ijmm

Nepal M, Choi HJ, Choi BY et al (2013) Hispidulin attenuates bone resorption and osteoclastogenesis via the RANKLinduced NF- $\kappa$ B and NFATc1 pathways. Eur J Pharmacol 715:96-104. doi:10.1016/j.ejphar.2013.06.002

Nomura M, Kaji A, He Z et al (2001) Inhibitory mechanisms of tea polyphenols on the ultraviolet B-activated phosphatidylinositol 3-kinase-dependent pathway. J Biol Chem 276:46624-46631. doi:10.1074/jbc.M107897200

Notoya M, Tsukamoto Y, Nishimura H et al (2004) Quercetin, a flavonoid, inhibits the proliferation, differentiation, and mineralization of osteoblasts in vitro. Eur $\mathrm{J}$ Pharmacol 485:89-96. doi:10.1016/j.ejphar.2003.11.058

Notoya M, Nishimura H, Woo JT et al (2006) Curcumin inhibits the proliferation and mineralization of cultured osteoblasts. Eur J Pharmacol 534:55-62. doi:10.1016/j.ejphar.2006.01. 028

O'Lone R, Frith MC, Karlsson EK, Hansen U (2004) Genomic targets of nuclear estrogen receptors. Mol Endocrinol 18:1859-1875. doi:10.1210/me.2003-0044

O'Shaughnessy MC, Polak JM, Afzal F et al (2000) Nitric oxide mediates 17 beta-estradiol-stimulated human and rodent osteoblast proliferation and differentiation. Biochem Biophys Res Commun 277:604-610. doi:10.1006/bbrc.2000. 3714

Oeckinghaus A, Ghosh S (2009) The NF-kappaB family of transcription factors and its regulation. Cold Spring Harb Perspect Biol 1:1-14. doi:10.1101/cshperspect.a000034

Oh S, Kyung T-W, Choi H-S (2008) Curcumin inhibits osteoclastogenesis by decreasing receptor activator of nuclear factor-kappaB ligand (RANKL) in bone marrow stromal cells. Mol Cells 26:486-489

Okamoto F, Okabe K, Kajiya H (2001) Genistein, a soybean isoflavone, inhibits inward rectifier $\mathrm{K}(+)$ channels in rat osteoclasts. Jpn J Physiol 51:501-509

Omori A, Yoshimura Y, Deyama Y, Suzuki K (2015) Rosmarinic acid and arbutin suppress osteoclast differentiation by inhibiting superoxide and NFATc1 downregulation in RAW 264.7 cells. Biomed Rep. doi:10.3892/br.2015.452

Ozaki K, Takeda H, Iwahashi H et al (1997) NF-kappaB inhibitors stimulate apoptosis of rabbit mature osteoclasts and inhibit bone resorption by these cells. FEBS Lett 410:297-300. doi:10.1016/S0014-5793(97)00653-4

Ozaki K, Kawata Y, Amano S, Hanazawa S (2000) Stimulatory effect of curcumin on osteoclast apoptosis. Biochem Pharmacol 59:1577-1581. doi:10.1016/S00062952(00)00277-X
Palacios VG, Robinson LJ, Borysenko CW et al (2005) Negative regulation of RANKL-induced osteoclastic differentiation in RAW264.7 cells by estrogen and phytoestrogens. J Biol Chem 280:13720-13727. doi:10.1074/jbc.M410995200

Palmqvist P, Persson E, Conaway HH, Lerner UH (2002) IL-6, leukemia inhibitory factor, and oncostatin $\mathrm{M}$ stimulate bone resorption and regulate the expression of receptor activator of $\mathrm{NF}-\kappa \mathrm{B}$ ligand, osteoprotegerin, and receptor activator of $\mathrm{NF}-\kappa \mathrm{B}$ in mouse calvariae. J Immunol 169:3353-3362. doi:10.4049/jimmunol.169.6.3353

Pan MH, Lin-Shiau SY, Ho CT et al (2000) Suppression of lipopolysaccharide-induced nuclear factor-kappaB activity by theaflavin-3,3'-digallate from black tea and other polyphenols through down-regulation of IkappaB kinase activity in macrophages. Biochem Pharmacol 59:357-367. doi:10.1016/S0006-2952(99)00335-4

Pan W, Quarles LD, Song L-H et al (2005) Genistein stimulates the osteoblastic differentiation via NO/cGMP in bone marrow culture. J Cell Biochem 94:307-316. doi:10.1002/ jcb. 20308

Pang JL, Ricupero DA, Huang S et al (2006) Differential activity of kaempferol and quercetin in attenuating tumor necrosis factor receptor family signaling in bone cells. Biochem Pharmacol 71:818-826. doi:10.1016/j.bcp.2005. 12.023

Papoutsi Z, Kassi E, Tsiapara A et al (2005) Evaluation of estrogenic/antiestrogenic activity of ellagic acid via the estrogen receptor subtypes ERalpha and ERbeta. J Agric Food Chem 53:7715-7720. doi:10.1021/jf0510539

Papoutsi Z, Kassi E, Chinou I et al (2008) Walnut extract (Juglans regia L.) and its component ellagic acid exhibit anti-inflammatory activity in human aorta endothelial cells and osteoblastic activity in the cell line KS483. Br J Nutr 99:715-722. doi:10.1017/S0007114507837421

Park JY, Pillinger MH (2007) Interleukin-6 in the pathogenesis of rheumatoid arthritis. Bull NYU Hosp Jt Dis 65:4-10. doi: $10.1155 / 2011 / 765624$

Park EK, Kim MS, Lee SH et al (2004) Furosin, an ellagitannin, suppresses RANKL-induced osteoclast differentiation and function through inhibition of MAP kinase activation and actin ring formation. Biochem Biophys Res Commun 325:1472-1480. doi:10.1016/j.bbrc.2004.10.197

Patisaul HB, Jefferson W (2011) The pros and cons of phytoestrogens. Front Neuroendocrinol. doi:10.1016/j.yfrne. 2010.03.003

Perkins ND (2007) Integrating cell-signalling pathways with NF-kappaB and IKK function. Nat Rev Mol Cell Biol 8:49-62. doi:10.1038/nrm2083

Petilli M, Fiorelli G, Benvenuti S et al (1995) Interactions between ipriflavone and the estrogen receptor. Calcif Tissue Int 56:160-165. doi:10.1007/BF00296349

Phan T-T, Lim IJ, Chan S-Y et al (2004) Suppression of transforming growth factor beta/smad signaling in keloidderived fibroblasts by quercetin: implications for the treatment of excessive scars. J Trauma 57:1032-1037. doi:10.1097/01.TA.0000114087.46566.EB

Pino AM, Rosen CJ, Pablo Rodríguez J (2012) In osteoporosis, differentiation of mesenchymal stem cells (MSCs) improves bone marrow adipogenesis. Biol Res 45:279-287. doi:10.4067/S0716-97602012000300009 
Pratt MAC, Bishop TE, White D et al (2003) Estrogen withdrawal-induced NF-kappaB activity and bcl-3 expression in breast cancer cells: roles in growth and hormone independence. Mol Cell Biol 23:6887-6900. doi:10.1128/ MCB.23.19.6887

Procházková D, Boušová I, Wilhelmová N (2011) Antioxidant and prooxidant properties of flavonoids. Fitoterapia 82:513-523. doi:10.1016/j.fitote.2011.01.018

Prossnitz ER, Arterburn JB, Smith HO et al (2008) Estrogen signaling through the transmembrane $\mathrm{G}$ protein-coupled receptor GPR30. Annu Rev Physiol 70:165-190. doi:10. 1146/annurev.physiol.70.113006.100518

Prouillet C, Mazière J-C, Mazière C et al (2004) Stimulatory effect of naturally occurring flavonols quercetin and kaempferol on alkaline phosphatase activity in MG-63 human osteoblasts through ERK and estrogen receptor pathway. Biochem Pharmacol 67:1307-1313. doi:10.1016/ j.bcp.2003.11.009

Puel C, Quintin A, Mathey J et al (2005) Prevention of bone loss by phloridzin, an apple polyphenol, in ovariectomized rats under inflammation conditions. Calcif Tissue Int 77:311-318. doi:10.1007/s00223-005-0060-5

Puel C, Mathey J, Agalias A et al (2006) Dose-response study of effect of oleuropein, an olive oil polyphenol, in an ovariectomy/inflammation experimental model of bone loss in the rat. Clin Nutr 25:859-868. doi:10.1016/j.clnu. 2006.03.009

Puel C, Mardon J, Agalias A et al (2008) Major phenolic compounds in olive oil modulate bone loss in an ovariectomy/inflammation experimental model. J Agric Food Chem 56:9417-9422

Qin S, Zhou W, Liu S et al (2015) Icariin stimulates the proliferation of rat bone mesenchymal stem cells via ERK and p38 MAPK signaling. Int J Clin Exp Med 8:7125-7133

Quinn JMW, Tam S, Sims NA et al (2010) Germline deletion of AMP-activated protein kinase $\beta$ subunits reduces bone mass without altering osteoclast differentiation or function. FASEB J 24:275-285. doi:10.1096/fj.09-137158

Rajesh E, Sankari LS, Malathi L, Krupaa JR (2015) Naturally occurring products in cancer therapy. J Pharm Bioallied Sci 7:S181-S183. doi:10.4103/0975-7406.155895

Rao LG, Kang N, Rao AV (2012) Polyphenol antioxidants and bone health: a review. In: Rao V (ed) Phytochemicals-a global perspective of their role in nutrition and health

Rassi CM, Lieberherr M, Chaumaz G et al (2002) Down-regulation of osteoclast differentiation by daidzein via caspase 3. J Bone Miner Res 17:630-638. doi:10.1359/jbmr.2002. 17.4 .630

Rassi CM, Lieberherr M, Chaumaz G et al (2005) Modulation of osteoclastogenesis in porcine bone marrow cultures by quercetin and rutin. Cell Tissue Res 319:383-393. doi:10. 1007/s00441-004-1053-9

Reuther JY, Reuther GW, Cortez D et al (1998) A requirement for NF-kB activation in Bcr-Abl-mediated transformation. Genes Dev 12:968-981

Roberfroid M, Gibson GR, Hoyles L et al (2010) Prebiotic effects: metabolic and health benefits. $\mathrm{Br} \mathrm{J}$ Nutr 104(Suppl):S1-S63. doi:10.1017/S0007114510003363

Roforth MM, Atkinson EJ, Levin ER et al (2014) Dissection of estrogen receptor alpha signaling pathways in osteoblasts using RNA-sequencing. PLoS ONE 9:e95987. doi:10. 1371/journal.pone.0095987

Rogerio P, Favarin DTM (2013) Anti-inflammatory effects of ellagic acid on acute lung injury induced by acid in mice. Mediators Inflamm 2013:13

Rothwell J, Pérez-Jiménez J, Neveu V et al (2013) Phenol-Explorer 3.0: a major update of the Phenol-Explorer database to incorporate data on the effects of food processing on polyphenol content. Database. doi:10.1093/database/ bat070

Routledge EJ, White R, Parker MG, Sumpter JP (2000) Differential effects of xenoestrogens on coactivator recruitment by estrogen receptor (ER) $\alpha$ and ER $\beta$. J Biol Chem 275:35986-35993. doi:10.1074/jbc.M006777200

Sakai E, Shimada-Sugawara M, Yamaguchi Y et al (2013) Fisetin inhibits osteoclastogenesis through prevention of RANKL-induced ROS production by Nrf2-mediated upregulation of phase II antioxidant enzymes. J Pharmacol Sci 121:288-298. doi:10.1254/jphs.12243FP

Santiago-Mora R, Casado-Díaz A, De Castro MD, QuesadaGómez JM (2011) Oleuropein enhances osteoblastogenesis and inhibits adipogenesis: the effect on differentiation in stem cells derived from bone marrow. Osteoporos Int 22:675-684. doi:10.1007/s00198-010-1270-x

Sareen D, Darjatmoko SR, Albert DM, Polans AS (2007) Mitochondria, calcium, and calpain are key mediators of resveratrol-induced apoptosis in breast cancer. Mol Pharmacol 72:1466-1475. doi:10.1124/mol.107.039040. therapeutic

Saura M, Tarin C, Zaragoza C (2010) Recent insights into the implication of nitric oxide in osteoblast differentiation and proliferation during bone development. Sci World J 10:624-632. doi:10.1100/tsw.2010.58

Scalbert A, Manach C, Morand C et al (2005) Dietary polyphenols and the prevention of diseases. Crit Rev Food Sci Nutr 45:287-306. doi:10.1080/1040869059096

Schneider-Stock R, Ghantous A, Bajbouj K et al (2012) Epigenetic mechanisms of plant-derived anticancer drugs. Front Biosci 17:129-173. doi:10.2741/3919

Sellappan S, Akoh CKG (2002) Phenolic compounds and antioxidant capacity of Georgia-grown blueberries and blackberries. J Agric Food Chem 50:2432-2438

Shah M, Kola B, Bataveljic A et al (2010) AMP-activated protein kinase (AMPK) activation regulates in vitro bone formation and bone mass. Bone 47:309-319. doi:10.1016/ j.bone.2010.04.596

Shakibaei M, Buhrmann C, Mobasheri A (2011) Resveratrolmediated SIRT-1 interactions with p300 modulate receptor activator of NF-kappaB ligand (RANKL) activation of NFkappaB signaling and inhibit osteoclastogenesis in bonederived cells. J Biol Chem 286:11492-11505. doi:10.1074/ jbc.M110.198713

Shakibaei M, Shayan P, Busch F et al (2012) Resveratrol mediated modulation of Sirt-1/Runx2 promotes osteogenic differentiation of mesenchymal stem cells: potential role of Runx2 deacetylation. PLoS ONE 7:e35712. doi:10.1371/ journal.pone.0035712

Shen C-L, Yeh JK, Cao JJ et al (2010) Green tea polyphenols mitigate bone loss of female rats in a chronic inflammationinduced bone loss model. J Nutr Biochem 21:968-974. doi:10.1016/j.jnutbio.2009.08.002 
Shen C-L, Yeh JK, Cao JJ et al (2011) Green tea and bone health: evidence from laboratory studies. Pharmacol Res 64:155-161. doi:10.1016/j.phrs.2011.03.012

Shen C-L, Cao JJ, Dagda RY et al (2012) Green tea polyphenols benefits body composition and improves bone quality in long-term high-fat diet-induced obese rats. Nutr Res 32:448-457. doi:10.1016/j.nutres.2012.05.001

Sheu S, Tsai C, Sun J et al (2012) Stimulatory effect of puerarin on bone formation through co-activation of nitric oxide and bone morphogenetic protein-2/mitogen-activated protein kinases pathways in mice. Chin Med $\mathrm{J}$ (Engl) 125:3646-3653. doi:10.3760/cma.j.issn.0366-6999.2012. 20.009

Shevde NK, Bendixen AC, Dienger KM, Pike JW (2000) Estrogens suppress RANK ligand-induced osteoclast differentiation via a stromal cell independent mechanism involving c-Jun repression. Proc Natl Acad Sci USA 97:7829-7834. doi:10.1073/pnas.130200197

Shin DK, Kim MH, Lee SH et al (2012) Inhibitory effects of luteolin on titanium particle-induced osteolysis in a mouse model. Acta Biomater 8:3524-3531. doi:10.1016/j.actbio. 2012.05.002

Siddiqui JA, Sharan K, Swarnkar G et al (2011) Quercetin-6-C$\beta$-D-glucopyranoside isolated from Ulmus wallichiana planchon is more potent than quercetin in inhibiting osteoclastogenesis and mitigating ovariectomy-induced bone loss in rats. Menopause 18:198-207. doi:10.1097/ gme.0b013e3181e84e67

Sims SM, Dixon SJ (1989) Inwardly rectifying K + current in osteoclasts. Am J Physiol 256:C1277-C1282

Smith BJ, Graef JL, Wronski TJ et al (2014) Effects of dried plum supplementation on bone metabolism in adult C57BL/6 male mice. Calcif Tissue Int 94:442-453. doi:10. 1007/s00223-013-9819-2

Soltanoff CS, Yang S, Chen W, Li Y-P (2009) Signaling networks that control the lineage commitment and differentiation of bone cells. Crit Rev Eukaryot Gene Expr 19:1-46. doi:10.1615/CritRevEukarGeneExpr.v19.i1.10

Son Y-O, Kook S-H, Choi K-C et al (2006) Quercetin, a bioflavonoid, accelerates TNF-alpha-induced growth inhibition and apoptosis in MC3T3-E1 osteoblastic cells. Eur J Pharmacol 529:24-32. doi:10.1016/j.ejphar.2005.10.041

Son Y-O, Kook S-H, Choi K-C et al (2008) Quercetin accelerates TNF- $\alpha$-induced apoptosis of MC3T3-E1 osteoblastic cells through caspase-dependent and JNK-mediated pathways. Eur J Pharmacol 579:26-33. doi:10.1016/j.ejphar. 2007.10.003

Song LH, Pan W, Yu YH et al (2006) Resveratrol prevents CsA inhibition of proliferation and osteoblastic differentiation of mouse bone marrow-derived mesenchymal stem cells through an ER/NO/cGMP pathway. Toxicol In Vitro 20:915-922. doi:10.1016/j.tiv.2006.01.016

Song L, Zhao J, Zhang X et al (2013) Icariin induces osteoblast proliferation, differentiation and mineralization through estrogen receptor-mediated ERK and JNK signal activation. Eur J Pharmacol 714:15-22. doi:10.1016/j.ejphar. 2013.05.039

Sovak MA, Bellas RE, Kim DW et al (1997) Aberrant nuclear factor-kappab/Rel expression and the pathogenesis of breast cancer. J Clin Invest 100:2952-2960. doi:10.1172/ JCI1 19848
Spilmont M, Léotoing L, Davicco M-J et al (2013) Pomegranate seed oil prevents bone loss in a mice model of osteoporosis, through osteoblastic stimulation, osteoclastic inhibition and decreased inflammatory status. J Nutr Biochem 24:1840-1848. doi:10.1016/j.jnutbio.2013.04.005

Spilmont M, Léotoing L, Davicco M-J et al (2015) Pomegranate peel extract prevents bone loss in a preclinical model of osteoporosis and stimulates osteoblastic differentiation in vitro. Nutrients 7:9265-9284. doi:10.3390/nu7115465

Stein B, Yang MX (1995) Repression of the interleukin-6 promoter by estrogen receptor is mediated by NF-kappa B and C/EBP beta. Mol Cell Biol 15:4971-4979

Su J-L, Yang C-Y, Zhao M et al (2007) Forkhead proteins are critical for bone morphogenetic protein-2 regulation and anti-tumor activity of resveratrol. $\mathrm{J}$ Biol Chem 282:19385-19398. doi:10.1074/jbc.M702452200

Su Y, Lin Y-Y, Chen P, Shi C (2015) Evaluation of the protective effects of curcuminoid (curcumin and bisdemethoxycurcumin)-loaded liposomes against bone turnover in a cell-based model of osteoarthritis. Drug Des Devel Ther 9:2285-2300

Sugimoto E, Yamaguchi M (2000a) Anabolic effect of genistein in osteoblastic MC3T3-E1 cells. Int J Mol Med 5:515-520

Sugimoto E, Yamaguchi M (2000b) Stimulatory effect of daidzein in osteoblastic MC3T3-E1 cells. Biochem Pharmacol 59:471-475. doi:10.1016/S0006-2952(99)00351-2

Suh KS, Koh G, Park CY et al (2003) Soybean isoflavones inhibit tumor necrosis factor- $\alpha$-induced apoptosis and the production of interleukin- 6 and prostaglandin E2 in osteoblastic cells. Phytochemistry 63:209-215. doi:10. 1016/S0031-9422(03)00101-8

Sulaiman M, Matta MJ, Sunderesan NR et al (2010) Resveratrol, an activator of SIRT1, upregulates sarcoplasmic calcium ATPase and improves cardiac function in diabetic cardiomyopathy. Am J Physiol Heart Circ Physiol 298:H833H843. doi:10.1152/ajpheart.00418.2009

Tabrez S, Priyadarshini M (2013) Cancer chemoprevention by polyphenols and their potential application as nanomedicine. J Environ Sci Heal Part C 31:67-98. doi:10.1080/ 10590501.2013.763577

Takai S, Matsushima-Nishiwaki R, Adachi S et al (2008) (-)Epigallocatechin gallate reduces platelet-derived growth factor-BB-stimulated interleukin-6 synthesis in osteoblasts: suppression of SAPK/JNK. Mediat Inflamm 2008:291808. doi:10.1155/2008/291808

Tamaki N, Cristina Orihuela-Campos R, Inagaki Y et al (2014) Resveratrol improves oxidative stress and prevents the progression of periodontitis via the activation of the Sirt1/ AMPK and the Nrf2/antioxidant defense pathways in a rat periodontitis model. Free Radic Biol Med 75:222-229. doi:10.1016/j.freeradbiomed.2014.07.034

Tanabe S, Santos J, La VD et al (2011) A-type cranberry proanthocyanidins inhibit the RANKL-dependent differentiation and function of human osteoclasts. Molecules 16:2365-2374. doi:10.3390/molecules16032365

Tang CH, Sen YR, Chien MY et al (2008a) Enhancement of bone morphogenetic protein-2 expression and bone formation by coumarin derivatives via p38 and ERK-dependent pathway in osteoblasts. Eur J Pharmacol 579:40-49. doi:10.1016/j.ejphar.2007.10.013 
Tang X, Zhu X, Liu S et al (2008b) Phytoestrogens induce differential estrogen receptor beta-mediated responses in transfected MG-63 cells. Endocrine 34:29-35. doi:10. 1007/s12020-008-9099-1

Tang X, Zhu X, Liu S et al (2011) Isoflavones suppress cyclic adenosine $3^{\prime}, 5^{\prime}$-monophosphate regulatory element-mediated transcription in osteoblastic cell line. J Nutr Biochem 22:865-873. doi:10.1016/j.jnutbio.2010.07.011

Thouverey C, Caverzasio J (2012) The p38a MAPK positively regulates osteoblast function and postnatal bone acquisition. Cell Mol Life Sci 69:3115-3125. doi:10.1007/ s00018-012-0983-8

Tiwari SK, Agarwal S, Seth B et al (2014) Curcumin-loaded nanoparticles potently induce adult neurogenesis and reverse cognitive deficits in Alzheimer's disease model via canonical Wnt/ $\beta$-catenin pathway. ACS Nano 8:76-103. doi:10.1021/nn405077y

Tiwari SK, Agarwal S, Tripathi A, Chaturvedi RK (2015) Bisphenol-A mediated inhibition of hippocampal neurogenesis attenuated by curcumin via canonical Wnt pathway. Mol Neurobiol 53:3010-3029

Tiyasatkulkovit W, Malaivijitnond S, Charoenphandhu N et al (2014) Pueraria mirifica extract and puerarin enhance proliferation and expression of alkaline phosphatase and type I collagen in primary baboon osteoblasts. Phytomedicine 21:1498-1503. doi:10.1016/j.phymed.2014. 06.019

Tokuda H, Takai S, Hanai Y et al (2007a) (-)-Epigallocatechin gallate suppresses endothelin-1-induced interleukin-6 synthesis in osteoblasts: inhibition of p44/p42 MAP kinase activation. FEBS Lett 581:1311-1316. doi:10.1016/j. febslet.2007.02.052

Tokuda H, Takai S, Matsushima-Nishiwaki R et al (2007b) (-)Epigallocatechin gallate enhances prostaglandin $\mathrm{F} 2 \alpha$-induced VEGF synthesis via upregulating SAPK/JNK activation in osteoblasts. J Cell Biochem 100:1146-1153. doi:10.1002/jcb.21104

Tominari T, Matsumoto C, Watanabe K et al (2015) Epigallocatechin gallate (EGCG) suppresses lipopolysaccharideinduced inflammatory bone resorption, and protects against alveolar bone loss in mice. FEBS Open Bio 5:522-527. doi:10.1016/j.fob.2015.06.003

Trzeciakiewicz A, Habauzit V, Mercier S et al (2010a) Hesperetin stimulates differentiation of primary rat osteoblasts involving the BMP signalling pathway. J Nutr Biochem 21:424-431. doi:10.1016/j.jnutbio.2009.01.017

Trzeciakiewicz A, Habauzit V, Mercier S et al (2010b) Molecular mechanism of hesperetin-7-O-glucuronide, the main circulating metabolite of hesperidin, involved in osteoblast differentiation. J Agric Food Chem 58:668-675. doi:10.1021/jf902680n

Tsai SH, Lin-Shiau SY, Lin JK (1999) Suppression of nitric oxide synthase and the down-regulation of the activation of NFkappaB in macrophages by resveratrol. Br J Pharmacol 126:673-680. doi:10.1038/sj.bjp.0702357

Tsai HY, Lin HY, Fong YC et al (2008) Paeonol inhibits RANKL-induced osteoclastogenesis by inhibiting ERK, p38 and NF-kappaB pathway. Eur $J$ Pharmacol 588:124-133. doi:10.1016/j.ejphar.2008.04.024

Tseng P-C, Hou S-M, Chen R-J et al (2011) Resveratrol promotes osteogenesis of human mesenchymal stem cells by upregulating RUNX2 gene expression via the SIRT1/ FOXO3A axis. J Bone Miner Res 26:2552-2563. doi:10. $1002 / \mathrm{jbmr} .460$

Tucakovic L, Colson N, Singh I (2015) Relationship between common dietary polyphenols and obesity-induced inflammation. Food Public Health 5:84-91

Uchechi O, Ogbonna JDN, Attama AA (2014) Nanoparticles for dermal and transdermal drug delivery. Appl Nanotechnol Drug Deliv. doi:10.5772/58672

Uchiyama S, Yamaguchi M (2007a) Genistein and zinc synergistically stimulate apoptotic cell death and suppress RANKL signaling-related gene expression in osteoclastic cells. J Cell Biochem 101:529-542. doi:10.1002/jcb.21208

Uchiyama S, Yamaguchi M (2007b) Genistein and zinc synergistically enhance gene expression and mineralization in osteoblastic MC3T3-E1 cells. Int J Mol Med 19:213-220. doi:10.1002/jcb. 21208

Van Der Woude H, Ter Veld MGR, Jacobs N et al (2005) The stimulation of cell proliferation by quercetin is mediated by the estrogen receptor. Mol Nutr Food Res 49:763-771. doi:10.1002/mnfr.200500036

Veprik A, Khanin M, Linnewiel-Hermoni K et al (2012) Polyphenols, isothiocyanates, and carotenoid derivatives enhance estrogenic activity in bone cells but inhibit it in breast cancer cells. Am J Physiol Endocrinol Metab 303:E815-E824. doi:10.1152/ajpendo.00142.2011

Vidal O, Kindblom LG, Ohlsson C (1999) Expression and localization of estrogen receptor-beta in murine and human bone. J Bone Min Res 14:923-929. doi:10.1359/jbmr. 1999.14.6.923

Viereck V, Gründker C, Blaschke S et al (2002) Phytoestrogen Genistein stimulates the production of osteoprotegerin by human trabecular osteoblasts. J Cell Biochem 84:725-735. doi:10.1002/jcb.10087

von Metzler I, Krebbel H, Kuckelkorn U et al (2009) Curcumin diminishes human osteoclastogenesis by inhibition of the signalosome-associated IкB kinase. J Cancer Res Clin Oncol 135:173-179. doi:10.1007/s00432-008-0461-8

Wang X, Zhen L, Zhang G et al (2011) Osteogenic effects of flavonoid aglycones from an osteoprotective fraction of Drynaria fortunei-an in vitro efficacy study. Phytomedicine 18:868-872. doi:10.1016/j.phymed.2011.01. 022

Wang H-D, Shi Y-M, Li L et al (2013a) Treatment with resveratrol attenuates sublesional bone loss in spinal cordinjured rats. Br J Pharmacol 170:796-806. doi:10.1111/ bph.12301

Wang Y, Wang WL, Xie WL et al (2013b) Puerarin stimulates proliferation and differentiation and protects against cell death in human osteoblastic MG-63 cells via ER-dependent MEK/ERK and PI3K/Akt activation. Phytomedicine 20:787-796. doi:10.1016/j.phymed.2013.03.005

Wang W, Wu C, Tian B et al (2014a) The inhibition of RANKLinduced osteoclastogenesis through the suppression of p38 signaling pathway by naringenin and attenuation of titanium-particle-induced osteolysis. Int $\mathrm{J}$ Mol Sci 15:21913-21934. doi:10.3390/ijms151221913

Wang X, Schröder HC, Feng Q et al (2014b) Isoquercitrin and polyphosphate co-enhance mineralization of human osteoblast-like SaOS-2 cells via separate activation of two 
RUNX2 cofactors AFT6 and Ets1. Biochem Pharmacol 89:413-421. doi:10.1016/j.bcp.2014.03.020

Wang Y, Yang C, Xie WL et al (2014c) Puerarin concurrently stimulates osteoprotegerin and inhibits receptor activator of NF- $\kappa \mathrm{B}$ ligand (RANKL) and interleukin- 6 production in human osteoblastic MG-63 cells. Phytomedicine 21:1032-1036. doi:10.1016/j.phymed.2014.04.012

Wang D, Ma W, Wang F et al (2015) Stimulation of Wnt/ $\beta$ Catenin signaling to improve bone development by naringin via interacting with AMPK and Akt. Cell Physiol Biochem 36:1563-1576. doi:10.1159/000430319

Wattel A, Kamel S, Mentaverri R et al (2003) Potent inhibitory effect of naturally occurring flavonoids quercetin and kaempferol on in vitro osteoclastic bone resorption. Biochem Pharmacol 65:35-42. doi:10.1016/S00062952(02)01445-4

Wattel A, Kamel S, Prouillet C et al (2004) Flavonoid quercetin decreases osteoclastic differentiation induced by RANKL via a mechanism involving NFKB and AP-1. J Cell Biochem 92:285-295. doi:10.1002/jcb.20071

Wei YJ, Tsai KS, Lin LC et al (2011) Catechin stimulates osteogenesis by enhancing PP2A activity in human mesenchymal stem cells. Osteoporos Int 22:1469-1479. doi:10.1007/s00198-010-1352-9

Welch AA, Hardcastle AC (2014) The effects of flavonoids on bone. Curr Osteoporos Rep 12:205-210. doi:10.1007/ s11914-014-0212-5

Williamson G, Manach C (2005) Bioavailability and bioefficacy of polyphenols in humans. I. Review of 93 intervention studies. Am J Clin Nutr 81:243S-255S

Windahl SH, Norgard M, Kuiper GG et al (2000) Cellular distribution of estrogen receptor beta in neonatal rat bone. Bone 26:117-121

Wong KC, Pang WY, Wang XL et al (2013) Drynaria fortuneiderived total flavonoid fraction and isolated compounds exert oestrogen-like protective effects in bone. Br J Nutr 110:475-485. doi:10.1017/S0007114512005405

Woo J-T, Nakagawa H, Notoya M et al (2004) Quercetin suppresses bone resorption by inhibiting the differentiation and activation of osteoclasts. Biol Pharm Bull 27:504-509. doi:10.1248/bpb.27.504

Wu BJ, Fong YC, Tsai HY et al (2008) Naringin-induced bone morphogenetic protein-2 expression via PI3K, Akt, c-Fos/ c-Jun and AP-1 pathway in osteoblasts. Eur J Pharmacol 588:333-341. doi:10.1016/j.ejphar.2008.04.030

Wu X, Li Z, Yang Z et al (2012) Caffeic acid 3,4-dihydroxyphenethyl ester suppresses receptor activator of NF- $\mathrm{\kappa B}$ ligand-induced osteoclastogenesis and prevents ovariectomy-induced bone loss through inhibition of mitogenactivated protein kinase/activator protein 1 and $\mathrm{Ca}^{2+}$-nuclear fact. J Bone Miner Res 27:1298-1308. doi:10.1002/ jbmr. 1576

Wu C, Wang W, Tian B et al (2015a) Myricetin prevents titanium particle-induced osteolysis in vivo and inhibits RANKL-induced osteoclastogenesis in vitro. Biochem Pharmacol 93:59-71. doi:10.1016/j.bcp.2014.10.019

Wu Y, Xia L, Zhou Y et al (2015b) Icariin induces osteogenic differentiation of bone mesenchymal stem cells in a MAPK-dependent manner. Cell Prolif. doi:10.1111/cpr. 12185
Xiao H-H, Fung C-Y, Mok S-K et al (2014a) Flavonoids from Herba epimedii selectively activate estrogen receptor alpha $(\mathrm{ER} \alpha)$ and stimulate ER-dependent osteoblastic functions in UMR-106 cells. J Steroid Biochem Mol Biol 143C:141-151. doi:10.1016/j.jsbmb.2014.02.019

Xiao H-H, Gao Q-G, Zhang Y et al (2014b) Vanillic acid exerts oestrogen-like activities in osteoblast-like UMR 106 cells through MAP kinase (MEK/ERK)-mediated ER signaling pathway. J Steroid Biochem Mol Biol 144(Pt B):382-391. doi:10.1016/j.jsbmb.2014.08.002

Xiao F, Zhai Z, Jiang C et al (2015) Geraniin suppresses RANKL-induced osteoclastogenesis in vitro and ameliorates wear particle-induced osteolysis in mouse model. Exp Cell Res 330:91-101. doi:10.1016/j.yexcr.2014.07.005

Yamagishi T, Otsuka E, Hagiwara H (2001) Reciprocal control of expression of mRNAs for osteoclast differentiation factor and OPG in osteogenic stromal cells by genistein: evidence for the involvement of topoisomerase II in osteoclastogenesis. Endocrinology 142:3632-3637. doi:10.1210/en.142.8.3632

Yamaguchi M (2011) Honokiol stimulates osteoblastogenesis by suppressing NF- $\kappa \mathrm{B}$ activation. Int $\mathrm{J}$ Mol Med. doi:10. 3892/ijmm.2011.786

Yamaguchi MWM (2012) The bone anabolic carotenoid p-hydroxycinnamic acid promotes osteoblast mineralization and suppresses osteoclast differentiation by antagonizing NF- $\kappa B$ activation. Int J Mol Med 30:708-712 doi:10.3892/ ijmm.2012.1043

Yamaguchi M, Gao YH (1997) Anabolic effect of genistein on bone metabolism in the femoral-metaphyseal tissues of elderly rats is inhibited by the anti-estrogen tamoxifen. Exp Med 197:101-107

Yamaguchi M, Gao YH (1998) Inhibitory effect of genistein on bone resorption in tissue culture. Biochem Pharmacol 55:71-76. doi:10.1159/000139013

Yamaguchi M, Sugimoto E (2000) Stimulatory effect of genistein and daidzein on protein synthesis in osteoblastic MC3T3-E1 cells: activation of aminoacyl-tRNA synthetase. Mol Cell Biochem 214:97-102. doi:10.1023/A: 1007199120295

Yamaguchi M, Weitzmann MN (2009a) The estrogen 17ßestradiol and phytoestrogen genistein mediate differential

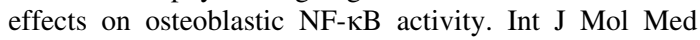
23:297-301. doi:10.3892/ijmm_00000131

Yamaguchi M, Weitzmann MN (2009b) The bone anabolic carotenoids p-hydroxycinnamic acid and beta-cryptoxanthin antagonize NF-kB activation in MC3T3 preosteoblasts. Mol Med Rep 1:641-644. doi:10.3892/mmr_ 00000150

Yamaguchi M, Weitzmann MN (2011) Quercetin, a potent suppressor of NF-kB and Smad activation in osteoblasts. Int J Mol Med 28:521-525. doi:10.3892/ijmm.2011.749

Yamaguchi M, Hamamoto R, Uchiyama S, Ishiyama K (2007) Effects of flavonoid on calcium content in femoral tissue culture and parathyroid hormone-stimulated osteoclastogenesis in bone marrow culture in vitro. Mol Cell Biochem 303:83-88. doi:10.1007/s11010-007-9458-x

Yamaguchi M, Lai YL, Uchiyama S, Nakagawa T (2008a) Oral administration of phytocomponent p-hydroxycinnamic acid prevents bone loss in ovariectomized rats. Mol Cell Biochem 311:31-36. doi:10.1007/s11010-007-9689-x 
Yamaguchi M, Lai YL, Uchiyama S, Nakagawa T (2008b) Phytocomponent p-hydroxycinnamic acid stimulates mineralization in osteoblastic MC3T3-E1 cells. Int J Mol Med 22:287-291. doi:10.3892/ijmm_00000021

Yamaguchi M, Baile C, Shoji M (2013) Bioactive flavonoid p-hydroxycinnamic acid stimulates osteoblastogenesis and suppresses adipogenesis in bone marrow culture. Cell Tissue Res 354:743-750. doi:10.1007/s00441-013-1707-6

Yamamoto N, Otsuka T, Kuroyanagi G et al (2015) Resveratrol reduces prostaglandin E1-stimulated osteoprotegerin synthesis in osteoblasts: suppression of stress-activated protein kinase/c-Jun N-terminal kinase. Prostaglandins Other Lipid Mediat 116:57-63. doi:10.1016/j.prostaglandins. 2015.01.003

Yamashita A, Takada T, Nemoto K et al (2006) Transient suppression of PPAR $\gamma$ directed ES cells into an osteoblastic lineage. FEBS Lett 580:4121-4125. doi:10. 1016/j.febslet.2006.06.057

Yang X, He B, Liu P et al (2015) Treatment with curcumin alleviates sublesional bone loss following spinal cord injury in rats. Eur J Pharmacol 765:209-216. doi:10.1016/j. ejphar.2015.08.036

Yao Z, Xing L, Qin C et al (2008) Osteoclast precursor interaction with bone matrix induces osteoclast formation directly by an interleukin-1-mediated autocrine mechanism. J Biol Chem 283:9917-9924. doi:10.1074/jbc. M706415200

Ying X, Sun L, Chen X et al (2013) Silibinin promotes osteoblast differentiation of human bone marrow stromal cells via bone morphogenetic protein signaling. Eur J Pharmacol 721:225-230. doi:10.1016/j.ejphar.2013.09.031

Ying X, Chen X, Feng Y et al (2014) Myricetin enhances osteogenic differentiation through the activation of canonical Wnt/ $\beta$-catenin signaling in human bone marrow stromal cells. Eur J Pharmacol 738:22-30. doi:10.1016/j. ejphar.2014.04.049

Yoshida H, Teramoto T, Ikeda K, Yamori Y (2011) Glycitein effect on suppressing the proliferation and stimulating the differentiation of osteoblastic MC3T3-E1 cells. Biosci Biotechnol Biochem 65:1211-1213

Yun J-H, Pang E-K, Kim C-S et al (2004) Inhibitory effects of green tea polyphenol (-)-epigallocatechin gallate on the expression of matrix metalloproteinase- 9 and on the formation of osteoclasts. J Periodontal Res 39:300-307. doi:10.1111/j.1600-0765.2004.00743.x

Yun JH, Kim CS, Cho KS et al (2007) (-)-Epigallocatechin gallate induces apoptosis, via caspase activation, in osteoclasts differentiated from RAW 264.7 cells. J Periodontal Res 42:212-218. doi:10.1111/j.1600-0765.2006. 00935.x

Zang M, Xu S, Maitland-Toolan KA et al (2006) Polyphenols stimulate AMP-activated protein kinase, lower lipids, and inhibit accelerated atherosclerosis in diabetic LDL receptor-deficient mice. Diabetes 55:2180-2191. doi:10.2337/ db05-1188

Zeng X, Tian J, Cai K et al (2014) Promoting osteoblast differentiation by the flavanes from Huangshan Maofeng tea is linked to a reduction of oxidative stress. Phytomedicine 21:217-224. doi:10.1016/j.phymed.2013.08.026
Zhai YK, Guo XY, Ge BF et al (2014) Icariin stimulates the osteogenic differentiation of rat bone marrow stromal cells via activating the PI3K-AKT-eNOS-NO-cGMP-PKG. Bone 66:189-198. doi:10.1016/j.bone.2014.06.016

Zhang J-P, Wu T, Hu Z, Qian D (1996) Inhibitory effect of quercetin on tumor necrosis factor and interleukin-1 $\beta$ proosteoblastic activities. Zhongguo Yao Li Xue Bao 17:261-263

Zhang W, Liu HT, Tu LIUH (2002) MAPK signal pathways in the regulation of cell proliferation in mammalian cells. Cell Res 12:9-18. doi:10.1038/sj.cr.7290105

Zhang Y, Zeng X, Zhang L, Zheng X (2007) Stimulatory effect of puerarin on bone formation through activation of PI3K/ Akt pathway in rat calvaria osteoblasts. Planta Med 73:341-347. doi:10.1055/s-2007-967168

Zhang JF, Li G, Meng CL et al (2009) Total flavonoids of Herba Epimedii improves osteogenesis and inhibits osteoclastogenesis of human mesenchymal stem cells. Phytomedicine 16:521-529. doi:10.1016/j.phymed.2009.01.003

Zhang J, Lazarenko OP, Wu X et al (2012) Differential effects of short term feeding of a soy protein isolate diet and estrogen treatment on bone in the pre-pubertal rat. PLoS ONE 7:e35736. doi:10.1371/journal.pone.0035736

Zhang Z, Zheng L, Zhao Z et al (2014) Grape seed proanthocyanidins inhibit H2O2-induced osteoblastic MC3T3-E1 cell apoptosis via ameliorating $\mathrm{H}_{2} \mathrm{O}_{2}$-induced mitochondrial dysfunction. J Toxicol Sci 39:803-813

Zhang X, Zhou C, Zha X et al (2015) Apigenin promotes osteogenic differentiation of human mesenchymal stem cells through JNK and p38 MAPK pathways. Mol Cell Biochem 407:41-50. doi:10.1007/s11010-015-2452-9

Zhao J, Ohba S, Shinkai M et al (2008) Icariin induces osteogenic differentiation in vitro in a BMP- and Runx2-dependent manner. Biochem Biophys Res Commun 369:444-448. doi:10.1016/j.bbrc.2008.02.054

Zhao J, Yue W, Zhu MJ et al (2010a) AMP-activated protein kinase (AMPK) cross-talks with canonical Wnt signaling via phosphorylation of beta-catenin at Ser 552. Biochem Biophys Res Commun 395:146-151. doi:10.1016/j.bbrc. 2010.03.161

Zhao Q, Wang X, Liu Y et al (2010b) NFATc1: functions in osteoclasts. Int J Biochem Cell Biol 42:576-579. doi:10. 1016/j.biocel.2009.12.018

Zhao L, Wang Y, Wang Z et al (2015) Effects of dietary resveratrol on excess-iron-induced bone loss via antioxidative character. J Nutr Biochem 26:1174-1182. doi:10. 1016/j.jnutbio.2015.05.009

Zhou H, Shang L, Li X et al (2009) Resveratrol augments the canonical Wnt signaling pathway in promoting osteoblastic differentiation of multipotent mesenchymal cells. Exp Cell Res 315:2953-2962. doi:10.1016/j.yexcr.2009.07.030

Zhou T, Chen D, Li Q et al (2013) Curcumin inhibits inflammatory response and bone loss during experimental periodontitis in rats. Acta Odontol Scand 71:349-356. doi:10. 3109/00016357.2012.682092

Zhou R, Wang Z, Ma C (2014) Hispidulin exerts anti-osteoporotic activity in ovariectomized mice via activating AMPK signaling pathway. Cell Biochem Biophys 69:311-317. doi:10.1007/s12013-013-9800-8 
Zhou Y, Wu Y, Jiang X et al (2015) The effect of quercetin on the osteogenesic differentiation and angiogenic factor expression of bone marrow-derived mesenchymal stem cells. PLoS ONE 10:e0129605. doi:10.1371/journal.pone. 0129605
Zych M, Folwarczna J, Pytlik M et al (2010) Administration of caffeic acid worsened bone mechanical properties in female rats. Planta Med 76:407-411. doi:10.1055/s-00291240603 